\title{
Front-end Electronics for Unattended Measurement (FEUM): Prototype Test Plan
}

Revision 1

RC Conrad

SJ Morris

LE Smith

D Keller

August 2015

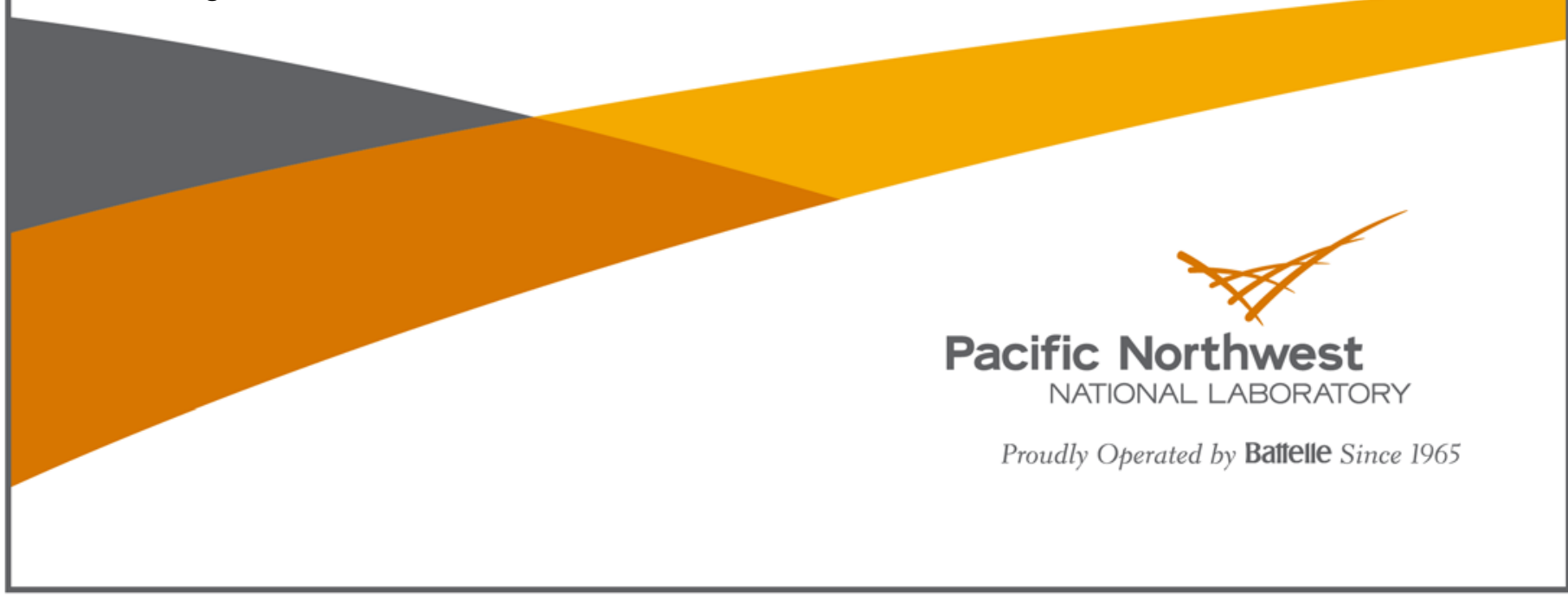




\title{
DISCLAIMER
}

This report was prepared as an account of work sponsored by an agency of the United States Government. Neither the United States Government nor any agency thereof, nor Battelle Memorial Institute, nor any of their employees, makes any warranty, express or implied, or assumes any legal liability or responsibility for the accuracy, completeness, or usefulness of any information, apparatus, product, or process disclosed, or represents that its use would not infringe privately owned rights. Reference herein to any specific commercial product, process, or service by trade name, trademark, manufacturer, or otherwise does not necessarily constitute or imply its endorsement, recommendation, or favoring by the United States Government or any agency thereof, or Battelle Memorial Institute. The views and opinions of authors expressed herein do not necessarily state or reflect those of the United States Government or any agency thereof.

\author{
PACIFIC NORTHWEST NATIONAL LABORATORY \\ operated by \\ BATTELLE \\ for the \\ UNITED STATES DEPARTMENT OF ENERGY \\ under Contract DE-AC05-76RL01830
}

Printed in the United States of America
Available to DOE and DOE contractors from the Office of Scientific and Technical Information,
P.O. Box 62, Oak Ridge, TN 37831-0062;
ph: (865) 576-8401
fax: $(865)$ 576-5728
email: reports@adonis.osti.gov

\begin{abstract}
Available to the public from the National Technical Information Service, U.S. Department of Commerce, 5285 Port Royal Rd., Springfield, VA 22161 ph: (800) 553-6847 fax: $(703) 605-6900$ email: orders@ntis.fedworld.gov online ordering: http://www.ntis.gov/ordering.htm
\end{abstract}

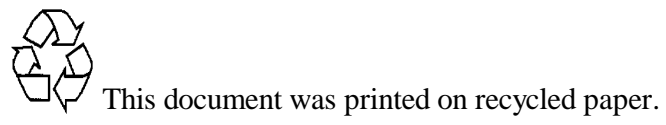




\title{
Front-end Electronics for Unattended Measurement (FEUM): Prototype Test Plan
}

\author{
RC Conrad \\ SJ Morris \\ LE Smith \\ D Keller
}

August 2015

Prepared for

the U.S. Department of Energy

under Contract DE-AC05-76RL01830

Pacific Northwest National Laboratory

Richland, Washington 99352 


\section{Revision Log and Approvals}

Front-end Electronics for Unattended Measurement (FEUM): Prototype Test Plan

\begin{tabular}{|c|c|c|c|}
\hline Rev. No. & Date & Describe Changes & Pages Changed \\
\hline 0 & $11 / 25 / 14$ & Original Issue & \\
\hline 1 & $5 / 20 / 15$ & $\begin{array}{l}\text { Removed references to use of charge injector - Arbitrary } \\
\text { Waverform Generator (AWG) to be use instead } \\
\text { Removed quantitative aspects of Test } 3 \text { (Pulse Shape). } \\
\text { Added reference AWG waveforms to Section 3. } \\
\text { Removed ground loop noise susceptibility test (Test 22) } \\
\text { Various edits for clarity } \\
\text { Removed Test } 9 \text { (impedance measurements) } \\
\text { Performance targets recalculated and updated in section } \\
1.2 \\
\text { Deleted references to performing NGAM verification } \\
\text { Added Appendix B (original IAEA specifications for } \\
\text { FEUM) in place of original appendix B (Charge Injector } \\
\text { Technical Specifications) } \\
\text { Updated the digital summing test procedure } \\
\text { Removed Test 21, Conducted EMI Susceptibility }\end{array}$ & Various \\
\hline
\end{tabular}

\begin{tabular}{|l|l|l|}
\hline Name and Title & Approvals & Date \\
\hline PNNL & & \\
\hline & & \\
\hline & & \\
\hline & & \\
\hline & & \\
\hline & & \\
\hline & & \\
\hline
\end{tabular}




\section{Acronyms and Abbreviations}

ADAM

AWG

CANDU

COTS

CZT

DAQ

DUT

ECP

ESD

EMI

FEUM

GRAND

IAEA

LED

MCA

NGAM

NGSI

RFI

SCA

TTL

UMS

UNAP

UNDA
Advanced Data Acquisition Module from Bot Eng.

arbitrary waveform generator

CANada Deuterium Uranium

commercial off the shelf

cadmium zinc telluride

data acquisition

device under test

Engineering Change Proposal

electrostatic discharge

electromagnetic interference

Front-end Electronics for Unattended Measurements

Gamma Ray and Neutron Detector from Canberra Ind.

International Atomic Energy Agency

light-emitting diode

multichannel analyzer

Next Generation ADAM Module

Next Generation Safeguards Initiative

radio frequency interference

Single channel analyzer

transistor-transistor logic

Unattended monitoring system(s)

Universal NDA Data Acquisition Platform

Unattended Non-Destructive Assay 


\section{Contents}

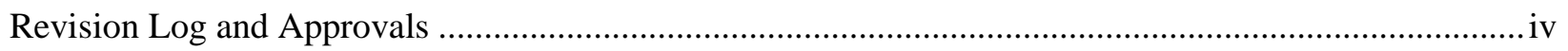

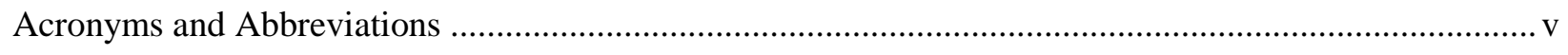

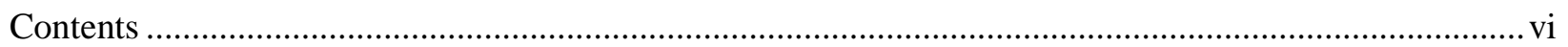

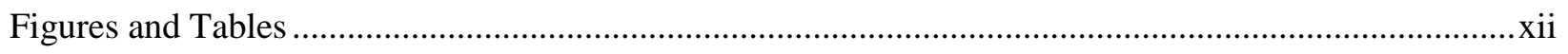

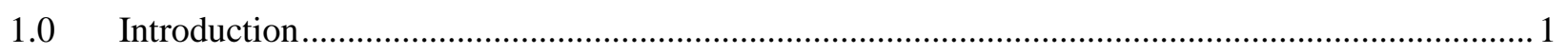

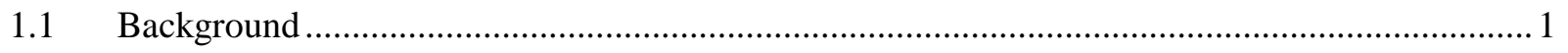

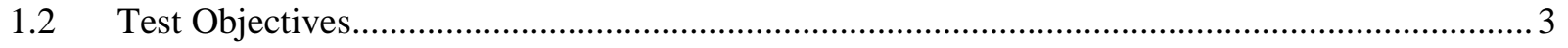

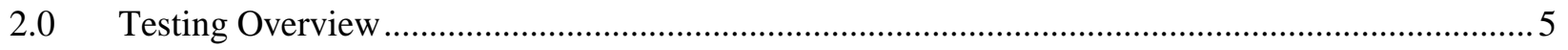

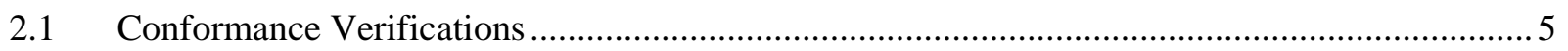

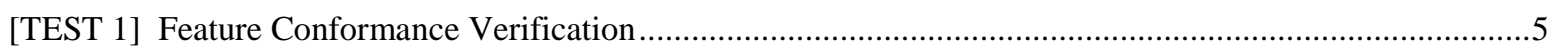

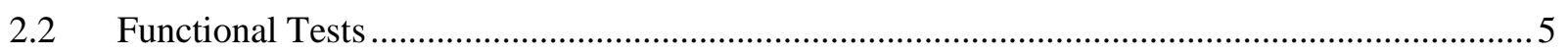

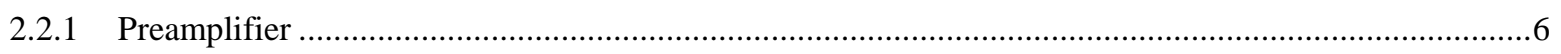

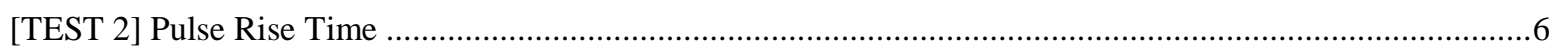

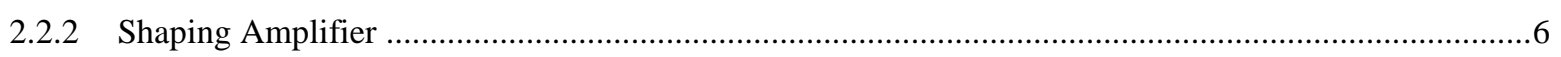

[TEST 3] Shaping Amplifier - Gain and Charge Calibration ................................................................6

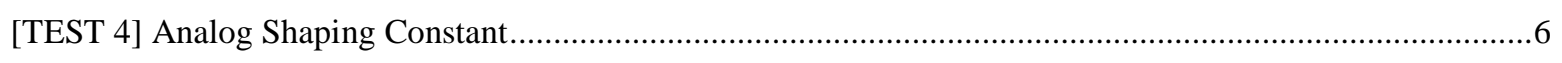

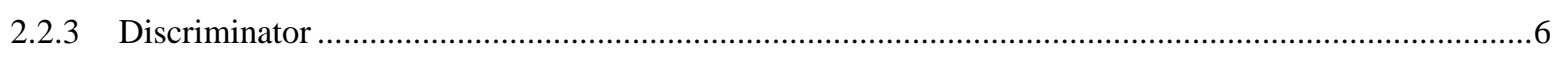

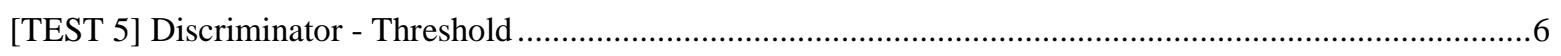

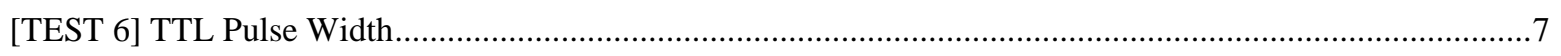

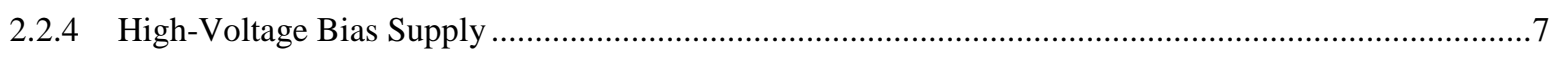

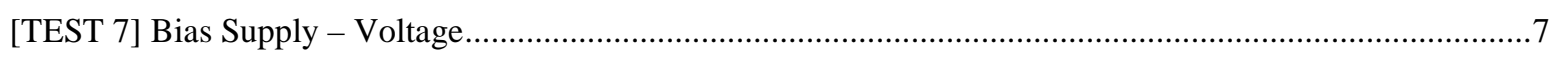

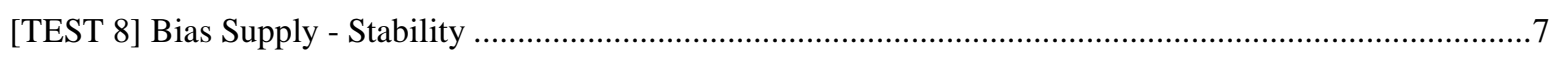

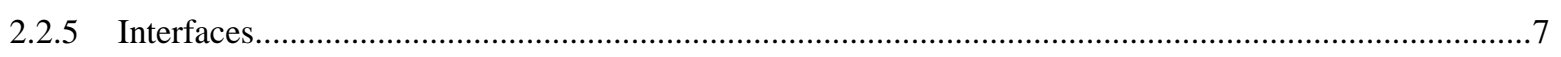

[TEST 9] Input/Output Port Resistance ……………........................................................................

[TEST 10] Count-Rate Indicator - LED Pulse ………..............................................................................

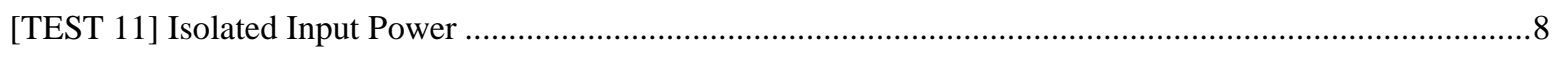

[TEST 12] Digital Input - Logic Voltage Levels .................................................................................

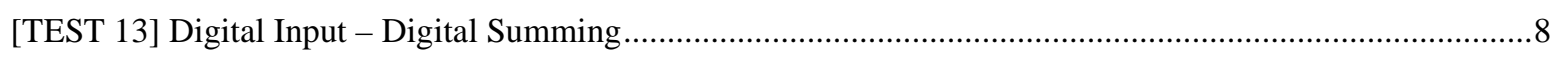

[TEST 14] $\mathrm{V}_{\text {cc }}$ Grounded Input Power .............................................................................................

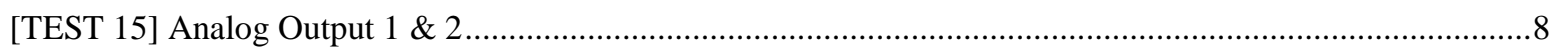

[TEST 16] Digital Output- Logic Voltage Levels......................................................................................

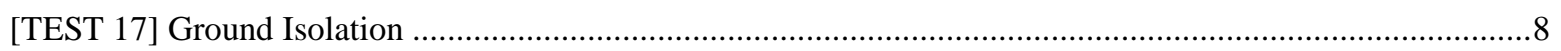




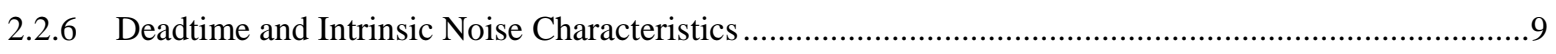

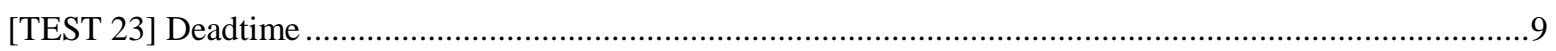

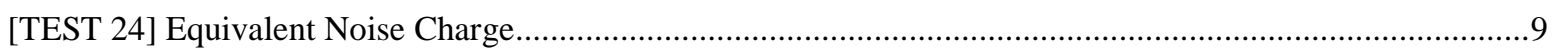

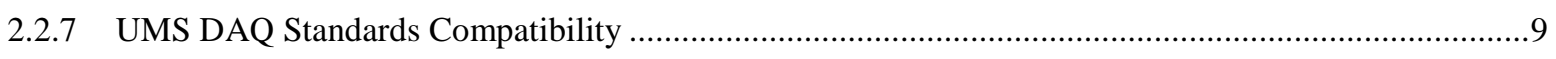

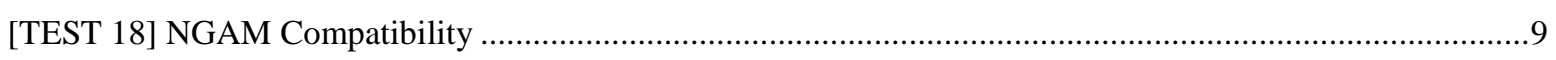

Test Removed. This test was a lower priority and removed due to schedule and budget constraints. .................9

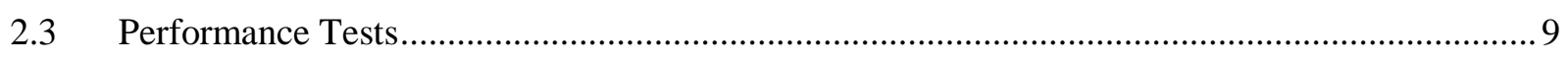

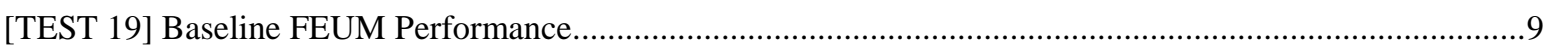

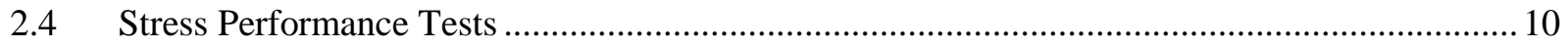

2.4.1 EMI/RFI Susceptibility ..........................................................................................................

[TEST 20] Radiated EMI/RFI Susceptibility ……………….....................................................................11

[TEST 21] Conducted EMI/RFI Susceptibility ..........................................................................................12

[TEST 25] High Radiation Field Susceptibility ………................................................................................13

2.4.2 Ground Loop Noise Susceptibility ...............................................................................................13

[TEST 22] Ground Loop Susceptibility …………….......................................................................13

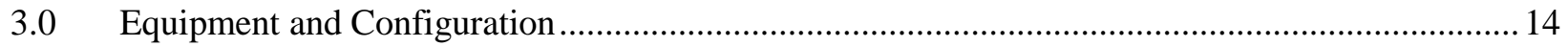

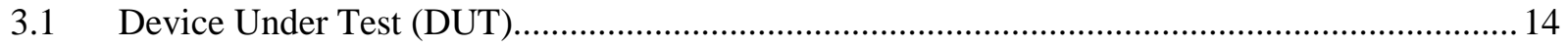

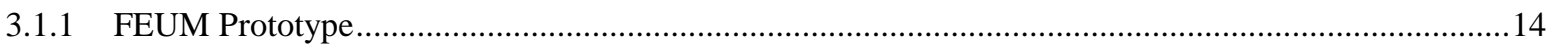

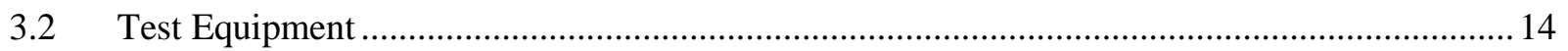

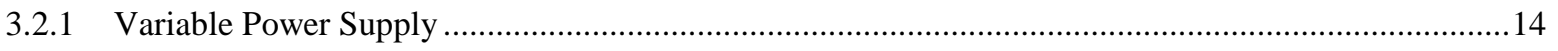

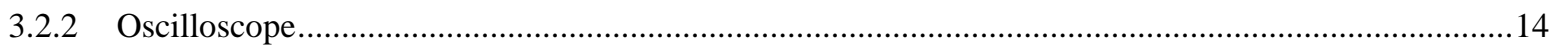

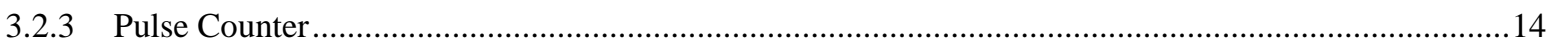

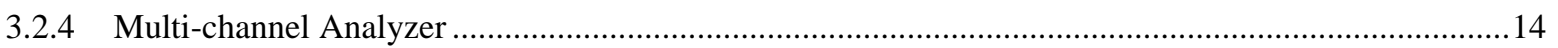

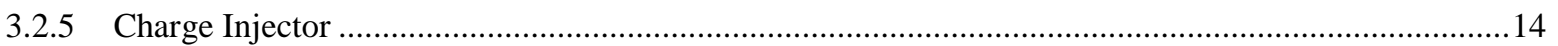

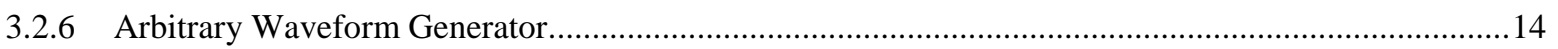

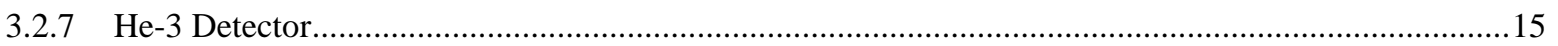

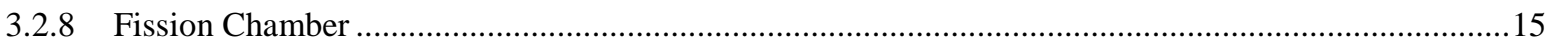

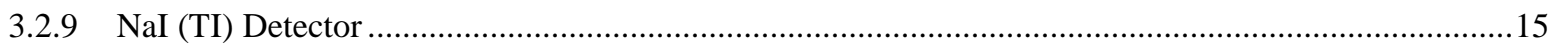

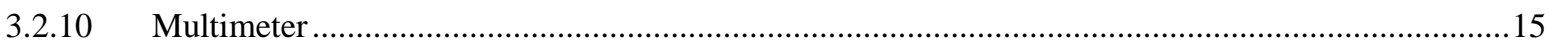

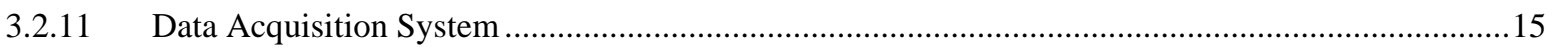

3.2.12 High Voltage, Precision Capacitor ....................................................................................................

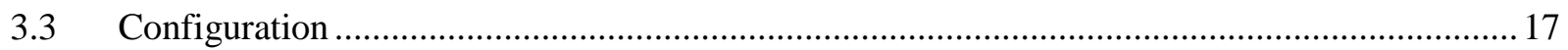

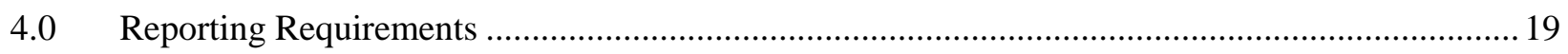

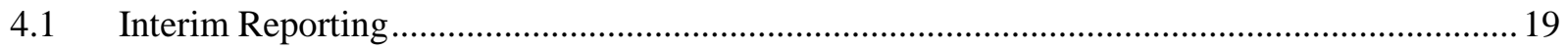




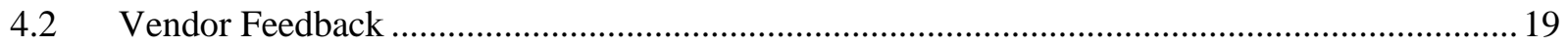

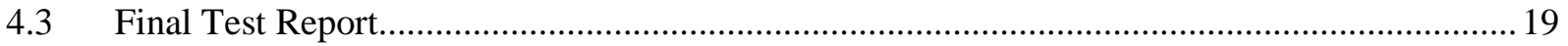

Appendix A Requirements Compliance Matrix........................................................................................ 22

Appendix B IAEA’s Technical Specifications for FEUM ........................................................................... 26

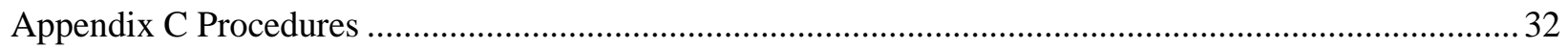

C.1 TEST 3, TEST 4 - Output Gain/Charge Calibration and Shaping Time Constant..................... 32

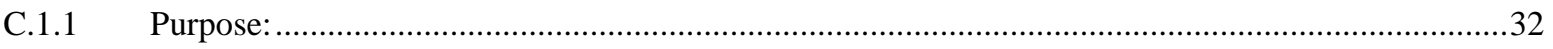

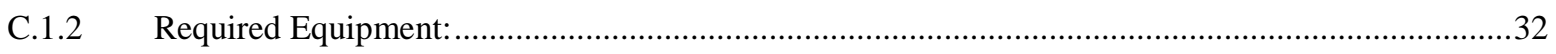

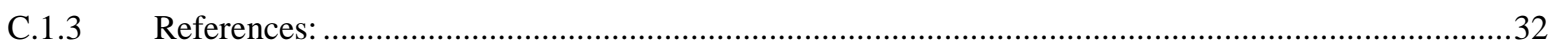

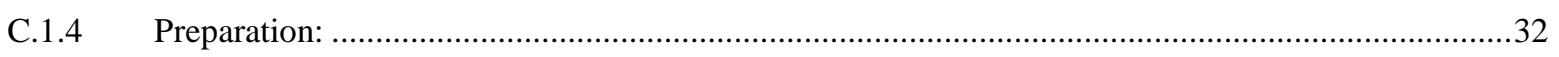

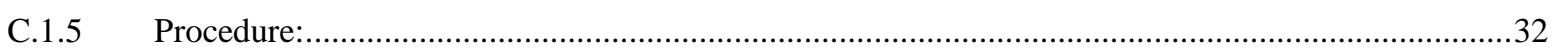

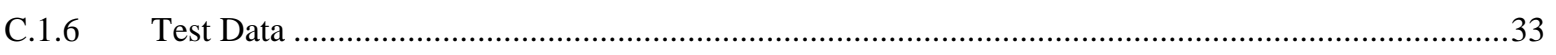

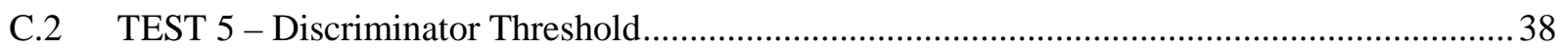

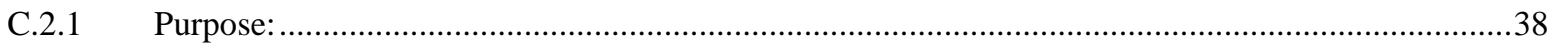

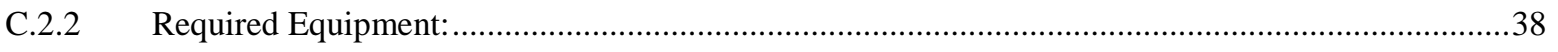

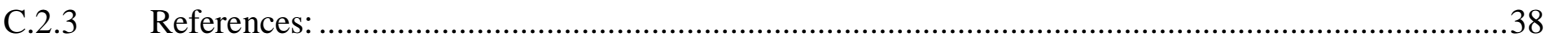

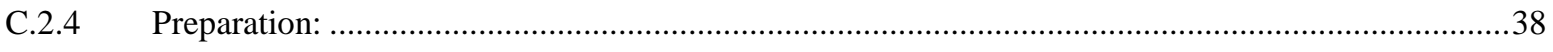

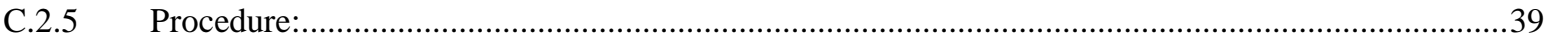

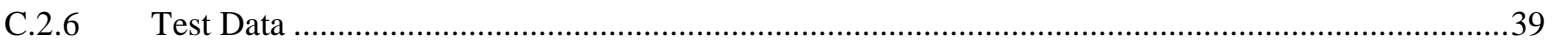

C.3 TEST 6, TEST 10, TEST 16 - TTL Pulse Width, LED Blink Rate Output Logic Levels ......... 44

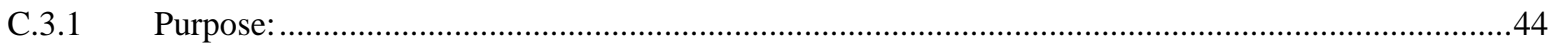

C.3.2 Required Equipment:........................................................................................................44

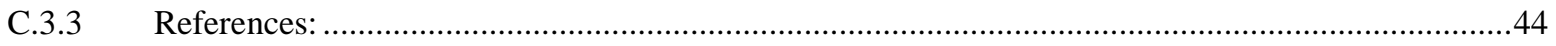

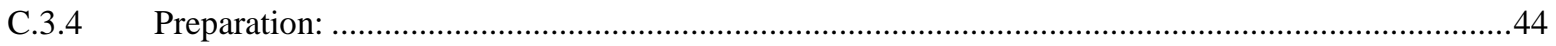

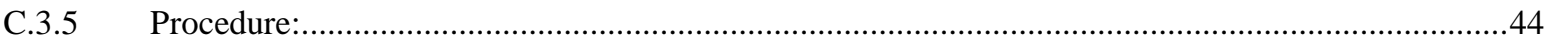

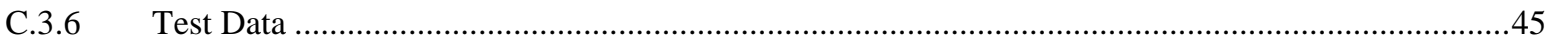

C.4 TEST 7- Bias Supply Output Voltage

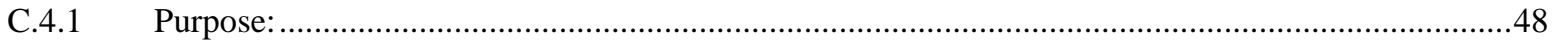

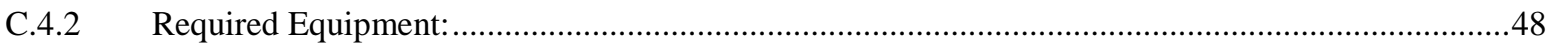

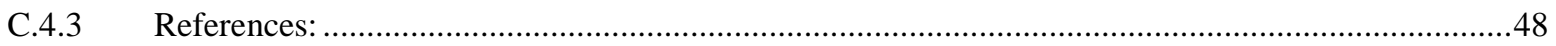

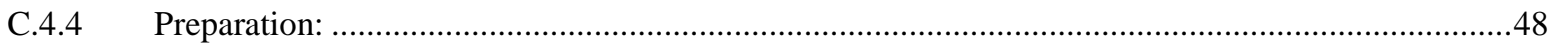

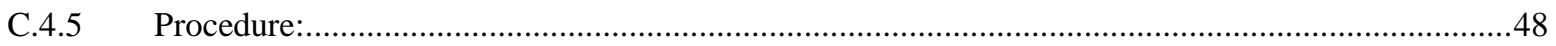

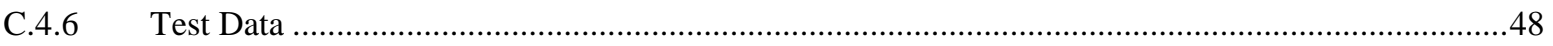

C.5 TEST 8 - Bias Supply Stability ………................................................................................ 51 
C.5.1 Purpose:

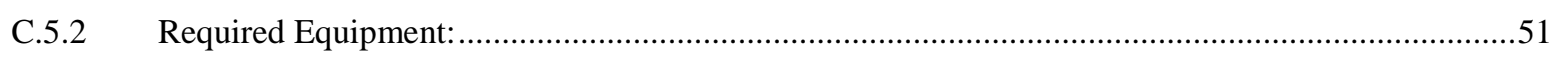

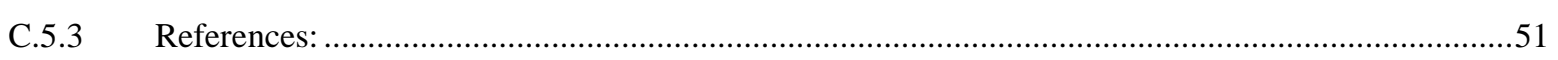

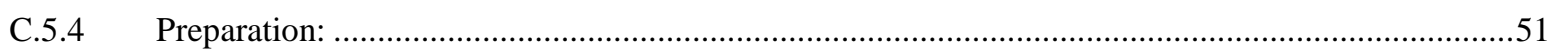

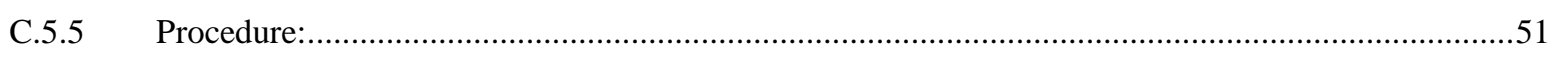

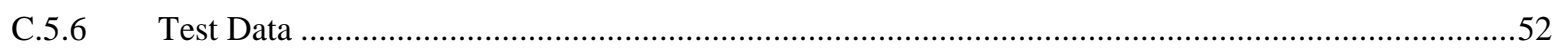

C.6 TEST 11, Test 14 - Isolated and Grounded Power Input Ranges...........................................53

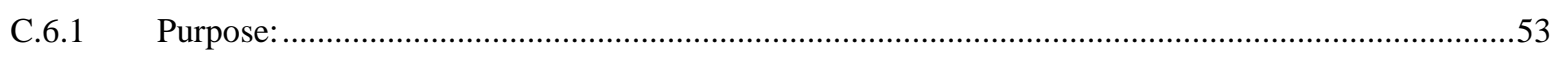

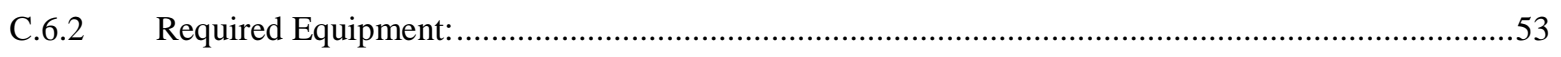

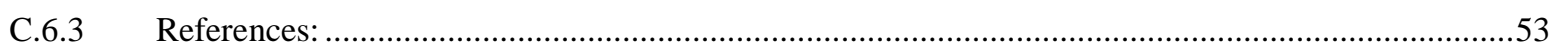

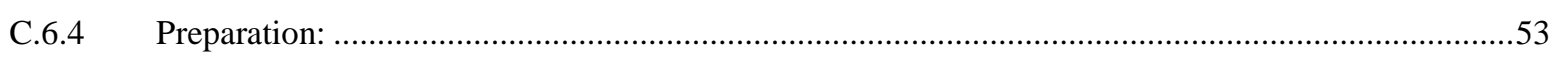

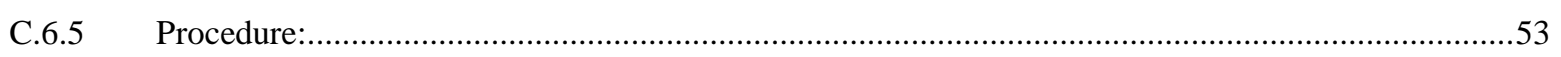

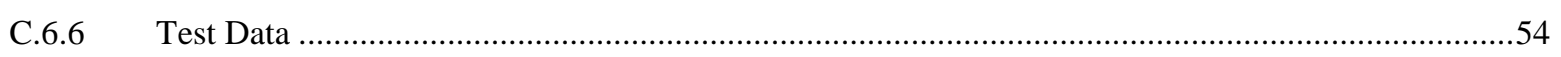

C.7 TEST 12, TEST 13 - Digital Input Logic Levels \& Summing ..............................................57

C.7.1 Purpose:

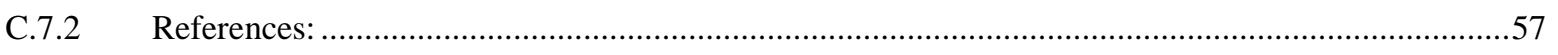

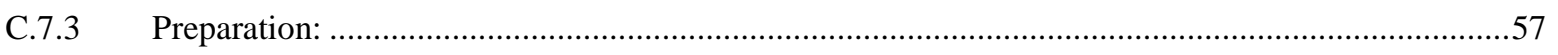

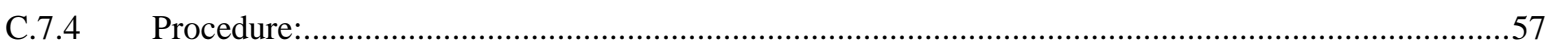

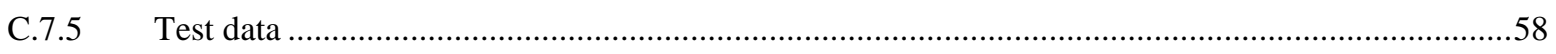

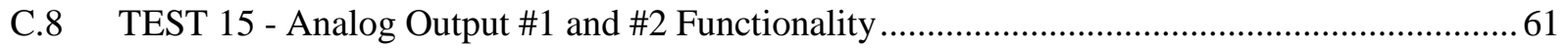

C.8.1 Purpose:

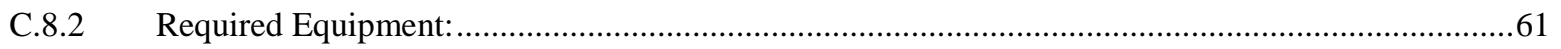

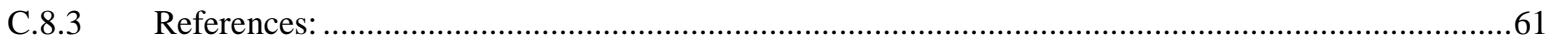

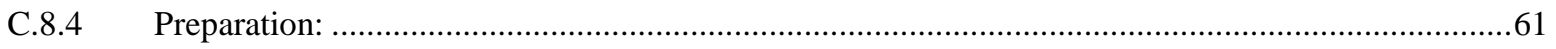

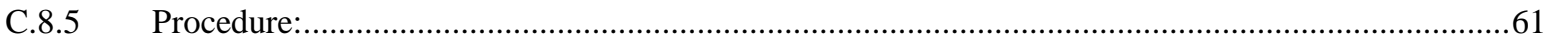

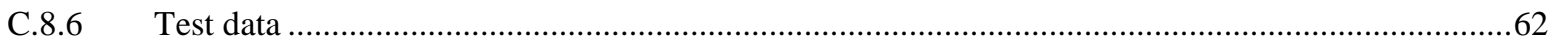

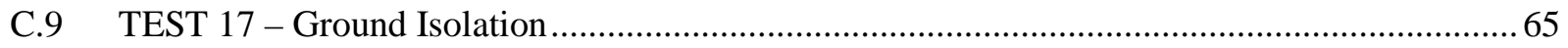

C.9.1 Purpose:

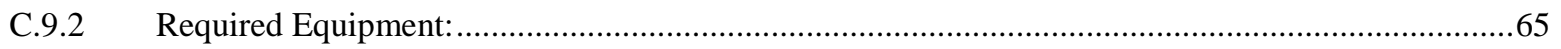

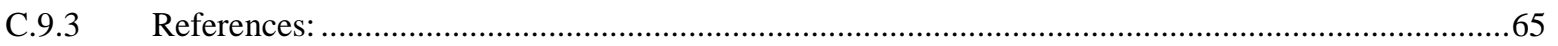

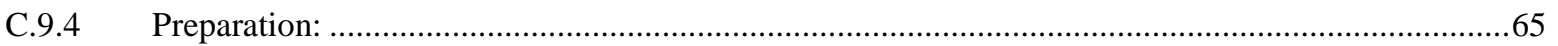

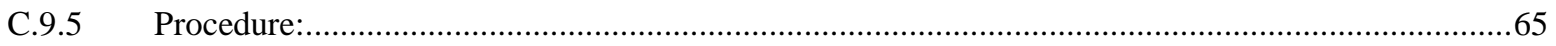

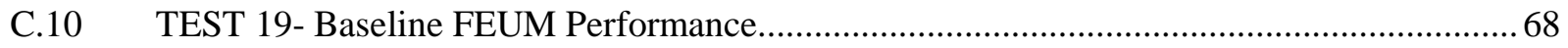

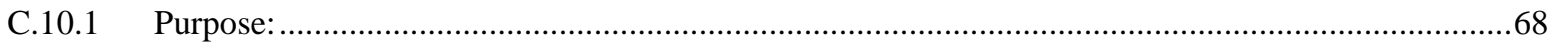




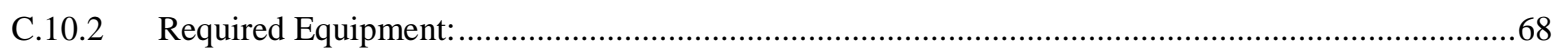

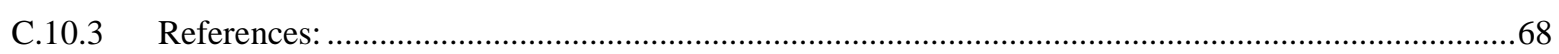

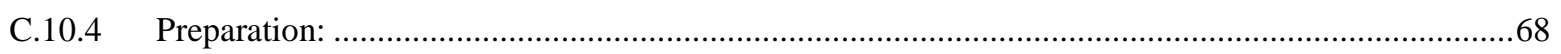

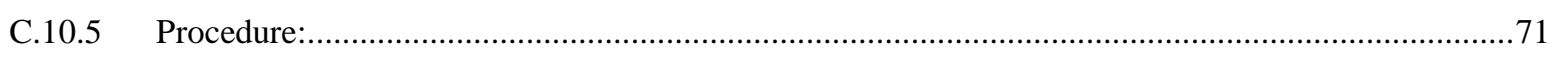

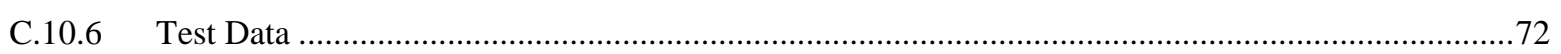

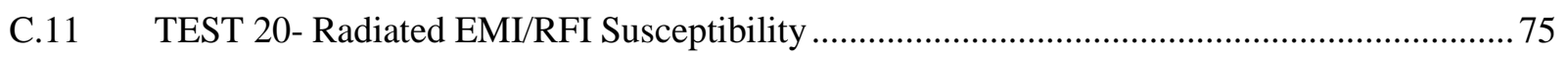

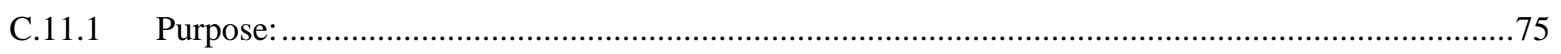

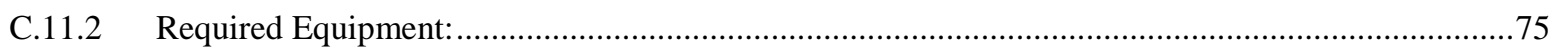

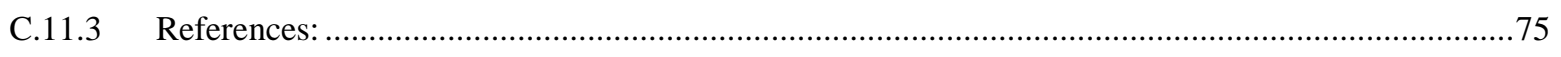

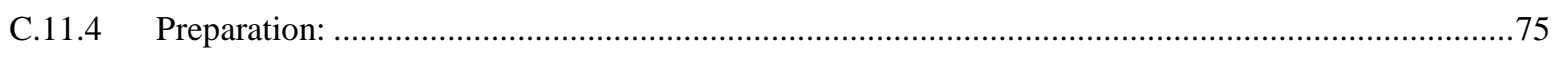

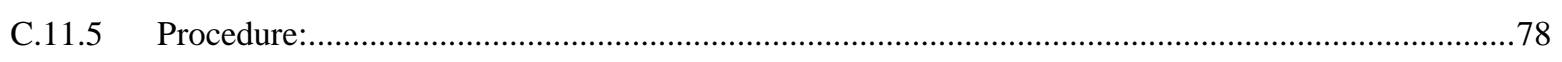

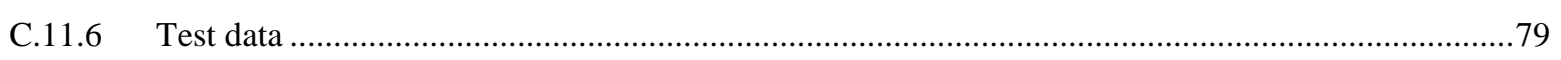

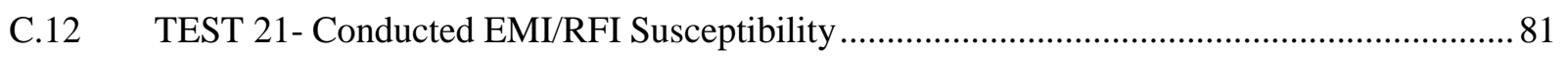

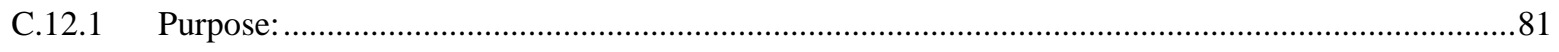

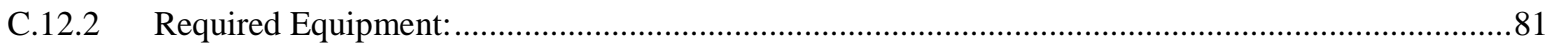

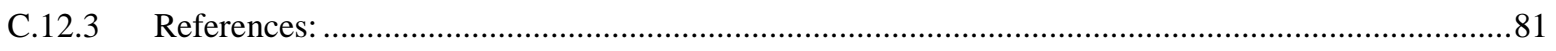

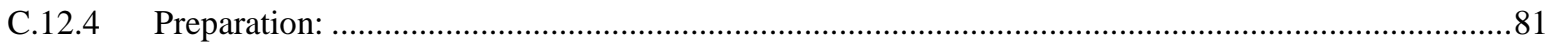

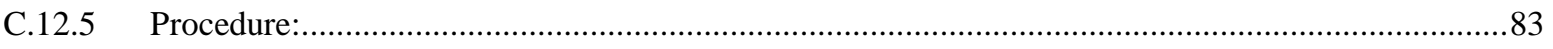

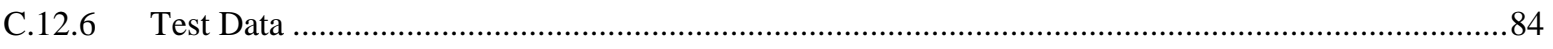

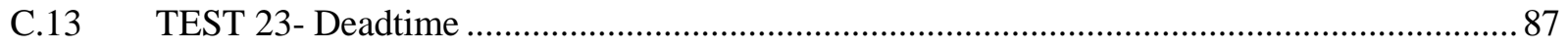

C.13.1 Purpose:

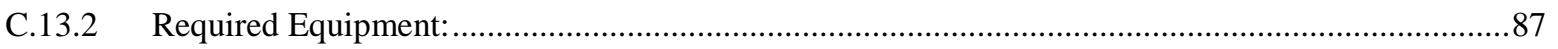

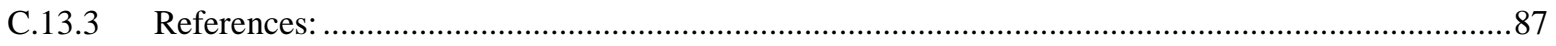

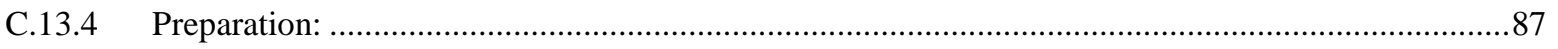

C.13.5 Procedure for Random Pulse Generator Method:...............................................................................89

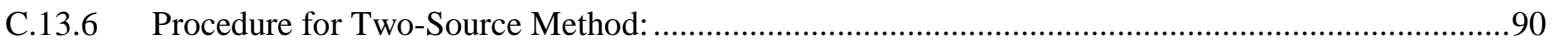

C.13.7 Procedure for Time Interval Histogram Method: ...............................................................................90

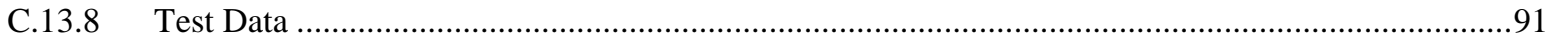

C.14 TEST 24- Equivalent Noise Charge

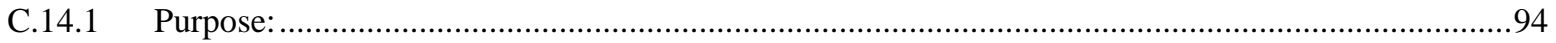

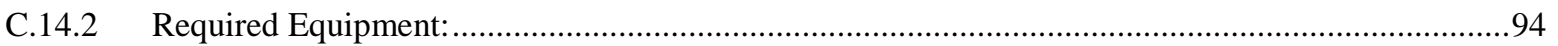

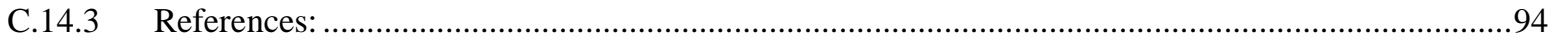

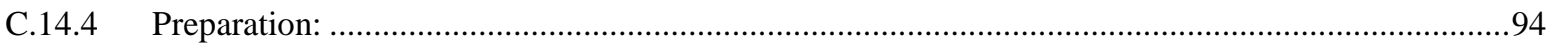

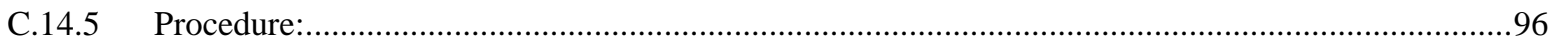




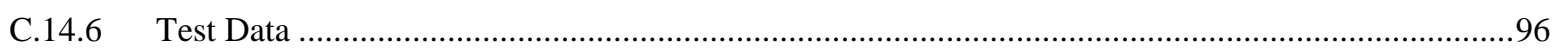

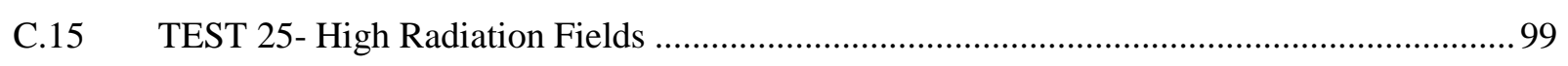

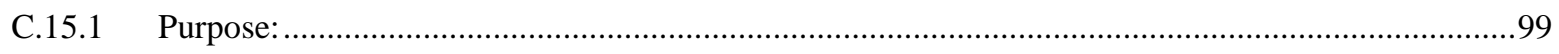

C.15.2 Required Equipment:.............................................................................................................99

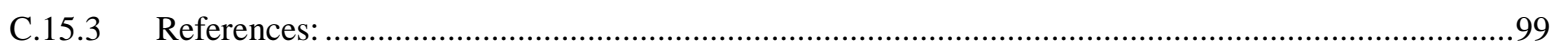

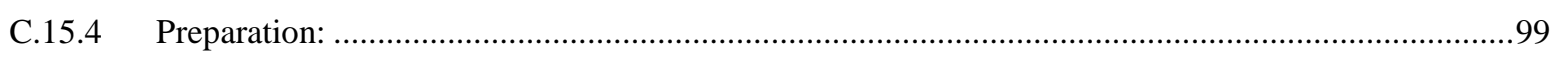

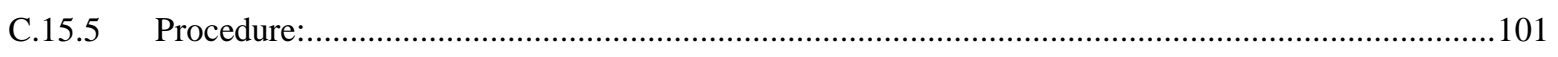

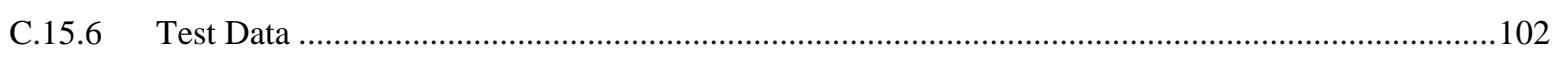




\section{Figures and Tables}

\section{Figures}

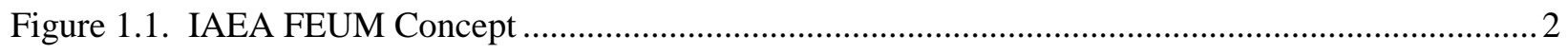

Figure 1.2. Graphical Representation of FEUM Performance Targets ...................................................... 3

Figure 2.1. Generic Test Setup for Functional Tests .................................................................... 6

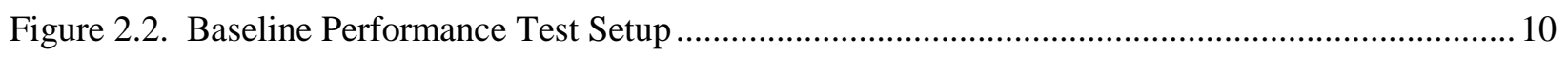

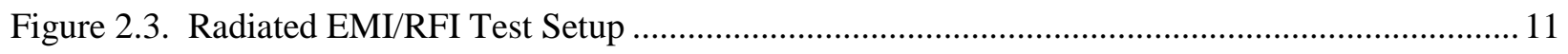

Figure 2.4. Conducted EMI/RFI Test Setup ..................................................................................... 12

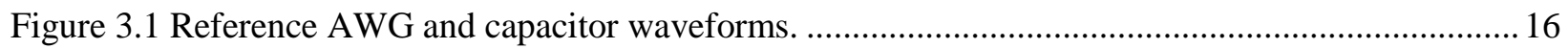

Figure 3.2 Reference AWG and capacitor waveform edges with reduced time scale............................. 16

Figure 3.3 Reference AWG and capacitor waveforms with $20 \mathrm{MHz}$ bandwidth................................... 17

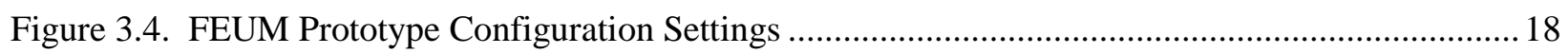

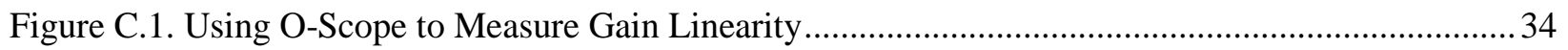

Figure C.2. Using MCA to Measure Gain Linearity and Charge Calibration .......................................... 34

Figure C.3. Discriminator Threshold Test Setup ….............................................................................. 40

Figure C.4. Using O-Scope to Measure Output Logic Levels Triggered by Pulse Generator................... 45

Figure C.5. Using Multimeter to Measure Bias Voltage ...................................................................... 49

Figure C.6. Using DAQ with Data Logger to Measure Bias Voltage...................................................... 52

Figure C.7. Measuring Detector Bias Voltage on the DUT ...............................................................54

Figure C.8. Using a Variable Power Supply to Verify DUT at Multiple Voltage Inputs ..........................55

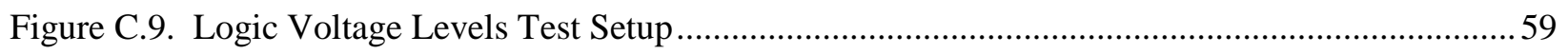

Figure C.10. Digital Summing Test Setup .......................................................................................... 59

Figure C.11. Using O-Scope to Measure Output Logic Levels ............................................................62

Figure C.12. Measuring Between Grounding Points ............................................................................6 66

Figure C.13. Measuring DC Port Input/Output Resistance....................................................................6 66

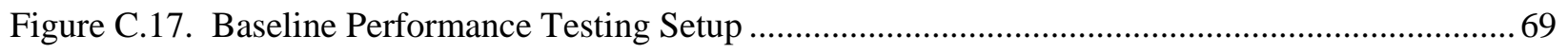

Figure C.18. Radiated EMI/RFI Performance Testing Setup ….......................................................... 76

Figure C.19. Conducted EMI/RFI Performance Testing Setup …......................................................... 81

Figure C.21. Performance Testing Setup for Dead Time, using Pulse Generator Method........................ 88

Figure C.22 Test Setup for Two-Source Deadtime Method ...................................................................... 89 
Figure C.23 Test Setup for Time Interval Histogram Deadtime Method ................................................ 90

Figure C.24. Performance Testing Setup for ENC ….............................................................................. 95

Figure C.25. Performance Testing Setup with Neutron Well ............................................................. 100 


\section{Tables}

Table 1. Summary of Requirements for Evaluation in Initial Test Phase............................................... 3

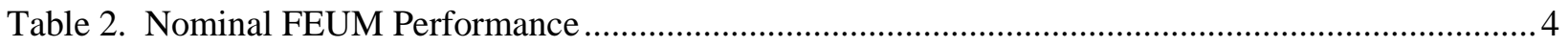

Table 3. Detection Parameters to Vary for Performance Testing ......................................................... 10

Table 4. Detection Parameters to Vary for Performance Testing .......................................................... 11

Table 5. Detection Parameters to Vary for Conducted Susceptibility Tests............................................ 12

Table 7. Summary of Tests, Data Collected, and Analyses .................................................................. 19

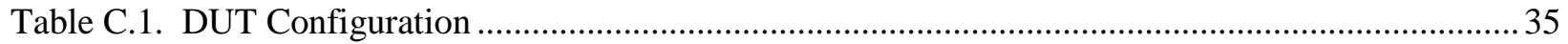

Table C.2. Gain Results for Low-Range Gain (Charge Sensitive) ......................................................... 35

Table C.3. Gain Results for Mid-Range Gain (Charge Sensitive) ...........................................................36

Table C.4. Gain Results for High-Range Gain (Charge Sensitive)....................................................... 36

Table C.5. Gain Results for Low-Range Gain (Current Sensitive)......................................................... 36

Table C.6. Gain Results for Mid-Range Gain (Current Sensitive) ...................................................... 37

Table C.7. Gain Results for High-Range Gain (Current Sensitive) ........................................................ 37

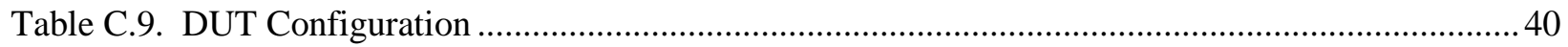

Table C.10. Discriminator Measurement Results (Charge Sensitive) …................................................ 41

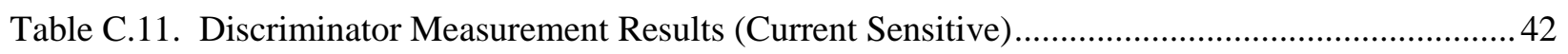

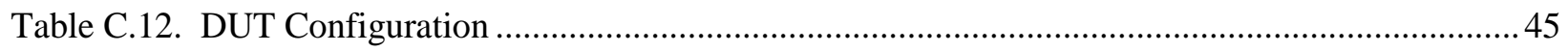

Table C.13. Output Logic Characteristics, pulse width 2.0 ss ................................................................46

Table C.14. Output Logic Characteristics, pulse width to 1.8 ss ............................................................. 46

Table C.15. Output Logic Characteristics, pulse width to 1.2 s ...........................................................46

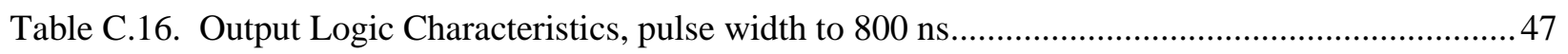

Table C.17. Output Logic Characteristics, pulse width to 400 ns......................................................... 47

Table C.18. Output Logic Characteristics, pulse width to $200 \mathrm{ns........................................................47}$

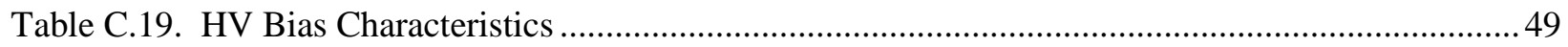

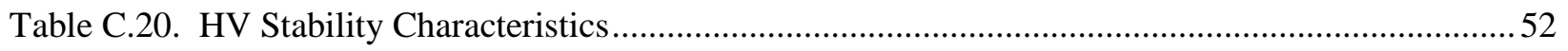

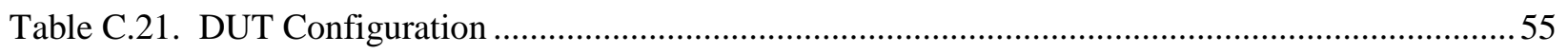

Table C.22. Variable Supply Voltage HV Characteristics...................................................................... 56

Table C.23. Gain Response for Isolated Power at Various Voltages..................................................... 56

Table C.24. Gain Response for Grounded Power Input at Various Voltages ............................................ 56

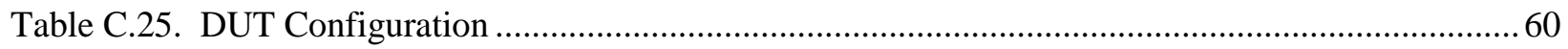

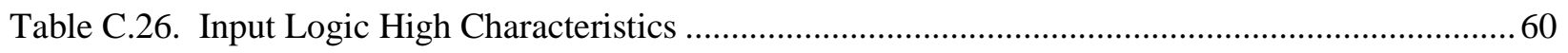




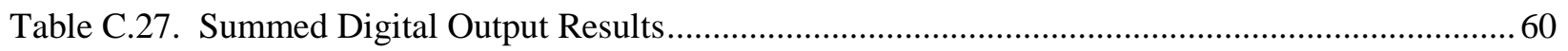

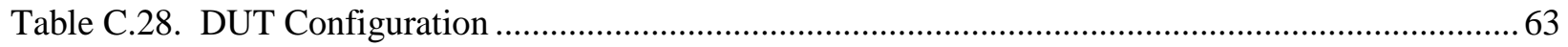

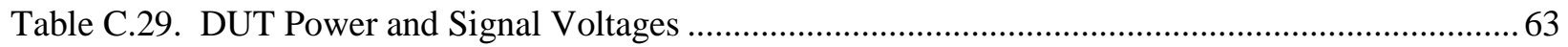

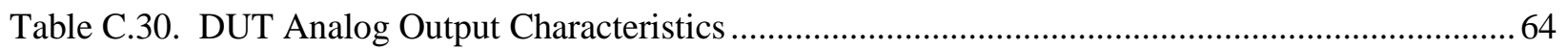

Table C.31. Grounding Schema: Record actual resistance measured, short or open................................ 67

Table C.35. Configurations for Baseline Performance Testing ............................................................... 69

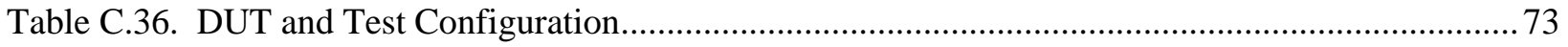

Table C.37. Baseline FEUM Performance Data ....................................................................................... 74

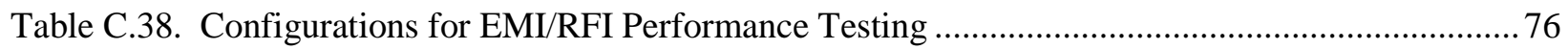

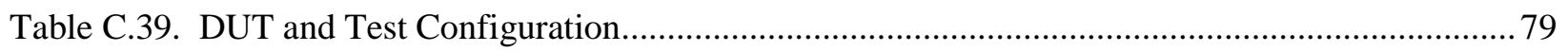

Table C.40. Performance Data for Radiated EMI/RFI ........................................................................... 80

Table C.41. Configurations for Conducted EMI/RFI Performance Testing ............................................82

Table C.42. Configuration Settings for Conducted EMI/RFI Testing ................................................... 85

Table C.43. Conducted Susceptibility Performance Data........................................................................ 85

Table C.47. Configurations for Deadtime Performance Testing with the Pulse Generator Method .......... 88

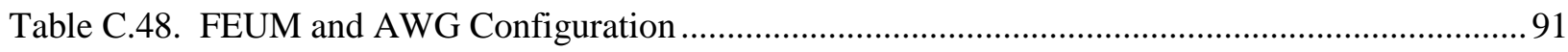

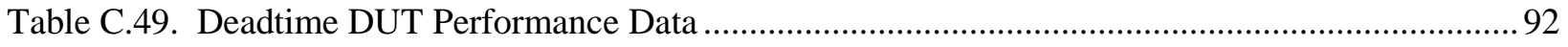

Table C.50. Configurations for ENC Performance Testing ...................................................................95

Table C.51. DUT, AWG and MCA Configuration.................................................................................97

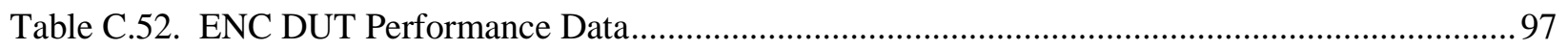

Table C.53. Configurations for High Neutron Performance Testing .....................................................100

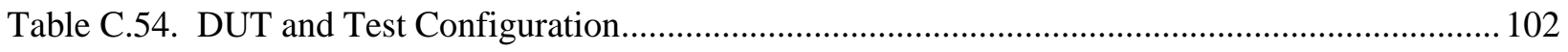

Table C.55. High Neutron DUT Performance Data............................................................................... 103 



\subsection{Introduction}

\subsection{Background}

The International Atomic Energy Agency (IAEA) deploys unattended monitoring systems (UMS) in facilities around the world to provide continuous monitoring of nuclear movements within safeguarded facilities. As the number of unattended monitoring instruments increases, the IAEA is challenged to become more efficient in the implementation of those systems. In 2010, the IAEA initiated development of the Front-end Electronics for Unattended Measurement (FEUM) project with the goals of a) greater flexibility in terms of the interfaces to various sensors and data acquisition systems, and b) improved capabilities for remotely located sensors (e.g., where sensor and front-end electronics might be separated by 10 s of meters) (Figure 1.1).

The majority of the IAEA's UMS are counting, rather than spectroscopic systems, where the measurement needs are more qualitative than quantitative. IAEA's UMS instruments are designed with simplicity, durability, and ease of maintenance in mind. The classes of detectors typically used in IAEA UMS instruments include

- gas-filled neutron detectors: predominantly pulse-mode fission ion chambers (U-235) and He-3 proportional counters, but also boron-lined proportional counters;

- gas-filled gamma-ray detectors: generally current-mode ion chambers but also Geiger-Mueller tubes;

- semiconductor gamma-ray detectors: predominantly Si PIN diodes used in gross-counting mode (no spectroscopy) or CZT diodes operated in spectroscopic mode;

- medium- and low-resolution gamma-ray spectrometers: $\mathrm{NaI}(\mathrm{Tl})$ and plastic scintillators, typically coupled to photomultiplier tubes.

The IAEA issued technical specifications for FEUM devices in 2012 [Appendix B], and the first FEUM prototype was delivered to the IAEA in May 2013. Basic functional testing of these devices were performed by the IAEA, but the IAEA does not have the resources to perform a comprehensive evaluation of FEUM characteristics, strengths, and limitations over the broad range of important parameters that includes sensor types, cable types, and the spectrum of industrial electromagnetic noise that can degrade signals from remotely located detectors. The IAEA indicated the need for a comprehensive and objective evaluation of FEUM in representative environments (e.g., high industrial noise, high radiation, widely varying temperatures) in order to define where and how FEUM should be implemented in the field. The Next Generation Safeguards Initiative (NGSI) FEUM project, a collaboration between Pacific Northwest National Laboratory (PNNL), Idaho National Laboratory and Los Alamos National Laboratory, is performing this evaluation on behalf of and in close consultation with the IAEA. The gas-filled neutron detector and gross-counting gamma-ray sensors account for the vast majority of deployed detectors, and therefore were the original focus of the IAEA's FEUM project, and the testing described in this document.

To help guide the FEUM development and constrain the scope to a manageable level, three scenarios have been defined to be representative of IAEA's UMS deployments around the world: 
- Scenario 1: He-3 and B-lined proportional counters (used for variety of qualitative and quantitative applications)

- Scenario 2: U-235 fission chamber (representative of the neutron portion of IAEA's Core Discharge Monitor for heavy-water reactors)

- Scenario 3: $\mathrm{NaI}(\mathrm{Tl})$ spectrometer sensor (e.g., for verification of mixed-oxide fuel rods).

In each of these scenarios, it will be assumed that the detector is physically separated from FEUM by a distance ranging from a few meters to 100 meters. A nominal configuration for FEUM's deployment in the field is depicted in Figure 1.1. In general, this device is required to provide pulse amplification, pulse shaping, and single-channel analyzer functionality for a range of radiation detector types, and interface with existing and new IAEA data acquisition (DAQ) systems.

This test plan documents methods used to provide testing and characterization of prototype FEUM modules to verify compliance with the core set of IAEA requirements, and to assess predicted performance of the FEUM devices in controlled as well as more challenging environments. The testing described in this report will inform IAEA's decision about whether to move forward with the current FEUM prototypes (e.g., by requesting modifications by the vendor) or to pursue alternative paths to the same end.

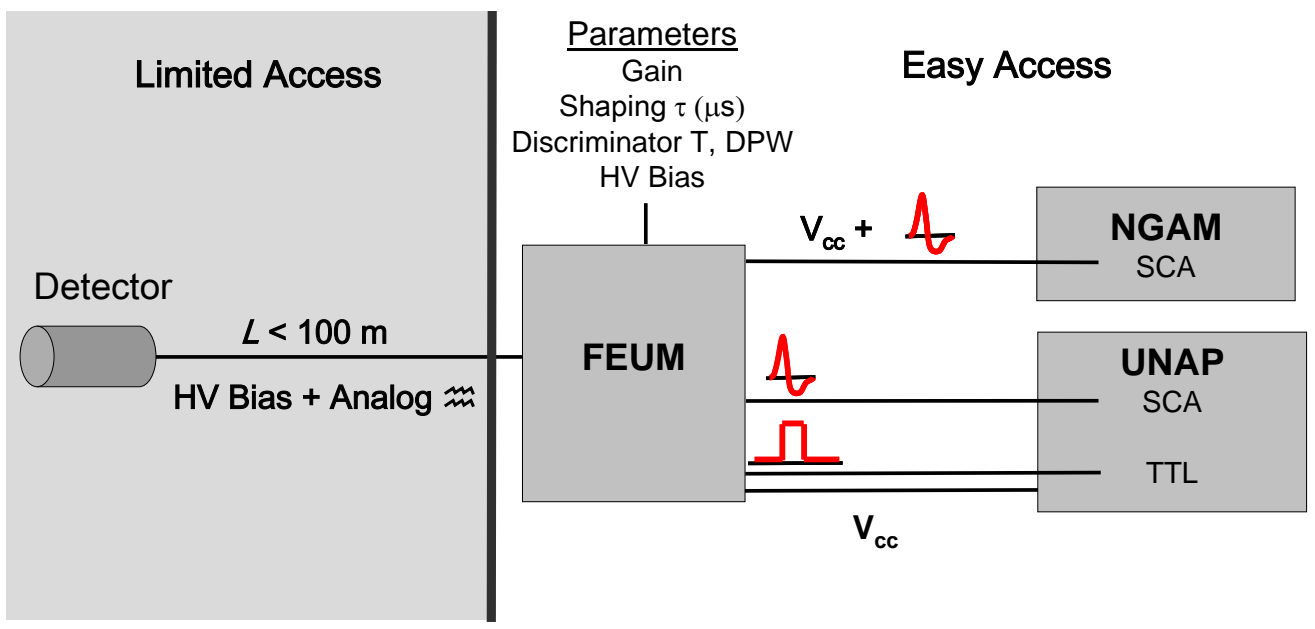

Figure 1.1. IAEA FEUM Concept 


\subsection{Test Objectives}

1. Verify compliance with a core set of the full requirements for the FEUM procurement [Appendix B]. The full set of requirements and selected test requirements are listed in Appendix A. A summary of items for testing or excluded from testing is listed in Table 1.

Table 1. Summary of Requirements for Evaluation in Initial Test Phase

\begin{tabular}{|l|l|}
\hline Requirement & Initial Test Applicability \\
\hline Functional Attributes & TESTED \\
\hline Compatibility with UMS DAQ & NOT TESTED AT THIS STAGE \\
\hline Environmental - EMI/RFI Susceptibility & TESTED \\
\hline Environmental - Other & NOT TESTED AT THIS STAGE \\
\hline
\end{tabular}

2. Measure performance of the FEUM prototype and compare against against the performance targets provided by the IAEA in the original FEUM specifications for ${ }^{3} \mathrm{He}$ detectors [Appendix A and Appendix B]. Those performance targets are founded on the use of an integral pulse height spectrum (IPHS) for data display and reduction, described by previous analysis ${ }^{1}$. Illustrative examples of IPHSs for various FEUM scenarios (i.e., cable length, shaping time, noise threshold) are shown qualitatively in Figure 1.2 for “easy” (green), “medium” (blue) and “difficult” (red) FEUM scenarios.

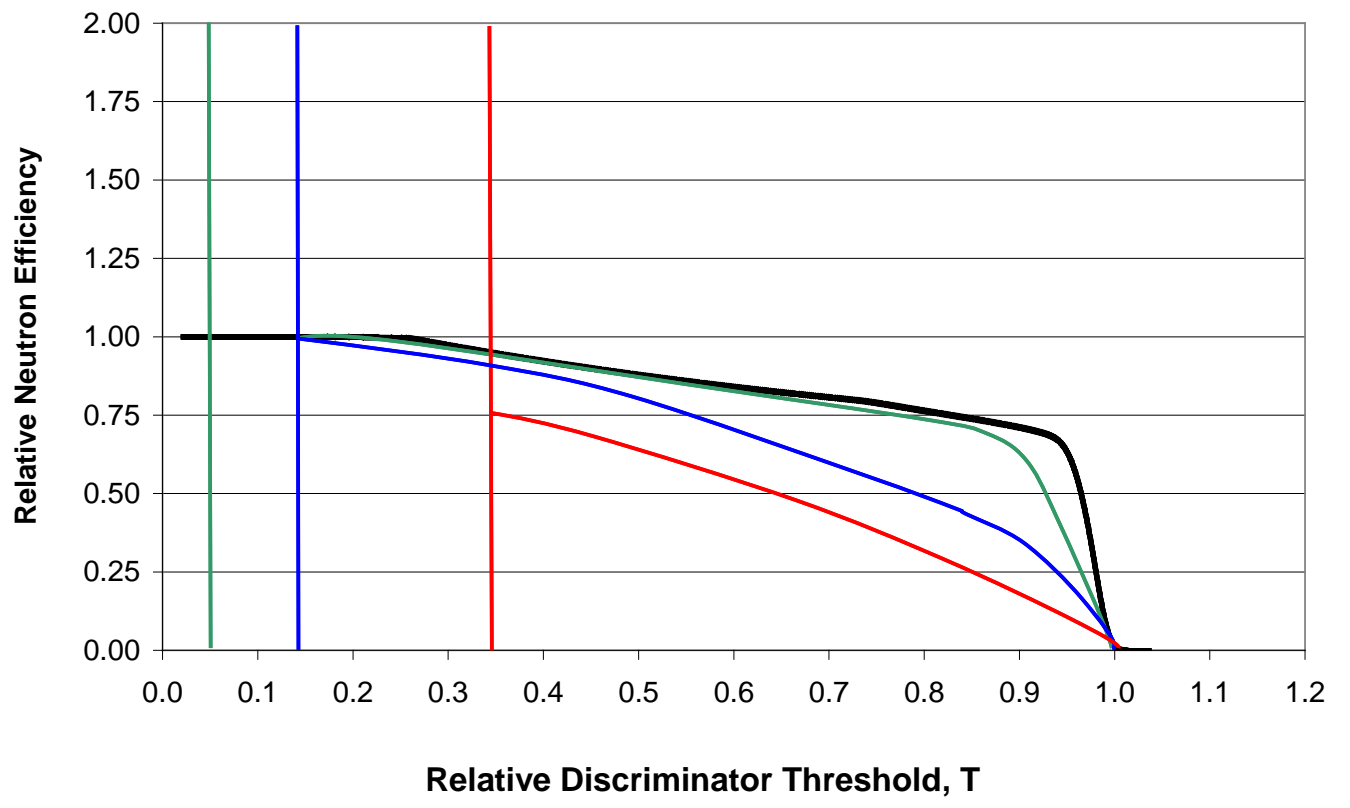

Figure 1.2. Graphical Representation of FEUM Performance Targets

${ }^{1}$ LE Smith et al., "Evaluation of Front-end Electronics for Unattended Safeguards Instruments”, IEEE Nuclear Science Symposium, 2011 
The IAEA then calculated quantitative performance targets for the relative neutron efficiency from the ${ }^{3} \mathrm{He}, \varepsilon_{\text {neutron }}$, for a set of representative scenarios using the following methodology:

- $\quad T_{\text {noise }}$ is the discrimination threshold where $R_{\text {noise }}<5$ cps with no neutron source present;

- $\quad \varepsilon_{\text {neutron }}(T)$ is the relative neutron efficiency defined to be $R_{\text {net }}(T) / R_{\text {ideal }}$

- $\quad R_{\text {ideal }}=$ net neutron count rate for $T=T_{\text {noise }}$ under assumptions of $L \sim 0, \tau \sim 2.0$;

- $\quad R_{\text {net }}(T)=$ net neutron count rate after subtraction of $R_{\text {noise }}(T)$

The IAEA's original table of performance targets is shown in Appendix A. PNNL believes, however, that the IAEA had an error in its calculational methodology-- $R_{\text {ideal }}$ was not held as a constant throughout the scenarios. Therefore, PNNL has developed a revised table using approximate target valuels for $\varepsilon_{\text {neutron }}(T)$ drawn from Figure 1.2. Table 2 tabulates these PNNL-calculated performance targets for relative neutron efficiencyas a function of discriminator threshold, cable length (capacitance), pulse shaping time, and noise-based minimum threshold. Additional discussion with the IAEA is needed to resolve the performance target question, but the values in Table 2 provide at least some context for the results of the FEUM prototype performance testing.

Table 2. Nominal FEUM Performance

\begin{tabular}{|l|l|l|}
\hline \multicolumn{1}{|c|}{$\boldsymbol{L}(\boldsymbol{m} \boldsymbol{R G - 7 1 )}, \tau(\boldsymbol{\mu s})$} & \multicolumn{1}{|c|}{$\boldsymbol{T}_{\text {noise }}$} & \multicolumn{1}{c|}{$\boldsymbol{T}, \boldsymbol{\varepsilon}_{\text {neutron }}$} \\
\hline$(1,2)(50,2)$ & 0.05 & $(0.20,0.80)(0.50,0.45)(0.80,0.15)$ \\
\hline$(1,0.1)(50,0.5)(100,0.5)(100,2)$ & 0.15 & $(0.20,0.70)(0.50,0.0 .40)(0.80,0.10)$ \\
\hline$(50,0.1)(100,0.1)$ & 0.35 & $(0.35,0.40)(0.50,0.20)(0.80,0.05)$ \\
\hline
\end{tabular}

Nominal FEUM Performance Targets for $T_{\text {noise }}$ and $\varepsilon_{\text {Neutron }}(T)$ for a Variety of Cable Lengths and Shaping Constants, assuming a ${ }^{3} \mathrm{He}$ neutron detector and RG-71 cable. Relative neutron efficiency targets are given for three notional classes of implementation scenario: "easy” (green), "medium” (blue) and "difficult" (red). Note: These values were calculated by PNNL and differ from original IAEA targets due to a possible error in IAEA calculations. 


\subsection{Testing Overview}

This section describes an overview of the testing approach and setups to be used. Specific procedures and data collection are located in the procedures, Appendix C. Tests will be conducted with the FEUM prototype configured for charge-sensitive mode, and where applicable, current-sensitive mode as well. Tests which are expected to be run in in charge-sensitive and current-sensitive mode are called out in each section. Several tests were added in revision 1 of this document but still apply to the functional testing section, and therefore some test numbering may be out of order.

\subsection{Conformance Verifications}

\section{[TEST 1] Feature Conformance Verification}

Conformance verifications typically take the form of a visual inspection or circuit analysis to note gaps between the FEUM requirements and FEUM prototype and to provide a first-order inspection of the FEUM prototype. There is no associated test procedure. General items to be evaluated are listed below but are not all-inclusive.

\section{Preamplifier}

Amplifier design variants and gain range

\section{Shaping Amplifier}

Shaping filter design and shaping-constant ranges

\section{Bias Supply}

High-voltage power supply design, range and isolation

High-voltage transient protection

\section{Enclosure}

Size and material of enclosure

Ease of access

\section{Interfaces}

Type of Connectors

Type of isolation employed

\subsection{Functional Tests}

The following tests are intended to verify individual electrical characteristics of the FEUM and that required functions of the FEUM are met. The FEUM prototype is the device under test (DUT) and will be connected to various test equipment (shown in gray) as notionally depicted in Figure 2.1. The test signal generator will typically be connected to the detector input port, but will alternatively be connected to the test input port in some tests to verify that port's functionality. 
The FEUM prototype will be tested to the IAEA-defined ranges where possible, or to the extent of the asbuilt prototype ranges, for cases where the IAEA-defined ranges cannot be achieved.

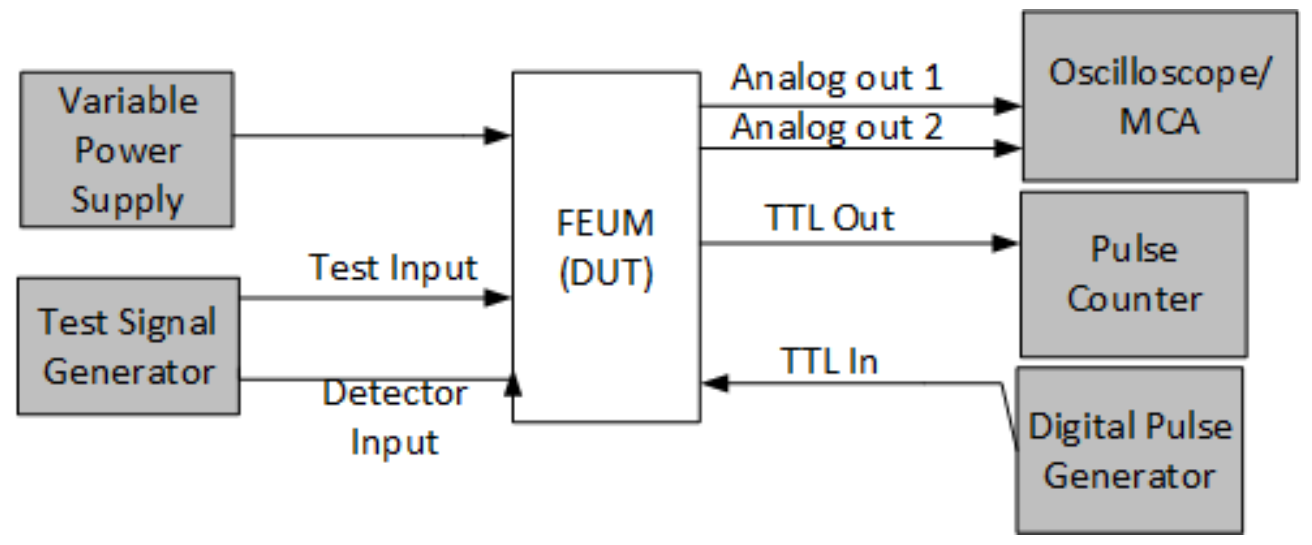

Figure 2.1. Generic Test Setup for Functional Tests

\subsubsection{Preamplifier}

[TEST 2] Pulse Rise Time

Test Removed. This test will not be pursued because it would require access to an internal test point that is not readily available in the FEUM prototypes.

\subsubsection{Shaping Amplifier}

[TEST 3] Shaping Amplifier - Gain and Charge Calibration

Measure the output pulse amplitude with various discrete gain settings. The target gain range is from $0.001 \mathrm{pC} / \mathrm{V}$ to $5000 \mathrm{pC} / \mathrm{V}$. Measurements will be performed in both charge-sensitive and current-sensitive mode. An absolute charge calibration will be performed as a part of this test.

[TEST 4] Analog Shaping Constant

Verify the pulse shape of output pulses using all variants for FEUM prototype shaping time constants. The target time constant range is from $0.05 \mu$ s to $2.0 \mu$ s. Measurements will be performed in both charge-sensitive and current-sensitive mode.

This test will verify on an oscilloscope that the output pulses are consistent with bipolar pulse shaping and that the output pulse widths are consistent with the shaping time constant selected. This test is a semi-quantitative confirmation.

\subsubsection{Discriminator}

[TEST 5] Discriminator - Threshold

Measure the output pulse height spectra on a multichannel analyzer (MCA) over the range of discrete discriminator thresholds from $0 \mathrm{~V}$ to $3.825 \mathrm{~V}$. This test will verify that the low level 
discriminator cutoff is consistent with the discriminator setting selected and the pulse injected and that it behaves in a linear manner. Visual verification will be performed using the oscilloscope and triggering on the TTL output. Measurements will be performed in both charge-sensitive and current-sensitive mode.

[TEST 6] TTL Pulse Width

Measure the TTL output pulse width for the FEUM prototype settable values. The target range is $50-500$ ns. This test will verify on an oscilloscope that $50 \%$ of peak at the rising edge to $50 \%$ of peak at the falling edge is consistent with the pulse width selected. Measurements will be performed in both charge-sensitive and current-sensitive mode.

\subsubsection{High-Voltage Bias Supply}

[TEST 7] Bias Supply - Voltage

Measure the DC bias voltage for each discrete high-voltage setting. The target range is from $200 \mathrm{~V}$ to $2000 \mathrm{~V}$. This test will verify that the bias voltage as measured by a DC voltmeter is consistent with the bias voltage selected over a range of settings.

[TEST 8] Bias Supply - Stability

Sample the DC output bias voltage for four bias voltages incrementally spaced over the range of the detector for a period of hours and days at millisecond and second time resolution. This test will verify that the instantaneous bias supply voltage is within $50 \mathrm{mV}$ of nominal by periodically sampling voltage with a data acquisition system (DAQ).

\subsubsection{Interfaces}

\section{[TEST 9] Input/Output Port Resistance}

Test Removed. The original test methods were not practical for all input/output ports. Some ports require the FEUM to be energized and measured in reference to test points which are not available on the FEUM prototype. Appropriate test points could be determined with detailed schematics, however these results are a lower priority and the outputs performed as expected with an oscilloscope input impedance set to $50 \Omega$,

[TEST 10] Count-Rate Indicator - LED Pulse

Measure the light-emitting diode (LED) blink rate when the FEUM is stimulated with a low pulse-rate input and visually verify that the blink rate is at least approximately representative of the input count rate. This test is purely qualitative-no effort is devoted to quantitatively comparing the blink rate to the actual count rate. 
[TEST 11] Isolated Input Power

For input voltage levels ranging from $9 \mathrm{~V}$ to $13.8 \mathrm{~V}$ in steps of $\sim 0.5 \mathrm{~V}$, verify basic FEUM functionality: correct bias voltage by digital voltmeter, and analog output pulse amplitude and shape using the oscilloscope.

[TEST 12] Digital Input - Logic Voltage Levels

Verify 5-V TTL input levels on the digital input, with $\mathrm{V}_{\mathrm{IH}}=2.4 \mathrm{~V}$. This test will measure the input voltage level at which logic high and logic low is registered $\left(\mathrm{V}_{\mathrm{IH}}\right.$ and $\left.\mathrm{V}_{\mathrm{IL}}\right)$ to ensure compatibility with typical 5-V TTL logic.

[TEST 13] Digital Input - Digital Summing

Verify the digital pulse summing functionality by measuring digital output pulses when stimulating the detector input and the TTL input simultaneously and sequentially. This test will use the AWG connected to the detector input port and the digital pulse generator connected to the digital input port. The output pulse is expected to be a logical OR or XOR of the two input pulses.

[TEST 14] $\vee_{c c}$ Grounded Input Power

This test will analyze the device operation with the external, non-isolated power supply input on analog port \#2, and compare against the isolated power supply on the standard power input. This quality comparison will be made by monitoring the low-voltage supply average voltage and noise, internal to the FEUM.

[TEST 15] Analog Output $1 \& 2$

Measure the output pulse on amplifier output \#1 and output \#2 with the AWG input. This test will verify that the output \#1 and \#2 pulse shape and amplitude are consistent with the charge injected input and that \#1 is completely decoupled from the input power supply while \#2 is superimposed on the Vcc Supply. This test will also verify that the two outputs are identical except for the DC offset.

[TEST 16] Digital Output- Logic Voltage Levels

Verify that the digital TTL output is compatible with 5-V TTL logic, with $\mathrm{V}_{\mathrm{OH}}=2.4 \mathrm{~V}$. This test will measure the output voltage level for a logic high and low ( $\mathrm{V}_{\mathrm{OH}}$ and $\left.\mathrm{V}_{\mathrm{OL}}\right)$ to ensure compatibility with typical 5-V TTL logic.

[TEST 17] Ground Isolation

Measure the port-to-port resistance and the port-to-ground resistance to determine how well the ports and ground are isolated. If the FEUM prototype supports multiple ground isolation configurations, test each configuration. 


\subsubsection{Deadtime and Intrinsic Noise Characteristics}

[TEST 23] Deadtime

The deadtime of the prototype FEUM device will be evaluated across different analog shaping times and discriminator output pulse widths. Three measurement methods will be utiilized: 1) Random pulse generator intended to be generically representative of IAEA UMS sensors, and 2) "two-source method" using a $\mathrm{NaI}(\mathrm{Tl})$ detector and gamma-ray sources to represent gamma-ray sensors, and 3) . a "time-interval histogram" method applied to a 3He detector, to represent UMS neutron sensors that must often operate in high gamma-ray fields.

\section{[TEST 24] Equivalent Noise Charge}

The equivalent noise charge (ENC) is a basic measure of instrument noise levels and will be measured in a manner consistent with open-literature protocols ${ }^{2}$. The ENC characterization test will use the AWG as the signal generator and will vary the shaping time and input capacitance across a wide range of values representative of IAEA UMS scenarios.

\subsubsection{UMS DAQ Standards Compatibility}

\section{[TEST 18] NGAM Compatibility}

Test Removed. This test was a lower priority and removed due to schedule and budget constraints.

Verify that an NGAM type DAQ is compatible with the FEUM and that the NGAM operates as expected. This is accomplished by taking count rate and peak channel measurements with both an MCA and an NGAM, with several different input amplitudes and varying the discriminator threshold on the FEUM prototype. This test will verify that the discriminator cutoff energies are similar for the MCA and the NGAM, and that the count rates also are consistent. This test is optional for this phase of testing (as schedule and budget permits).

\subsection{Performance Tests}

\section{[TEST 19] Baseline FEUM Performance}

The baseline FEUM performance will first be evaluated in controlled conditions, and this baseline will provide a reference for performance in more challenging environments. The basic setup depicted in Figure 2.2 will used for this test. Ideally, the baseline performance will be measured in the "quiet" atmosphere of an anechoic chamber but if the chamber is not available, testing will be performed in a standard laboratory environment. The MCA will be used to record the differential pulse height spectra which can then be analyzed to produce the integral pulse height spectra, as specified by the IAEA (see Section 1.2 and Appendix A for more discussion). The MCA-based integral pulse-height spectra will be spot-checked using the discriminator of the

\footnotetext{
${ }^{2}$ IEEE Standard 301-1976 IEEE Standard Test Procedures for Amplifiers and Preamplifiers for Semiconductor Radiation Detectors for Ionizing Radiation
} 
FEUM device and a digital counter. These tests will be performed on the FEUM in both chargesensitive and current-sensitive modes, as supported by the FEUM prototype and the detector to be measured. Not all detector types are compatible with current sensitive mode of operation.

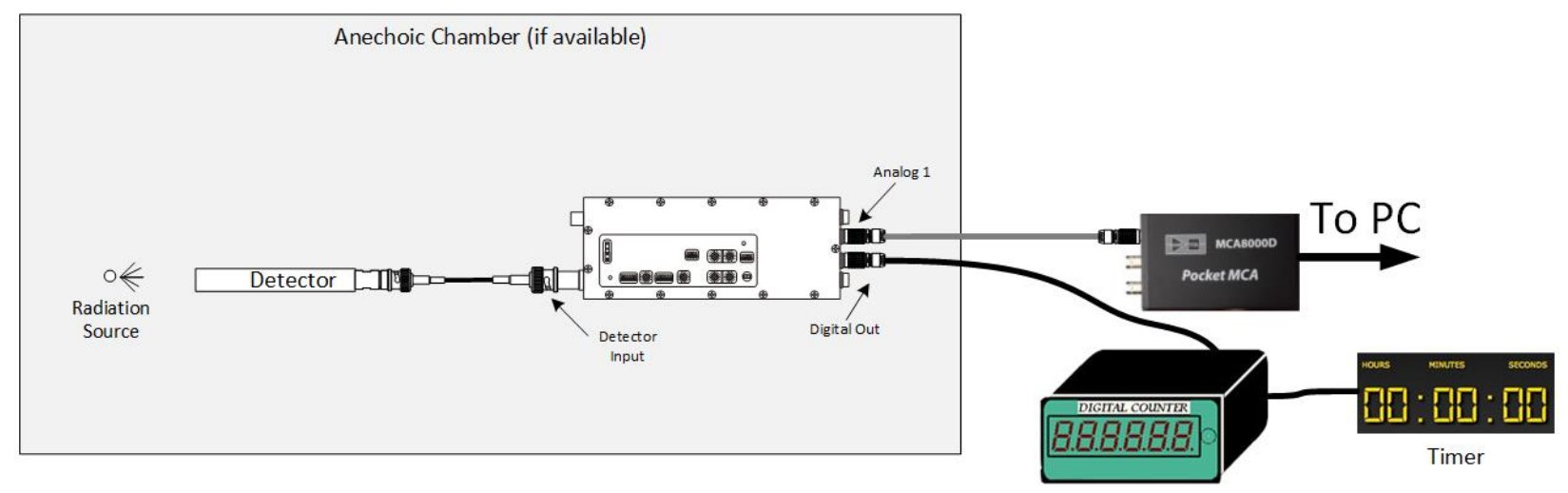

Figure 2.2. Baseline Performance Test Setup

The baseline FEUM performance will be studied over the range of detector, cabling and pulseshaping parameters recommended by the IAEA's FEUM specifications, as detailed in Table 3. The detector types are listed in order of descending priority.

Table 3. Detection Parameters to Vary for Performance Testing

\begin{tabular}{|l|l|l|l|}
\hline Detector Type & Cable/Length & Pulse Shaping Time & Output Port \\
\hline AWG & RG-71/1 m & $0.1 \mu \mathrm{s}$ & Isolated \\
He-3 & RG-71/50 m & $0.4 \mu \mathrm{s}$ & Ground-Coupled (Vcc Coupled)* \\
Fission Chamber & RG-71/100 m** & $2.4 \mu \mathrm{s}$ & \\
NaI (TI) & RG-174/100 m & & \\
\hline
\end{tabular}

*Fewer measurements will be taken with the ground-coupled output, since the two outputs should be similar.

**If reasonable results with $100 \mathrm{~m}$ cable are not achievable, shorter length cables such as $10 \mathrm{~m}$ and $25 \mathrm{~m}$ may be used

\subsection{Stress Performance Tests}

\subsubsection{EMI/RFI Susceptibility}

Because EMI/RFI susceptibility is an important implementation issue for FEUM devices in the anticpated operating environments, this testing will explore FEUM prototype performance under varying EMI/RFI conditions. These tests will consist of radiated RF resistance at higher frequencies ( $30 \mathrm{MHz}$ to $2.45 \mathrm{GHz}$ ) and conducted RF resistance at lower frequencies ( $10 \mathrm{kHz}$ to $30 \mathrm{MHz}$ ), based on analysis per NUREG/CR-6782, Comparison of U.S. Military and International Electromagnetic Compatibility Guidance. Conducted susceptibility is performed at the lower frequencies because it is generally accepted that typical cable lengths are not adequately long for testing radiated susceptibility at low 
frequencies (long wavelengths). Test methods are based on MIL-STD-461E. While not an exhaustive test for EMI/RFI susceptibility, these tests should inform IAEA planning for additional evaluation.

\section{[TEST 20] Radiated EMI/RFI Susceptibility}

The test setup in Figure 2.3 will be used for radiated susceptibility tests. The same set of detector, cable and shaping time parameters used in the baseline performance tests will be applied. Because the double-shielded RG-71 cabling is the most prevalent cable used in new IAEA deployments and is expected to provide more robust performance in noisy environments, priority will be placed on testing with this cable type (and less on the RG-174). Typical test methods require $10 \mathrm{~V} / \mathrm{m}$ field strength; however 5 and $20 \mathrm{~V} / \mathrm{m}$ may also be tested to explore the bounds of FEUM performance in RF fields. Table 4 summarizes the parameters and parameter variants to be considered during EMI/RFI susceptibility testing. Detector types are listed in order of descending priority.

Table 4. Detection Parameters to Vary for Performance Testing

\begin{tabular}{|l|l|l|l|l|}
\hline & Cable/Length & $\begin{array}{l}\text { Pulse } \\
\text { Shaping } \\
\text { Time }\end{array}$ & $\begin{array}{l}\text { Radiated Field } \\
\text { Strength }\end{array}$ & Output Port \\
\hline AWG & RG-71/1 m & $0.1 \mathrm{us}$ & $10 \mathrm{~V} / \mathrm{m}$ & Isolated \\
He3 & RG-71/50 m & $0.5 \mathrm{us}$ & $(5 \mathrm{~V} / \mathrm{m})^{*}$ & Ground-coupled \\
Fission Chamber & RG-71/100 m** & 2 us & $(20 \mathrm{~V} / \mathrm{m})^{*}$ & \\
NaI (TI) & RG-174/100 m* & & & \\
\hline
\end{tabular}

* To be tested if time permits and initial results warrant

**If reasonable results with $100 \mathrm{~m}$ cable are not achievable, shorter length cables such as $10 \mathrm{~m}$ and $25 \mathrm{~m}$ may be used

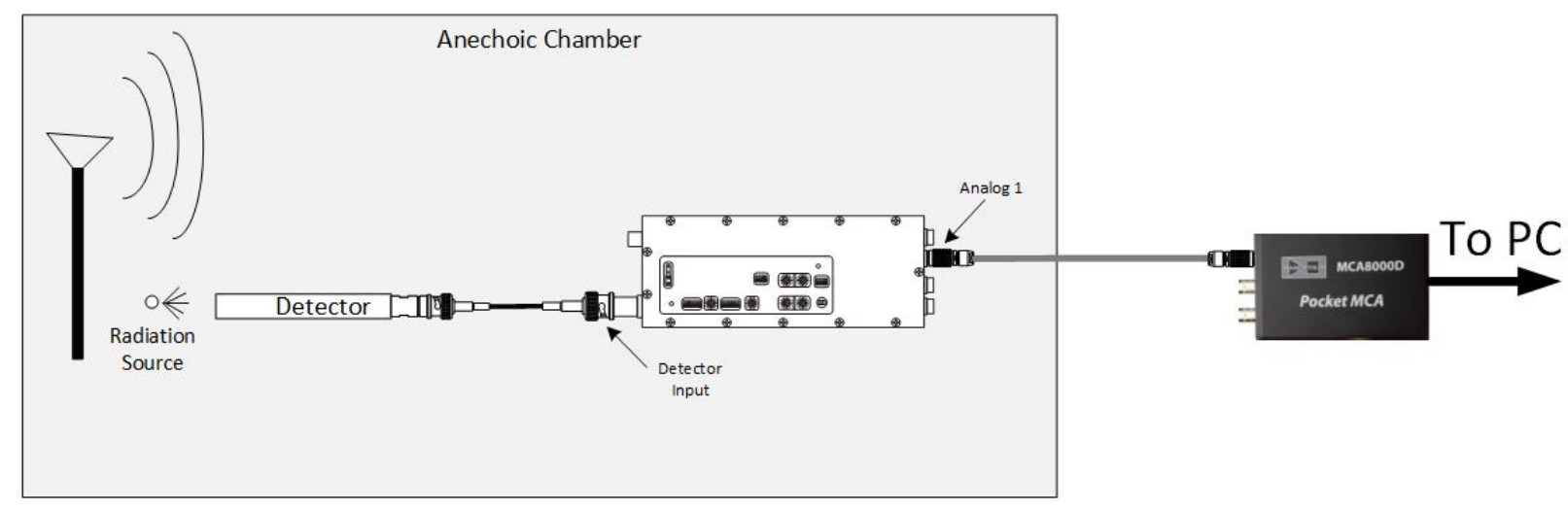

Figure 2.3. Radiated EMI/RFI Test Setup 
[TEST 21] Conducted EMI/RFI Susceptibility

Test Removed. This test was removed because conducted EMI susceptibility can be considered a system-level test, while the FEUM evaluation is focused on component-level tests. The results are highly dependent on the power supply chosen for use, and as such have limited value for practical FEUM use.

The test setup in Figure 2.4 will be used for conducted susceptibility tests. The tests will focus on the standard RG-71 cable, using setup permutations shown in Table 5. (Detector variants shown in order of descending priority) MIL-STD-461E allows for both power source injection and signal injection. Signal noise injection is chosen for this test as it is expected to be more consistent with the industrial noise experienced in IAEA's UMS deployments. The arbitrary waveform generator will be coupled to the detector input either by inductive injection or direct injection.

Table 5. Detection Parameters to Vary for Conducted Susceptibility Tests

\begin{tabular}{|l|l|l|l|l|}
\hline Detector Type & Cable/Length & $\begin{array}{l}\text { Pulse } \\
\text { Shaping } \\
\text { Time }\end{array}$ & $\begin{array}{l}\text { Noise } \\
\text { Amplitude }\end{array}$ & Output Port \\
\hline AWG & RG-71/1 m & $0.1 \mu \mathrm{s}$ & $(110 \mathrm{dBuV})^{*}$ & Isolated \\
He3 & RG-71/50 m & $0.5 \mu \mathrm{s}$ & $(120 \mathrm{dBuV})^{*}$ & Ground-coupled \\
Fission Chamber & RG-71/100 m** & $2 \mu \mathrm{s}$ & $130 \mathrm{dBuV}$ & \\
NaI (TI) & RG-171/100 m* & & & \\
\hline
\end{tabular}

* To be tested if time permits and initial results warrant

**If reasonable results with $100 \mathrm{~m}$ cable are not achievable, shorter length cables such as $10 \mathrm{~m}$ and $25 \mathrm{~m}$ may be used

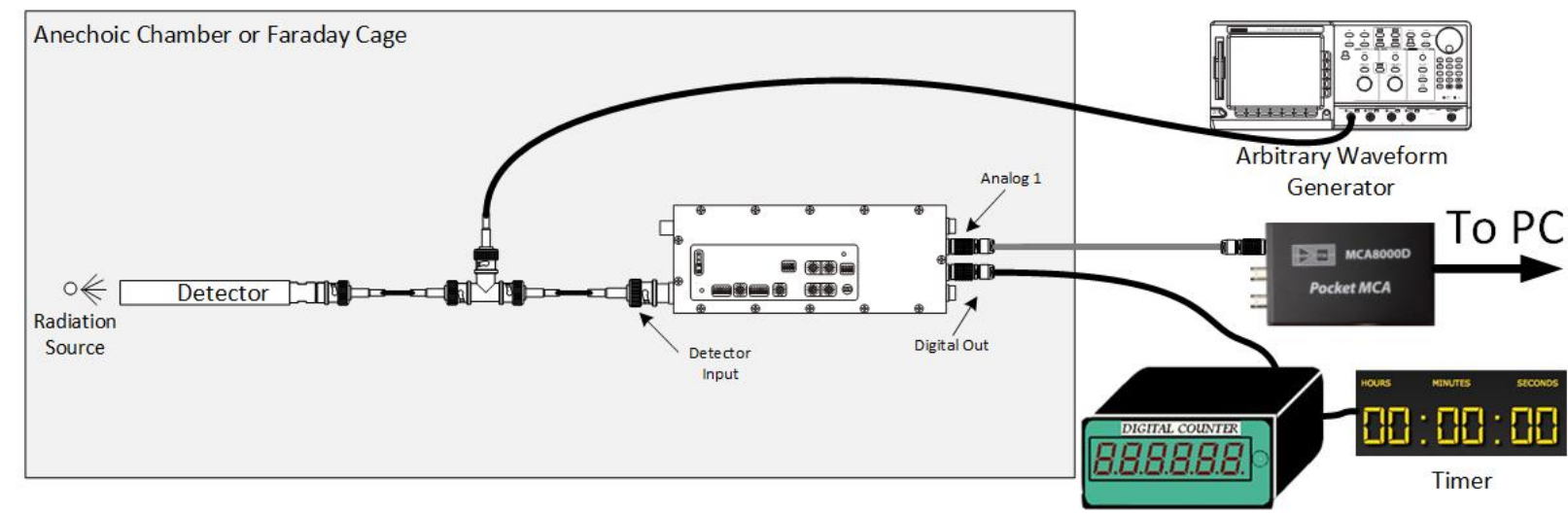

Figure 2.4. Conducted EMI/RFI Test Setup 
[TEST 25] High Radiation Field Susceptibility

IAEA's unattended monitoring systems are often deployed in high radiation fields. A particular concern is the ability of neutron counting systems to sufficiently discriminate high gamma-ray fields. In these tests, the setup described in Figure 2.2 will be deployed at a PNNL facility where intense neutron and gamma-ray sources are available. ${ }^{3} \mathrm{He}$ and fission chambers operating at representative neutron detection rates will be subjected to increasing gamma-ray fields. MCA spectra at each field intensity will allow study of gamma-ray pileup effects on both the differential and integral pulse height spectra. These tests will be limited to RG-71 cable at varying lengths as shown in Table 6.

Table 6. Detection Parameters to Vary for High Radiation Field Test

\begin{tabular}{|c|c|c|c|}
\hline Detector Type & Cable/Length & $\begin{array}{l}\text { Pulse } \\
\text { Shaping } \\
\text { Time }\end{array}$ & Output Port \\
\hline $\begin{array}{l}\text { Fission Chamber } \\
\text { He3 }\end{array}$ & $\begin{array}{l}\text { RG-71/1 m } \\
\text { RG-71/50 m } \\
\text { RG-71/100 m }\end{array}$ & $\begin{array}{l}0.1 \mu \mathrm{s} \\
0.5 \mu \mathrm{s} \\
2 \mu \mathrm{s}\end{array}$ & Isolated \\
\hline
\end{tabular}

\subsubsection{Ground Loop Noise Susceptibility}

[TEST 22] Ground Loop Susceptibility

Test Removed. IAEA has indicated that ground-loop noise can be a significant degrading issue in field deployments, but because ground-loop effects are highly dependent on the specific conditions of the facility (e.g., frequency and voltage of supply power, ground quality) and IAEA deployment (e.g., sensor types, collimator contact to the sensor), the effects in question cannot be reproduced for meaningful quantitative testing. Any qualtitative testing does not adequately prove the FEUM is free of specific noise issues observed from ground loops. 


\subsection{Equipment and Configuration}

This section describes the applicable test equipment, settings, and documentation.

\subsection{Device Under Test (DUT)}

\subsubsection{FEUM Prototype}

In the test procedures, the devices under test (DUTs) are assumed to be the FEUM v1.0 or 1.1 from BOT Engineering unless otherwise explicitly stated.

\subsection{Test Equipment}

\subsubsection{Variable Power Supply}

The power supply will be a standard commercial-off-the-shelf (COTS) supply, 0-24 V+/-100 mV, 3 A or greater.

\subsubsection{Oscilloscope}

The oscilloscope for testing will be a standard COTS unit, >500 MHz bandwidth, >1 GSa/s, capable of $2000 \mathrm{~V}$ with a high voltage probe for high-voltage measurements. .

\subsubsection{Pulse Counter}

An Ortec 773 timer counter Nuclear Instrumentation Module (NIM) will be used for counting digital pulses.

\subsubsection{Multi-channel Analyzer}

The MCA used for testing will have at least 16k channels of resolution, Amptek Pocket MCA 8000 or similar.

\subsubsection{Charge Injector}

This test component has been removed. All uses of the charge injector have been replaced with the arbitrary waveform generator..

\subsubsection{Arbitrary Waveform Generator}

The arbitrary waveform generator (AWG) to be used will be a $30 \mathrm{MHz}$, Agilent 33522A AWG or equivalent. General settings were a sawtooth output at a frequency of $1 \mathrm{KHz}$. The output impedance was set to high-Z. 


\subsubsection{He-3 Detector}

The He-3 detector to be used will be a Reuter-Stokes RS-P4-0825-203, 1” x 25” (Dia x L) He-3 proportional counter at $10 \mathrm{~atm}$.

\subsubsection{Fission Chamber}

RS-P6-0805-134 used by the IAEA or equivalent, in a similar moderation configuration.

\subsubsection{Nal (TI) Detector}

The NaI detector for performance measurements will be a Ludlum Measurements, Inc. Model 44-2, scintillator, 2.5 x $2.5 \mathrm{~cm}$ (1 x 1 in.) (Dia x L) thick NaI(Tl).

\subsubsection{Multimeter}

Multimeter measurements will be made using COTS digital voltmeters CAT III or CAT IV rated, Fluke 87 or equivalent. For higher voltage measurements a 1000:1 high-voltage probe may be used.

\subsubsection{Data Acquisition System}

For long term data acquisition, a National Instruments 0-10 V, 100 ms data logger will be used, in conjunction with a voltage divider for higher voltage measurements.

\subsubsection{High Voltage, Precision Capacitor}

Connecting a capacitor in series with the an AWG will produce a charge pulse. The charge generated is determined by the voltage change from the AWG and the size of the capacitor. The shape of the pulse is determined by the rate of voltage change. Two precision capacitors were used with nominal values of 15 $\mathrm{pF}$ and $2 \mathrm{nF}$. They were placed inside an aluminum box with a BNC connector on one side and a SHV connector on the other. Reference waveforms form the AWG and precision capacitor outputs are shown in the following figures. 


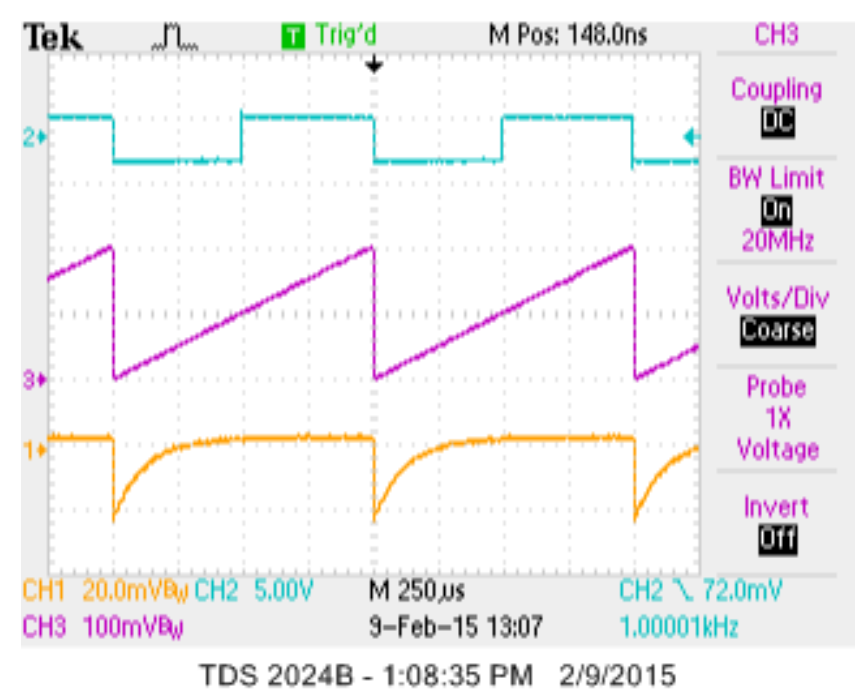

Figure 3.1 Reference AWG and capacitor waveforms.

Yellow(1)-Capacitor Output, Blue(2)-AWG Sync Signal, Magenta(3)-AWG Waveform Output

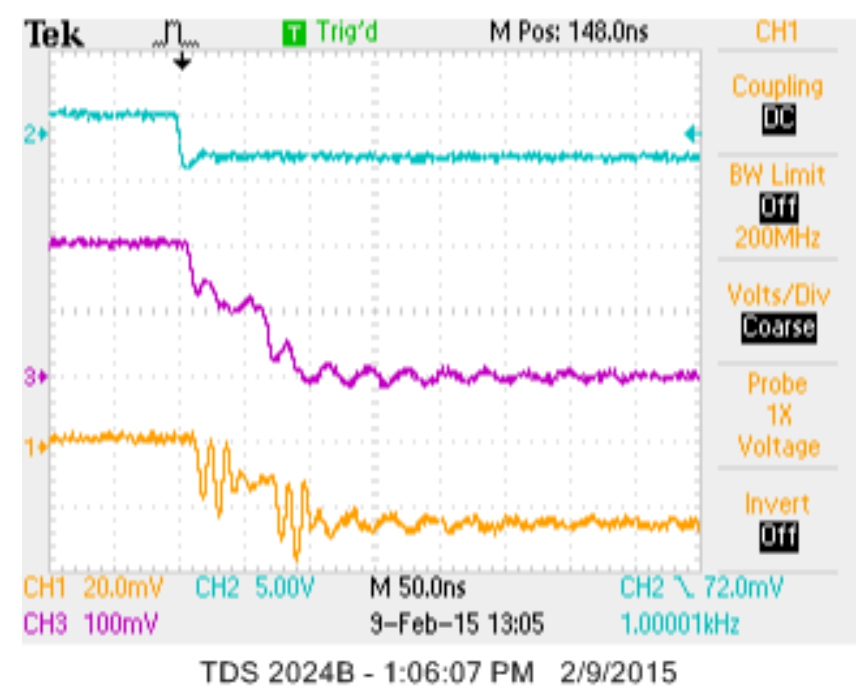

Figure 3.2 Reference AWG and capacitor waveform edges with reduced time scale. Yellow(1)-Capacitor Output, Blue(2)-AWG Sync Signal, Magenta(3)-AWG Waveform Output 


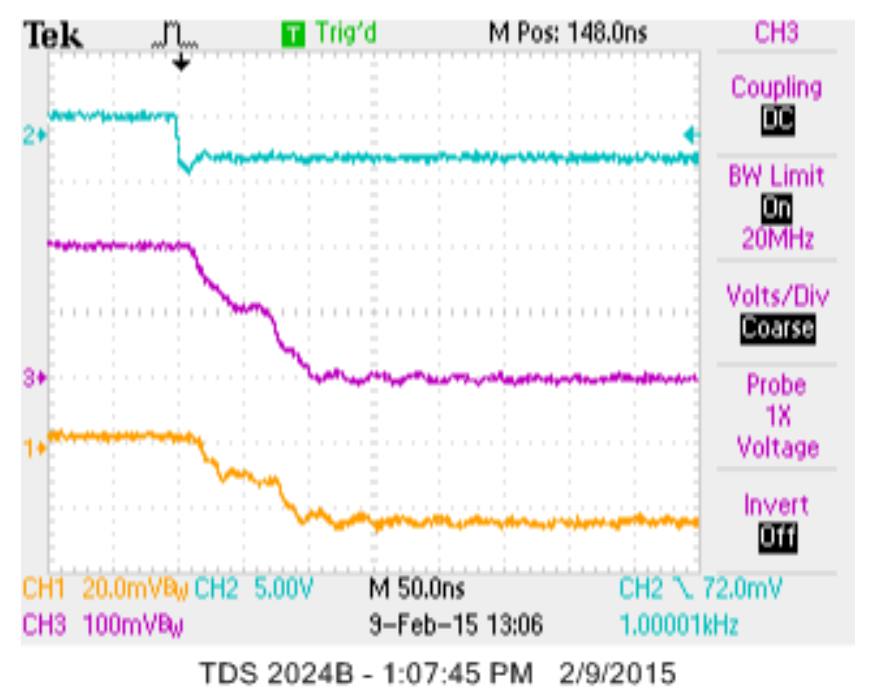

Figure 3.3 Reference AWG and capacitor waveforms with $20 \mathrm{MHz}$ bandwidth. Yellow(1)-Capacitor Output, Blue(2)-AWG Sync Signal, Magenta(3)-AWG Waveform Output

\subsection{Configuration}

Figure 3.4 shows the configurable settings available on the FEUM v1.x devices. Nominal settings for the device are all switches set at the median setting. Specific procedures will direct settings different from the nominal settings.

Test equipment configuration settings will be set as directed by specific procedures. 


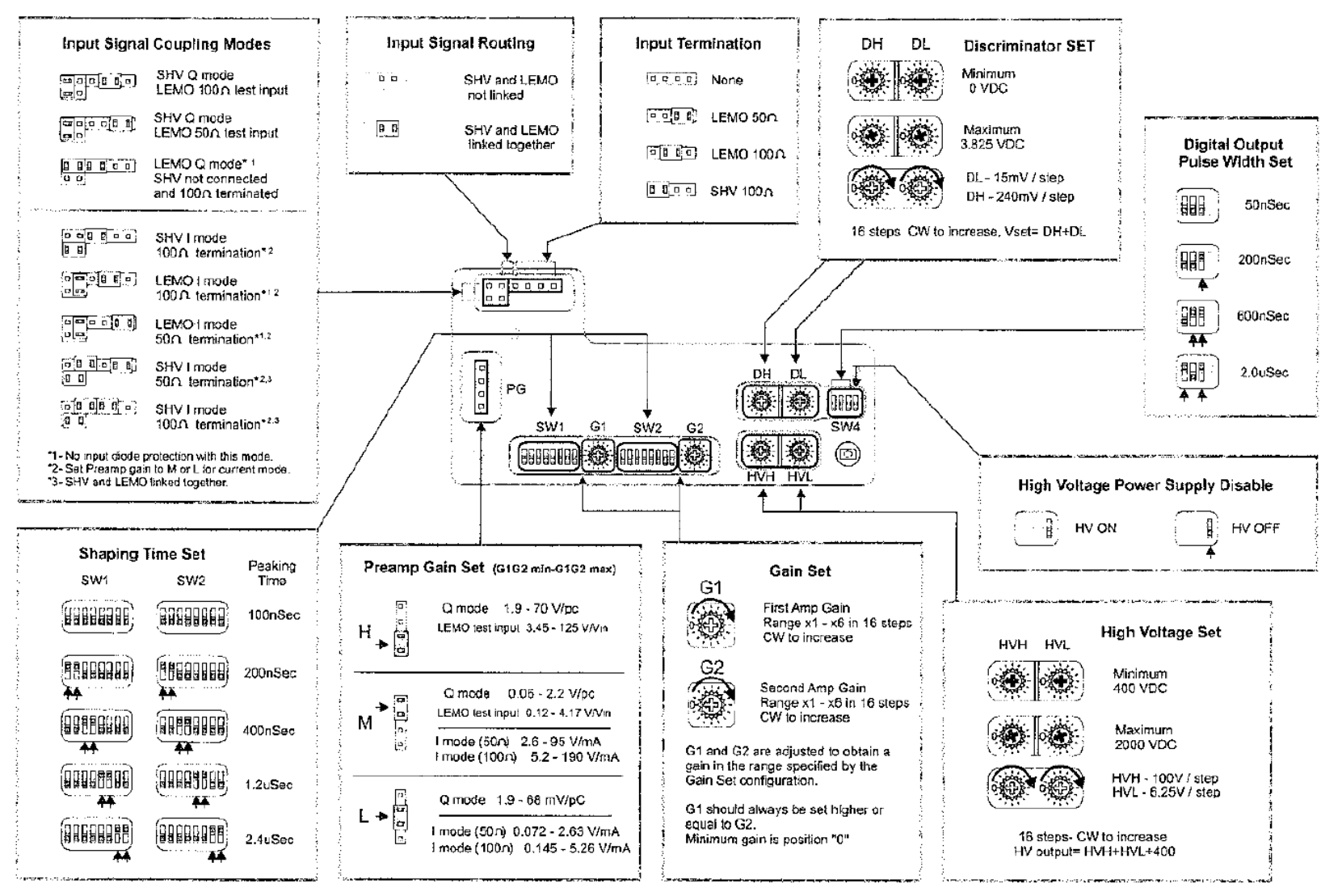

Figure 3.4. FEUM Prototype Configuration Settings 


\subsection{Reporting Requirements}

\subsection{Interim Reporting}

The data to be collected for post-test analysis consist of primarily:pulse waveforms as collected on the oscilloscope;pulse height spectra collected by the MCA;series of data points used to characterize the variable of interest (e.g., linearity of gain, discriminator threshold).

The primary analysis will be processing spectral data into integral pulse height spectra, which will lead into reporting on relative FEUM neutron detection efficiency as a function of cable length, discriminator threshold, and environmental noise.

Interim test results will be provided to project stakeholders after initial phases of performance testing, and compared to those reported from previous IAEA testing relevant to the FEUM prototypes ("Evaluation of Front-End Electronics for Unattended Safeguards Instruments”, 2011 IEEE Nuclear Science Symposium Conference Record, L.E. Smith et al.). Interim results will also include any results from tests already completed which provide early input to the IAEA in regards to the FEUM prototype suitability.

\subsection{Vendor Feedback}

PNNL will compile a list of comments for the FEUM prototype vendor. These items will be logged during testing and FEUM prototype review, and submitted to the vendor during or at the completion of testing, as appropriate.

\subsection{Final Test Report}

The final test report will be generated at the end of testing and after all analysis has been completed. The report is to include completed data sheets from the test procedures, and analysis of all data collected per the descriptions in this document and additional methods as defined after testing has begun.

The final content of the test report will be determined after all data have been collected and analyses have been performed. Table 7 provides a summary of the data to be collected and the expected analyses and/or metrics expected to be used for each test conducted.

Table 7. Summary of Tests, Data Collected, and Analyses

\begin{tabular}{|l|l|l|l|}
\hline Test \# & Section & Data Collected & Analysis/Metric \\
\hline $\begin{array}{l}\text { Test 1 - Feature } \\
\text { Conformance } \\
\text { Verification }\end{array}$ & N/A & Engineering analyses of design & Various \\
\hline $\begin{array}{l}\text { Test 2 - Pulse } \\
\text { Rise Time }\end{array}$ & $\begin{array}{l}\text { Test } \\
\text { Removed }\end{array}$ & N/A & N/A \\
\hline $\begin{array}{l}\text { Test 3 - Gain and } \\
\text { Charge } \\
\text { Calibration }\end{array}$ & C.1 & $\begin{array}{l}\text { Input/output waveforms, data } \\
\text { tables of gain vs. gain setting }\end{array}$ & Quantitative linearity \\
\hline
\end{tabular}




\begin{tabular}{|c|c|c|c|}
\hline Test \# & Section & Data Collected & Analysis/Metric \\
\hline $\begin{array}{l}\text { Test } 4-\text { Analog } \\
\text { Shaping Constant }\end{array}$ & C.1 & $\begin{array}{l}\text { Output Waveforms, Data } \\
\text { Tables of pulse width and } \\
\text { amplitude }\end{array}$ & $\begin{array}{l}\text { Qualitative-pulse shape, } \\
\text { Qualitative - pulse width and } \\
\text { amplitude }\end{array}$ \\
\hline $\begin{array}{l}\text { Test } 5- \\
\text { Discriminator } \\
\text { Threshold }\end{array}$ & C.2 & $\begin{array}{l}\text { Data tables of threshold vs. } \\
\text { threshold setting }\end{array}$ & Quantitative linearity \\
\hline $\begin{array}{l}\text { Test } 6 \text { - TTL } \\
\text { Pulse Width }\end{array}$ & C.3 & $\begin{array}{l}\text { Data tables of pulse width vs. } \\
\text { settings }\end{array}$ & $\begin{array}{l}50 \% \text { to } 50 \% \text { pulse width vs. } \\
\text { expected }\end{array}$ \\
\hline $\begin{array}{l}\text { Test } 7-\text { Bias } \\
\text { Supply Voltage }\end{array}$ & C. 4 & $\begin{array}{l}\text { Data tables of average voltage } \\
\text { versus expected }\end{array}$ & Quantitative linearity. \\
\hline $\begin{array}{l}\text { Test } 8-\text { Bias } \\
\text { Supply Stability }\end{array}$ & C.5 & $\begin{array}{l}\text { Data plots of voltage over short } \\
\text { periods on order of days or less }\end{array}$ & $\begin{array}{l}\text { Verify all voltages are }+/-50 \mathrm{mV} \\
\text { of expected }\end{array}$ \\
\hline $\begin{array}{l}\text { Test } 9- \\
\text { Input/Output Port } \\
\text { Resistance }\end{array}$ & $\begin{array}{l}\text { Test } \\
\text { Removed }\end{array}$ & N/A & N/A \\
\hline $\begin{array}{l}\text { Test } 10-\text { LED } \\
\text { Count Rate }\end{array}$ & C.3 & N/A & $\begin{array}{l}\text { Visually verify } 10-\mathrm{Hz} \text { count rate } \\
\sim \text { as expected }\end{array}$ \\
\hline $\begin{array}{l}\text { Test } 11 \text { - Isolated } \\
\text { Input Power }\end{array}$ & C.6 & $\begin{array}{l}\text { Data tables of high voltages vs. } \\
\text { input voltage } \\
\text { Data tables of output amplitude } \\
\text { vs expected gain }\end{array}$ & $\begin{array}{l}\text { Plot measured high voltage vs. } \\
\text { expected } \\
\text { Compute linearity of gain for } \\
\text { each voltage input }\end{array}$ \\
\hline $\begin{array}{l}\text { Test } 12 \text { - Digital } \\
\text { Input Logic } \\
\text { Voltage Levels }\end{array}$ & C.7 & $\begin{array}{l}\text { Data tables of input voltage } \\
\text { required to trigger output }\end{array}$ & $\begin{array}{l}\text { Calculate } \mathrm{V}_{\mathrm{IH}} \text { and } \mathrm{V}_{\mathrm{IL}} \text { and } \\
\text { compare to spec and TTL }\end{array}$ \\
\hline $\begin{array}{l}\text { Test } 13-\text { Digital } \\
\text { Summing }\end{array}$ & C.7 & Pulse width and separation & $\begin{array}{l}\text { Verify two discrete output pulses } \\
\text { for independent and coincident } \\
\text { inputs }\end{array}$ \\
\hline $\begin{array}{l}\text { Test } 14- \\
\text { Grounded Input } \\
\text { Power }\end{array}$ & C.6 & $\begin{array}{l}\text { Data tables of high voltages vs. } \\
\text { input voltage } \\
\text { Data tables of output amplitude } \\
\text { vs expected gain }\end{array}$ & $\begin{array}{l}\text { Compare measured high voltage } \\
\text { vs. expected } \\
\text { Compute linearity of gain for } \\
\text { each voltage input }\end{array}$ \\
\hline $\begin{array}{l}\text { Test } 15-\text { Analog } \\
\text { Output \#1 and \#2 }\end{array}$ & C.8 & $\begin{array}{l}\text { DC offset with grounded power } \\
\text { input } \\
\text { Data tables of pulse width and } \\
\text { height with grounded power } \\
\text { input }\end{array}$ & $\begin{array}{l}\text { Verify offset is } 0 \text { and Vcc } \\
\text { Verify pulse shapes are similar } \\
\text { Compare input amplitude to } \\
\text { output amplitude and gain }\end{array}$ \\
\hline
\end{tabular}




\begin{tabular}{|c|c|c|c|}
\hline Test \# & Section & Data Collected & Analysis/Metric \\
\hline $\begin{array}{l}\text { Test } 16 \text { - Digital } \\
\text { Output Logic } \\
\text { Voltage Levels }\end{array}$ & C.3 & $\begin{array}{l}\text { Voltages at which output is } \\
\text { logic } 1 \text { or } 0\left(\mathrm{~V}_{\mathrm{OH}} \text { and } \mathrm{V}_{\mathrm{OL}}\right)\end{array}$ & $\begin{array}{l}\text { Verify voltages are within spec } \\
\text { and TTL norms }\end{array}$ \\
\hline $\begin{array}{l}\text { Test } 17-\text { Ground } \\
\text { Isolation }\end{array}$ & C.9 & $\begin{array}{l}\text { Data tables of port ground } \\
\text { isolation }\end{array}$ & $\begin{array}{l}\text { Verify isolation and note } \\
\text { abnormal impedance }\end{array}$ \\
\hline $\begin{array}{l}\text { Test } 18 \text { - NGAM } \\
\text { Compatibility } \\
\text { (Optional) }\end{array}$ & $\begin{array}{l}\text { Test } \\
\text { Removed }\end{array}$ & N/A & N/A \\
\hline $\begin{array}{l}\text { Test } 19 \text { - Baseline } \\
\text { FEUM } \\
\text { Performance }\end{array}$ & C.10 & $\begin{array}{l}\text { MCA pulse height spectra } \\
\text { Limited comparison to } \\
\text { discriminator/SCA response }\end{array}$ & $\begin{array}{l}\text { Construct integral pulse height } \\
\text { curves, as a function of cable } \\
\text { length and shaping time per } \\
\text { IAEA performance targets }\end{array}$ \\
\hline $\begin{array}{l}\text { Test } 20 \text {-Radiated } \\
\text { EMI/RFI } \\
\text { Susceptibility }\end{array}$ & C.11 & $\begin{array}{l}\text { MCA pulse height spectra } \\
\text { Limited comparison to } \\
\text { discriminator/SCA response }\end{array}$ & $\begin{array}{l}\text { Construct integral pulse height } \\
\text { curves, as a function of cable } \\
\text { length and shaping time per } \\
\text { IAEA performance targets }\end{array}$ \\
\hline $\begin{array}{l}\text { Test } 21 \text { - } \\
\text { Conducted } \\
\text { EMI/RFI } \\
\text { Susceptiblity }\end{array}$ & $\begin{array}{l}\text { Test } \\
\text { Removed }\end{array}$ & N/A & N/A \\
\hline $\begin{array}{l}\text { Test } 22-\text { Ground } \\
\text { Loop oise }\end{array}$ & $\begin{array}{l}\text { Test } \\
\text { Removed }\end{array}$ & N/A & N/A \\
\hline $\begin{array}{l}\text { Test } 23- \\
\text { Deadtime }\end{array}$ & C.13 & $\begin{array}{l}\text { Count rates from detector based } \\
\text { on known input rates and/or } \\
\text { time interval histograms }\end{array}$ & $\begin{array}{l}\text { Fitting of measured count rate vs. } \\
\text { input count rate to determine } \\
\text { dead time values and } \\
\text { characteristics (paralyzableor } \\
\text { non-paralyzable), and } \\
\text { investigation of leading edges in } \\
\text { the time-interval histogram }\end{array}$ \\
\hline $\begin{array}{l}\text { Test } 24- \\
\text { Equivalent Noise } \\
\text { Charge }\end{array}$ & C.14 & $\begin{array}{l}\text { Centroid and FWHM of } \\
\text { calibrated pulser peaks }\end{array}$ & $\begin{array}{l}\text { Calculation of ENC and } \\
\text { construction of input capacitance } \\
\text { vs ENC and shaping time vs ENC } \\
\text { graphs }\end{array}$ \\
\hline $\begin{array}{l}\text { Test } 25-\text { High } \\
\text { Radiation Field } \\
\text { Susceptibility }\end{array}$ & C.15 & $\begin{array}{l}\text { MCA pulse height spectra } \\
\text { Limited comparison to } \\
\text { discriminator/SCA response }\end{array}$ & $\begin{array}{l}\text { Construct integral pulse height } \\
\text { curves, as a function of cable } \\
\text { length and shaping time per } \\
\text { IAEA performance targets }\end{array}$ \\
\hline
\end{tabular}




\section{Appendix A}

\section{Requirements Compliance Matrix}

\begin{tabular}{|c|c|c|c|c|}
\hline \multirow{2}{*}{$\begin{array}{l}\text { Requirement } \\
\text { Preamplifier }\end{array}$} & \multicolumn{2}{|c|}{ Source of Requirement } & \multirow[t]{2}{*}{ Verification } & \multirow[t]{2}{*}{ Comments } \\
\hline & & & & \\
\hline Charge- or Current-Sensitive & Specifications & Ver 1 & Various & \\
\hline Rise Time $<20$ ns & Specifications & Ver 1 & Test 2 & \\
\hline \multicolumn{5}{|l|}{ Shaping Amplifier } \\
\hline Bipolar Shaping & Specifications & Ver 1 & Test 1 & \\
\hline$\tau=0.05,0.1,0.25,0.5,1.0,2.0 \mu \mathrm{s}$ & Specifications & Ver 1 & Test 3 & \\
\hline Gain $0.001-5000 \mathrm{pC} / \mathrm{V}$ & Specifications & Ver 1 & Test 4 & \\
\hline Vout 0 to $0.9 \mathrm{Vcc}$ & Specifications & Ver 1 & Test 4 & \\
\hline 1 Vout superimposed on Vcc & Specifications & Ver 1 & $\begin{array}{l}\text { Test } 14 \text {, } \\
\text { Test } 15\end{array}$ & \\
\hline 1 Vout decoupled from Vcc & Specifications & Ver 1 & Test 15 & \\
\hline \multicolumn{5}{|l|}{ Discriminator } \\
\hline Adjustable $0-0.9$ Vcc & Specifications & Ver 1 & Test 5 & \\
\hline$>100$ settings & Specifications & Ver 1 & Test 1 & \\
\hline TTL pulse width 50-500 ns & Specifications & Ver 1 & Test 6 & \\
\hline \multicolumn{5}{|l|}{ Bias Supply } \\
\hline Adjustable 200-2000 V & Specifications & Ver 1 & Test 7 & \\
\hline Vbias increments of $50 \mathrm{~V}$ & Specifications & Ver 1 & Test 7 & \\
\hline Noise $<0.02 \mathrm{~V}$ over entire range & Specifications & Ver 1 & Test 7 & \\
\hline $\begin{array}{l}\text { Stability } \pm 0.05 \mathrm{~V} \text { over entire } \\
\text { range }\end{array}$ & Specifications & Ver 1 & Test 8 & \\
\hline $\begin{array}{l}\text { Bias protection network for } \mathrm{HV} \\
\text { transients }\end{array}$ & Specifications & Ver 1 & Test 1 & $\begin{array}{l}\text { This is verified by visual } \\
\text { inspection/design analysis } \\
\text { because testing would } \\
\text { likely be destructive }\end{array}$ \\
\hline \multicolumn{5}{|l|}{ Detector Input } \\
\hline $\operatorname{Zin}=93 \Omega$ & Specifications & Ver 1 & Test 9 & \\
\hline SHV type connector & Specifications & Ver 1 & Test 1 & \\
\hline Input NEMA rated & $\overline{\text { Specifications }}$ & Ver 1 & Test 1 & \\
\hline \multicolumn{5}{|l|}{ Test Input } \\
\hline $\operatorname{Zin}=50 \Omega$ & Specifications & Ver 1 & Test 9 & \\
\hline Connector LEMO (HGP.00.250) & Specifications & Ver 1 & Test 1 & \\
\hline
\end{tabular}




\begin{tabular}{|c|c|c|c|c|}
\hline \multirow{2}{*}{$\frac{\text { Requirement }}{\text { Vcc Input }}$} & \multicolumn{2}{|c|}{ Source of Requirement } & \multirow[t]{2}{*}{ Verification } & \multirow[t]{2}{*}{ Comments } \\
\hline & & & & \\
\hline $\begin{array}{l}\text { Nominal voltage } 12 \text { VDC, rated } \\
\text { for } 9 \text { to } 13.8 \text { VDC }\end{array}$ & Specifications & Ver 1 & Test 11 & \\
\hline Connector LEMO (HGP.00.302) & Specifications & Ver 1 & Test 1 & \\
\hline \multicolumn{5}{|l|}{ Digital TTL Input (Summing) } \\
\hline $\operatorname{Zin}=50 \Omega$ & Specifications & Ver 1 & Test 9 & \\
\hline $\begin{array}{l}\text { Logic: } 2.4 \mathrm{~V} \text { to } 4 \mathrm{~V} \text { (high); } \\
\text { maximum of } 5.5 \mathrm{~V}\end{array}$ & Specifications & Ver 1 & Test 13 & \\
\hline Connector LEMO (HGP.00.250) & Specifications & Ver 1 & Test 1 & \\
\hline \multicolumn{5}{|l|}{ Shaping Amplifier \#1 } \\
\hline Superimposed on Vcc Supply & Specifications & Ver 1 & Test 14 & \\
\hline Zout $=50 \Omega$ & Specifications & Ver 1 & Test 9 & \\
\hline Connector LEMO (HGP.00.250) & Specifications & Ver 1 & Test 1 & \\
\hline \multicolumn{5}{|l|}{ Shaping Amplifier \#2 } \\
\hline Zout $=50 \Omega$ & Specifications & Ver 1 & Test 9 & \\
\hline Connector LEMO (HGP.00.250) & Specifications & Ver 1 & Test 9 & \\
\hline \multicolumn{5}{|l|}{ Discriminator Digital Output } \\
\hline $\begin{array}{l}\text { Logic: } 2.4 \mathrm{~V} \text { to } 4 \mathrm{~V} \text { (high); } \\
\text { maximum of } 5.5 \mathrm{~V}\end{array}$ & Specifications & Ver 1 & Test 16 & \\
\hline Zout $=50 \Omega$ & Specifications & Ver 1 & Test 9 & \\
\hline Connector LEMO (HGP.00.250) & Specifications & Ver 1 & Test 1 & \\
\hline \multicolumn{5}{|l|}{ LED count-rate indicator } \\
\hline $\begin{array}{l}\text { Blinks once for each TTL output } \\
\text { pulse }\end{array}$ & Specifications & Ver 1 & Test 10 & \\
\hline \multicolumn{5}{|l|}{ Form Factor } \\
\hline Stainless Steel & Specifications & Ver 1 & Test 1 & \\
\hline $100 \mathrm{~cm} 3$ volume, $>2$ ratio & Specifications & Ver 1 & Test 1 & \\
\hline$<4$ fasteners access & Specifications & Ver 1 & Test 1 & \\
\hline $\begin{array}{l}\text { Discriminator threshold } \\
\text { externally visible }\end{array}$ & Specifications & Ver 1 & Test 1 & \\
\hline \multicolumn{5}{|l|}{ Ground Isolation } \\
\hline $\begin{array}{l}\text { Input ground isolated from output } \\
\text { ground and chassis ground }\end{array}$ & Specifications & Ver 1 & Test 17 & $\begin{array}{l}\text { DUT may not have all of } \\
\text { the configurable options } \\
\text { listed in specification }\end{array}$ \\
\hline $\begin{array}{l}\text { Input ground connected to output } \\
\text { ground, isolated from chassis } \\
\text { ground }\end{array}$ & Specifications & Ver 1 & Test 17 & \\
\hline
\end{tabular}




\begin{tabular}{|c|c|c|c|c|}
\hline \multirow{2}{*}{$\begin{array}{l}\text { Requirement } \\
\text { Input ground connected to chassis } \\
\text { ground but isolated from output } \\
\text { ground }\end{array}$} & \multicolumn{2}{|c|}{ Source of Requirement } & \multirow{2}{*}{$\begin{array}{l}\text { Verification } \\
\text { Test } 17\end{array}$} & \multirow[t]{2}{*}{ Comments } \\
\hline & Specifications & Ver 1 & & \\
\hline $\begin{array}{l}\text { Output ground connected to } \\
\text { chassis ground but isolated from } \\
\text { input ground }\end{array}$ & Specifications & Ver 1 & Test 17 & \\
\hline \multicolumn{5}{|l|}{ UMS DAQ Compatibility } \\
\hline Compatible with NGAM & $\begin{array}{l}\text { Desired } \\
\text { Functionality } \\
\text { Pg } 5\end{array}$ & Ver 1 & Test 18 & Optionally tested \\
\hline Compatible with UNAP & $\begin{array}{l}\text { Desired } \\
\text { Functionality } \\
\text { Pg } 5\end{array}$ & Ver 1 & N/A & $\begin{array}{l}\text { Test equipment is not } \\
\text { readily available. TTL } \\
\text { output tests check part of } \\
\text { functionality. }\end{array}$ \\
\hline Compatible with ADAM & $\begin{array}{l}\text { Desired } \\
\text { Functionality } \\
\text { Pg } 5\end{array}$ & Ver 1 & N/A & $\begin{array}{l}\text { Demonstration of NGAM } \\
\text { functionality suffices for } \\
\text { ADAM. }\end{array}$ \\
\hline Compatible with mini-GRAND & $\begin{array}{l}\text { Desired } \\
\text { Functionality } \\
\text { Pg } 5\end{array}$ & Ver 1 & N/A & $\begin{array}{l}\text { Test equipment is not } \\
\text { readily available. TTL } \\
\text { output tests check part of } \\
\text { functionality. }\end{array}$ \\
\hline \multicolumn{5}{|l|}{ Environmental } \\
\hline Operating Temp $-10^{\circ} \mathrm{C}$ to $50^{\circ} \mathrm{C}$ & Specifications & Ver 1 & N/A & $\begin{array}{l}\text { Environmental not tested at } \\
\text { this stage }\end{array}$ \\
\hline Storage Temp $-40^{\circ} \mathrm{C}$ to $80^{\circ} \mathrm{C}$ & Specifications & Ver 1 & N/A & $\begin{array}{l}\text { Environmental not tested at } \\
\text { this stage }\end{array}$ \\
\hline $\begin{array}{l}\text { Radiation Resistance Class } 3 \text { per } \\
\text { NRTP } 1.0\end{array}$ & Specifications & Ver 1 & N/A & $\begin{array}{l}\text { Environmental not tested at } \\
\text { this stage }\end{array}$ \\
\hline Vibration per MIL-STD 810F & Specifications & Ver 1 & N/A & $\begin{array}{l}\text { Environmental not tested at } \\
\text { this stage }\end{array}$ \\
\hline Shock per MIL-STD-810F & Specifications & Ver 1 & N/A & $\begin{array}{l}\text { Environmental not tested at } \\
\text { this stage }\end{array}$ \\
\hline High Temp per MIL-STD-810F & Specifications & Ver 1 & N/A & $\begin{array}{l}\text { Environmental not tested at } \\
\text { this stage }\end{array}$ \\
\hline Low Temp per MIL-STD-810F & Specifications & Ver 1 & N/A & $\begin{array}{l}\text { Environmental not tested at } \\
\text { this stage }\end{array}$ \\
\hline Humidity per MIL-STD-810F & Specifications & Ver 1 & N/A & $\begin{array}{l}\text { Environmental not tested at } \\
\text { this stage }\end{array}$ \\
\hline Moisture per IP-62 & Specifications & Ver 1 & N/A & $\begin{array}{l}\text { Environmental not tested at } \\
\text { this stage }\end{array}$ \\
\hline Seismic per MIL-STD-461E & Specifications & Ver 1 & N/A & $\begin{array}{l}\text { Environmental not tested at } \\
\text { this stage }\end{array}$ \\
\hline
\end{tabular}




\begin{tabular}{|l|l|l|l|l|}
\hline Requirement & Source of Requirement & Verification & Comments \\
\hline $\begin{array}{l}\text { Radiated Emissions per MIL- } \\
\text { STD-461E }\end{array}$ & Specifications & Ver 1 & N/A & $\begin{array}{l}\text { Environmental not tested at } \\
\text { this stage }\end{array}$ \\
\hline $\begin{array}{l}\text { Radiated Susceptibility per MIL- } \\
\text { STD-461E, 10 V/m field strength } \\
14 \mathrm{kHz} \text { to } 18 \mathrm{GHz}\end{array}$ & Specifications & Ver 1 & Test 20 & $\begin{array}{l}\text { Partial testing Performed to } \\
\text { verify concerning EMI } \\
\text { issues }\end{array}$ \\
\hline $\begin{array}{l}\text { Electrostatic Discharge per } \\
\text { EN61000-4-2, 15 kV }\end{array}$ & Specifications & Ver 1 & N/A & $\begin{array}{l}\text { Environmental not tested at } \\
\text { this stage }\end{array}$ \\
\hline Performance Targets & $\begin{array}{l}\text { Specifications } \\
\text { Pg 20 }\end{array}$ & Ver 1 & $\begin{array}{l}\text { Test 19, 20, } \\
21\end{array}$ & \\
\hline
\end{tabular}

* References in the source column refer to the FEUM Work Plan Version 1, 2/20/14 


\section{Appendix B}

\section{IAEA's Technical Specifications for FEUM}

Definitions
$L$
$C_{\text {ext }}$
$\bigvee_{\mathrm{CC}}$
$\mathrm{HV}$ Bias
$\tau_{\mathrm{CR}}=\tau_{\mathrm{RC}}=\tau$
$T$
$\mathrm{DPW}$
$R$
$Z$
DAQ
SCA

\section{Definitions}

$C_{\text {ext }}$

$\mathrm{V}_{\mathrm{CC}}$

$\tau_{\mathrm{CR}}=\tau_{\mathrm{RC}}=\tau$

DPW

$R$

SCA
Revised 17 February 2012

Length of coaxial cable (typically RG-71B/U) between detector and FEUM

External capacitive loading on the preamplifier (e.g. cable + detector)

DC supply voltage for FEUM

High-voltage bias provided to detector (e.g. He-3 or fission chamber)

Shaping time constant for differentiator-integrator pulse shaping

Lower-level discriminator threshold

Digital pulse width (ns) of discriminator TTL output signal

Count rate (counts per second, cps) above the discriminator threshold

Characteristic impedance of input and output interfaces (Ohm, $\Omega$ )

Data acquisition instrumentation

Single channel analyzer with lower and upper discriminator thresholds

\section{Architecture and General Specifications}

A schematic overview of FEUM deployment is given in Figure 1. The text that follows provides additional detail about the system architecture and technical specifications.

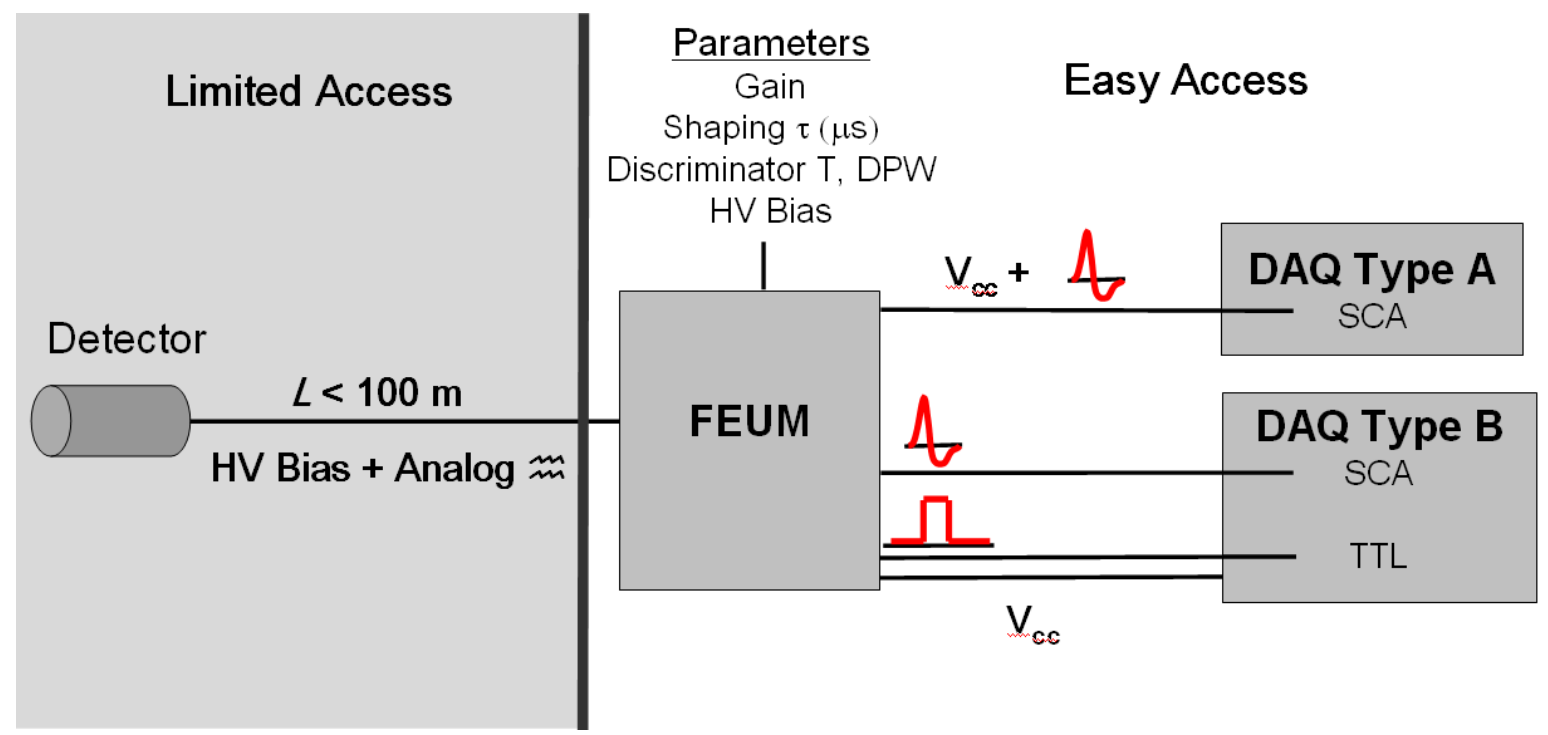

Figure 1. Conceptual overview of FEUM implementation. FEUM will be separated from the detector by distances up to $100 \mathrm{~m}$ (dependent on facility and instrument constraints) so that it can be located in easily accessible areas. FEUM will be coupled to one of two different data acquisition (DAQ) instruments currently utilized by the IAEA. 
Preamplifier

- Charge-sensitive and/or current-sensitive

- Rise time $<20$ ns at $C_{\text {ext }}=0 \mathrm{pF},<50$ ns at $C_{\text {ext }}=100 \mathrm{pF}$

Shaping Amplifier

- $\quad$ Bipolar $\left(C R^{2}-R C\right)$ shaping

- $\tau$ : internally adjustable to discrete settings. The nominal range and values are $\tau=0.05,0.1$, $0.25,0.5,1.0,2.0 \mu \mathrm{s}$

- Gain: internally adjustable to discrete settings with a range to accommodate sensors ranging from U-235 fission chambers $\left(\sim 1 \times 10^{-3} \mathrm{pC}\right.$ per event) to $\mathrm{Nal}(\mathrm{Tl})$ with photomultiplier tubes $(\sim 5000 \mathrm{pC}$ per event). The nominal range and discrete values are $0.001,0.005,0.01,0.05,0.1,0.25,0.5,1$, $5,10,50,100,500,1000,5000 \mathrm{pC} / \mathrm{V}_{\text {out }}$.

- $\quad$ Output amplitude range: 0 to $\sim 0.9^{*} \mathrm{~V}_{\mathrm{cc}}$

- Output is delivered in two different forms for compatibility with DAQ instruments:

0 Superimposed on $V_{c c}$

o Decoupled from $V_{c c}$ (i.e. referenced to ground)

Discriminator

- $\quad$ Lower level discriminator (LLD): External adjustable from 0 to $\sim 0.9^{*} \mathrm{~V}_{\mathrm{cc}}$, with controls that allow a high number of discrete (e.g. >100) settings.

- TTL output pulse width: internally adjustable to discrete settings. The nominal range and values are $50,100,200,500$ ns.

Bias Supply

- Adjustable from $+200 \mathrm{~V}$ to $+2000 \mathrm{~V}$ : internal discrete settings, nominally in increments of $50 \mathrm{~V}$.

- Noise: $\sim 0.02 \mathrm{~V}$ over operating range

- Stability per hour: $\sim 0.05 \mathrm{~V}$ over operating range

- Bias protection network for HV transients

\section{Detailed Specifications}

$\underline{\text { Input }}$

- From detector

o $\quad Z_{\text {in }}=93 \Omega$

o Connector: SHV type consistent with NEMA Standard IP-62 (see Quality Specifications section)

- $\quad$ Test Input

$0 \quad Z_{\text {in }}=50 \Omega$

o Connector: LEMO type coaxial connector (nominal HGP.00.250)

- $\mathrm{V}_{\mathrm{cc}}$ Input

o +12 VDC (+9 to $13.8 \mathrm{VDC})$

o Connector: LEMO type coaxial connector (nominal HGP.00.302)

- $\quad$ Digital (TTL) summing

$0 \quad Z_{\text {in }}=50 \Omega$

o Logic: $2.4 \mathrm{~V}$ to $4 \mathrm{~V}$ (high); maximum of $5.5 \mathrm{~V}$

o Connector: LEMO type coaxial connector (nominal HGP.00.250)

Output

- Shaping Amplifier \#1

0 Superimposed on $V_{c c}$ supply

o $Z_{\text {out }}=50 \Omega$

o Connector: LEMO type coaxial connector (nominal HGP.00.250)

- Shaping Amplifier \#2 
o $Z_{\text {out }}=50 \Omega$

o Connector: LEMO type coaxial connector (nominal HGP.00.250)

- Discriminator Digital (TTL)

$0 \quad Z_{\text {out }}=50 \Omega$

$0 \quad$ Logic: $2.4 \mathrm{~V}$ to $4 \mathrm{~V}$ (high); maximum of $5.5 \mathrm{~V}$

o Connector: LEMO type coaxial connector (nominal HGP.00.250)

- LED count-rate indicator

o Blinks once for each Discriminator digital output pulse

Note: To reduce the complexity and size of the field-prototype enclosures, the inputs and outputs can take the form of short cables rather than bulkhead connectors. Cable types and connectors should be compatible with the requirements stated above.

Form Factor

- $\quad$ Polished stainless steel enclosure with nominal volume of $\sim 100 \mathrm{~cm}^{3}$ and nominal aspect ratio of $>$ 2 (i.e. length to cross-sectional dimension). Significant departures from this enclosure size or shape need to be negotiated with the IAEA.

- Enclosure should be capable of being opened with fewer than four fasteners

- Numerical discriminator threshold value must be externally visible

Ground Isolation

To provide flexibility in the deployment of FEUM at facilities where ground loop problems may arise, specific ground isolation options are required. The design should allow for the following options via internal jumper settings:

- Input ground isolated from output ground and FEUM chassis ground;

- Input ground connected to output ground but isolated from FEUM chassis ground;

- Input ground connected to FEUM chassis ground but isolated from output ground;

- Output ground connected to FEUM chassis ground but isolated from input ground. 


\section{Environmental and Quality Targets}

The following environmental and quality information is given to inform FEUM development, not as strict requirements for the initial field prototypes. The initial prototypes do not need to be tested to these requirements before delivery to the IAEA.

The list below indicates the range and types of tests that will likely be required of future production versions of FEUM. Therefore, design choices for the FEUM field prototypes should be consistent with these targets.

- Operating Temperature: $-10^{\circ} \mathrm{C}$ to $50^{\circ} \mathrm{C}$;

- Storage Temperature: $-40^{\circ} \mathrm{C}$ to $80^{\circ} \mathrm{C}$;

- Radiation Resistance

o Reference Nuclear Radiation Test Procedures for IAEA Safeguards Systems NRTP 1.0;

o Should meet Special Applications Class 3 (use $50 \mathrm{mSv} / \mathrm{hr}$ for 7 years as the ambient dose equivalent).

- Vibration Test per Military Standard 810F, Method 514.5, Procedure II-Loose Cargo Transportation, 5 hour test;

- Shock Testing per Military Standard 810F, Method 516.5, Procedure IV-Transportation Drop;

- High Temperature Test per Military Standard 810F, Method 501.4, Procedure I (storage), test under condition HOT, 7 cycles, 4 hours per cycle;

- Low Temperature Test per Military Standard 810F, Method 502.4; Procedure I (storage), test under condition COLD, 24 hour soak;

- Humidity Tests per Military Standard 810F, Method $507.4\left(30^{\circ} \mathrm{C}, 95 \%\right.$ Relative Humidity);

- Moisture Intrusion per NEMA Standard IP-62;

- Seismic (Earthquake) Testing per IEEE Standard 344-2004, Zone 4, 2 G vertical, 3 G horizontal;

- Radiation Emissions per Military Standards 461E, technique RE102, $14 \mathrm{KHz}$ to $18 \mathrm{GHz}$, equipment classification for Navy Fixed/Air Force, or equivalent European Norm Standard;

- Radiation Emissions per Military Standards 461E, technique RS103, 10 Volts/meter field strength, $14 \mathrm{KHz}$ to $18 \mathrm{GHz}$, equipment classification for Navy Ground, or equivalent European Norm Standard;

- Electrostatic Discharge per European Norm Standard EN61000-4-2, 15KV. 


\section{Performance Targets}

The integral pulse-height spectrum (PHS) [1] is the basis of the FEUM performance targets (additional discussion of the integral PHS can be found in Appendix A). These performance targets are intended to ensure that FEUM can support the wide range of radiation detection scenarios where IAEA Unattended Monitoring Systems (UMS) are applied. In this context, a "scenario" is defined by a number of factors that include the detector type (e.g. He-3, B-lined, fission chamber), distance between the detector and frontend electronics and the type of cable used (e.g. $50 \mathrm{~m}$ of RG-71 cable), and maximum event rate (e.g. $400,000 \mathrm{cps})$.

The performance targets have been defined in a way that can be tested in typical radiation detection laboratory using the following components:

- He-3 proportional counter (2.54-cm diameter, poly-moderated);

- Neutron source (e.g. Cf-252, tens of $\mu \mathrm{Ci}$ );

- FEUM prototype;

- RG-71B/U cables with lengths of 1,50 , and 100 meters;

- Counter/timer.

FEUM Performance Requirements are shown qualitatively in Figure 2 and quantitatively in Table 1 . There are two primary metrics in these requirements, $\varepsilon_{\text {neutron }}$ and $T_{\text {noise }}$ where:

- $\quad T_{\text {noise }}$ is the threshold where $R_{\text {noise }}<5 \mathrm{cps}$ with no neutron source present;

- $\varepsilon_{\text {neutron }}(T)$ is the relative neutron efficiency defined to be $R_{\text {net }}(T) / R_{\text {ideal }}$

- $\quad R_{\text {ideal }}=$ net neutron count rate for $T=T_{\text {noise }}$ under assumptions of $L \sim 0, \tau \sim 2.0$;

- $\quad R_{\text {net }}(T)=$ net neutron count rate after subtraction of $R_{\text {noise }}(T)$

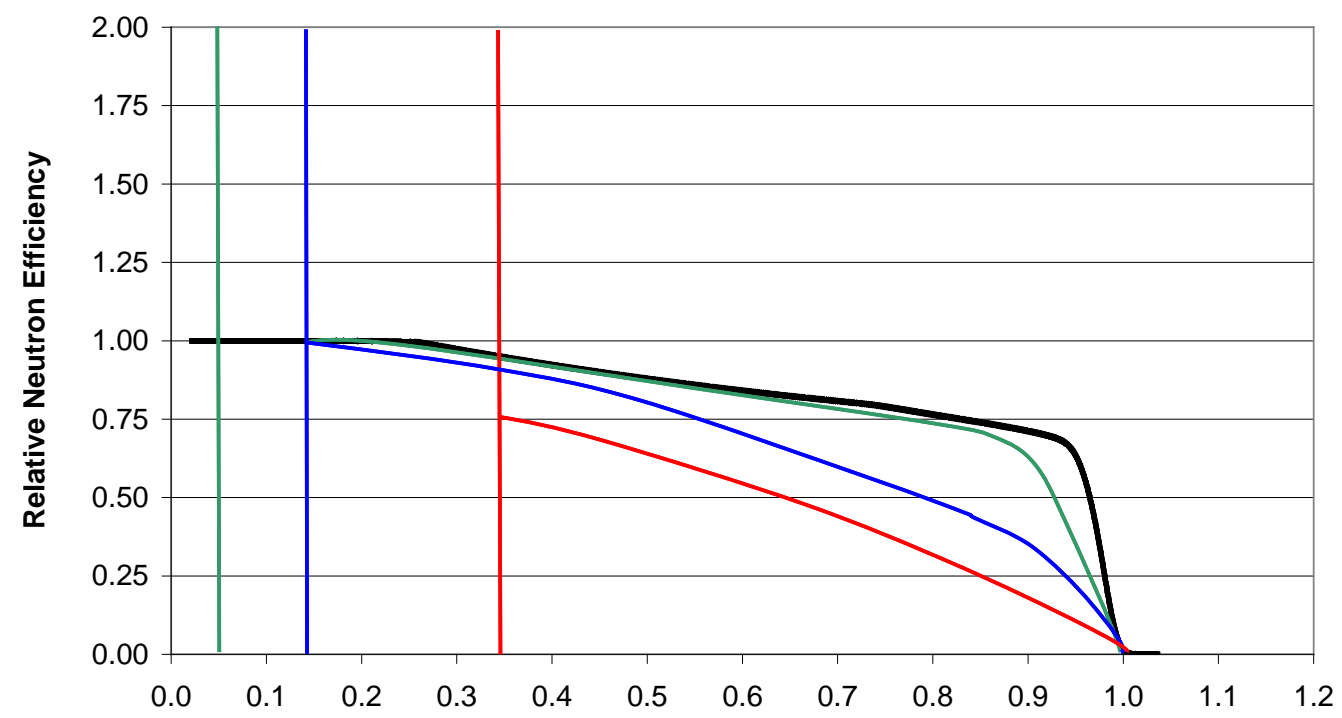

Relative Discriminator Threshold, T

Figure 2. Qualitative depiction of the FEUM performance metrics, $T_{\text {noise }}$ and $\varepsilon_{\text {neutron }}(T)$ in an integral PHS form. Quantitative target values for the three scenarios are given in Table 1. 
Table 1. Quantitative FEUM performance targets for $T_{\text {noise }}$ and $\varepsilon_{\text {neutron }}(T)$ for a variety of cable length and shaping constant.

\begin{tabular}{|l|c|c|}
\hline \multicolumn{1}{|c|}{$\boldsymbol{L}(\boldsymbol{m} \boldsymbol{R G}-71), \tau(\mu \mathbf{s})$} & $\boldsymbol{T}_{\text {noise }}$ & $\boldsymbol{T}, \boldsymbol{\varepsilon}_{\text {neutron }}$ \\
\hline$(1,2)(50,2)$ & 0.05 & $(0.20,1.00)(0.50,0.85)(0.80,0.75)$ \\
\hline$(1,0.1)(50,0.5)(100,0.5)(100,2)$ & 0.15 & $(0.20,0.90)(0.50,0.75)(0.80,0.50)$ \\
\hline$(50,0.1)(100,0.1)$ & 0.35 & $(0.35,0.75)(0.50,0.60)(0.80,0.30)$ \\
\hline
\end{tabular}

References

[1] G.F. Knoll, Radiation Detection and Measurement, $3^{\text {rd }}$ Edition, 2000. 


\section{Appendix C}

\section{Procedures}

\section{C.1 TEST 3, TEST 4 - Output Gain/Charge Calibration and Shaping Time Constant}

\section{C.1.1 Purpose:}

This test is to measure the gain and the pulse shaping time constant to verify they are as expected and suitable for a FEUM. This test will also measure/calculate the absolute charge calibration.

\section{C.1.2 Required Equipment:}

Power supply for DUT

AWG Multi-Channel Analyzer

Oscilloscope

Testing cable to connect DUT digital input to BNC jack

Jewelers’ screwdriver (for toggling configuration dipswitches, if applicable)

Tweezers (for changing jumper settings, if applicable)

High Voltage, Precision Capacitor

\section{C.1.3 References:}

DUT documentation provided by vendor

\section{C.1.4 Preparation:}

Ensure that the testing surface is ESD safe.

\section{C.1.5 Procedure:}

\section{C.1.5.1 Gain}

1. Connect the AWG and precision capacitor to the detector input port and the oscilloscope to the analog output ports \#1 and \#2 as shown in

2. Figure C.1.

3. Connect a 12V DC power supply to the DUT isolated power input (not shown).

4. Configure the DUT for nominal operation (charge-sensitive).

5. Record the DUT settings if different than nominal.

6. Set the AWG to output pulses suitable for the DUT in the low gain range. Record the setting selected (input pulse amplitude) in Table C.1. 
7. Select five gain settings and set the DUT to each setting. Measure each output pulse amplitude and record the gain setting, output pulse amplitude and calculated gain for each.

8. Verify the expected gain for all gain settings by comparing the calculated and measured amplitudes.

9. Repeate steps 1-7 for current sensitive mode.

10. Disconnect the oscilloscope and connect the MCA to the isolated analog output as shown in Figure C.2. (This can alternatively be done in parallel with the preceding steps using a T coupler to connect both the MCA and Oscilloscope).

11. Repeat steps 5-7 with the MCA, instead recording the peak channel from the MCA for each gain setting. Record the data in Table C.2 through Table C.7. These data will be used to construct linearity plots and charge calibration for the amplifier.

12. Repeat steps 5-10for the mid-gain and high-gain range.

13. Calculate the absolute charge calibration for each gain setting, by dividing the amount of known input charge to measured peak channel on the MCA.

\section{C.1.5.2 Shaping Time Constant}

14. Return all DUT settings to the nominal settings.

15. Cycle through all the shaping time constant settings and verify the pulse shape is consistent with bipolar output pulses.

16. Save the oscilloscope waveforms for each test and MCA spectra.

17. Repeat all steps for the DUT in current-sensitive mode.

\section{C.1.6 Test Data}

DUT Serial Number:

DUT Part Number:

Tested By:

Test Date: 


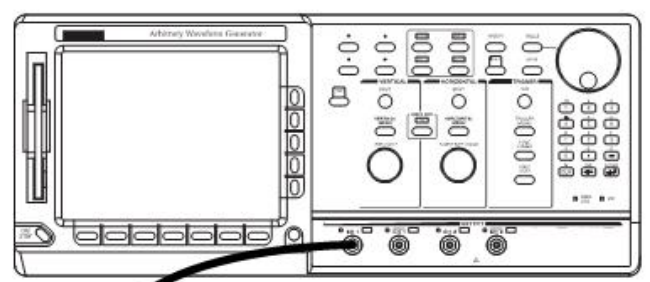

Random Pulse Generator

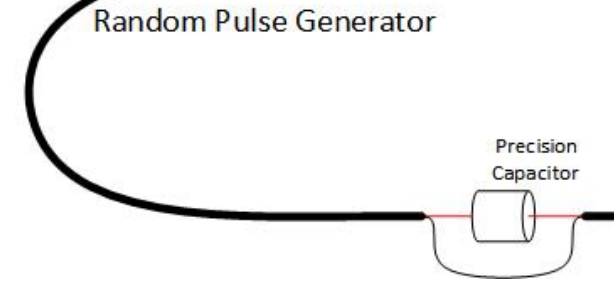

Figure C.1. Using O-Scope to Measure Gain Linearity

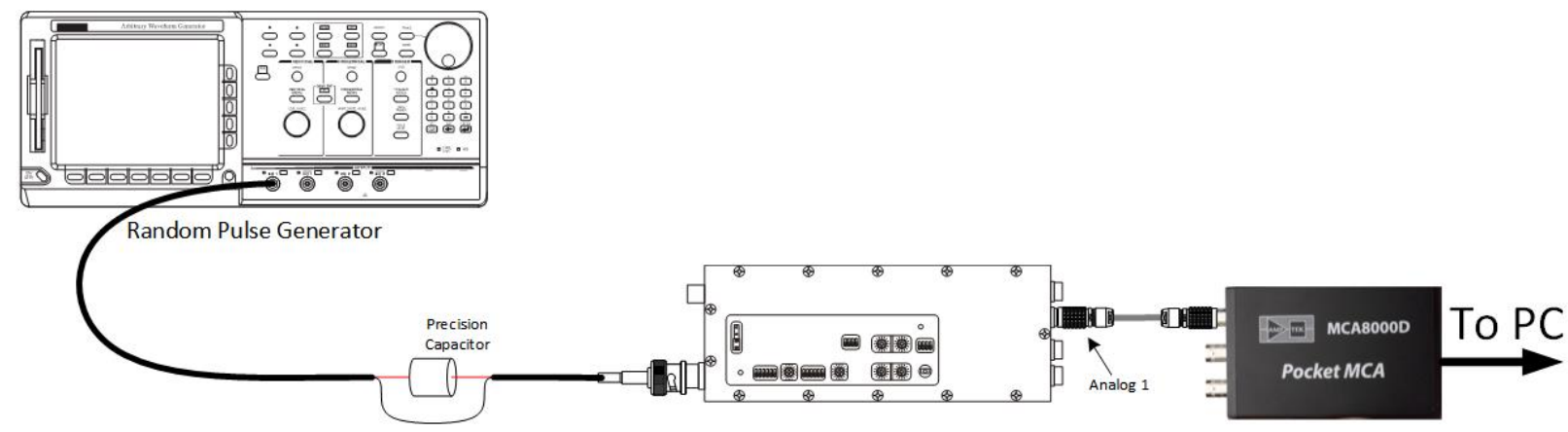

Figure C.2. Using MCA to Measure Gain Linearity and Charge Calibration 


\section{C.1.6.1 Data Tables:}

Table C.1. DUT Configuration

\begin{tabular}{|l|l|}
\hline \multicolumn{1}{|c|}{ Parameter } & \multicolumn{1}{c|}{ Setting } \\
\hline Input Signal Mode (Q or I) & \\
\hline Input Termination & \\
\hline Charge Gain (range) & \\
\hline G1 - Gain & \\
\hline G2 - Gain & \\
\hline HVH - High Voltage & \\
\hline HVL - High Voltage & \\
\hline SW1 - Shaping Time & \\
\hline SW2 - Shaping Time & \\
\hline DH - Discriminator High & \\
\hline DL - Discriminator Low & \\
\hline Digital Ouput Pulse Width & \\
\hline
\end{tabular}

Table C.2. Gain Results for Low-Range Gain (Charge Sensitive)

\begin{tabular}{|c|c|l|l|l|l|}
\hline $\begin{array}{c}\text { Test } \\
\#\end{array}$ & $\begin{array}{c}\text { Input } \\
\text { Pulse } \\
\text { Charge }\end{array}$ & Gain & $\begin{array}{c}\text { Output } \\
\text { Pulse } \\
\text { Amplitude }\end{array}$ & $\begin{array}{c}\text { Calculated } \\
\text { Gain }\end{array}$ & $\begin{array}{c}\text { Peak } \\
\text { Channel }\end{array}$ \\
\hline 1 & & & & & \\
\hline 2 & & & & & \\
\hline 3 & & & & & \\
\hline 4 & & & & & \\
\hline 5 & & & & & \\
\hline
\end{tabular}


Table C.3. Gain Results for Mid-Range Gain (Charge Sensitive)

\begin{tabular}{|c|c|l|c|l|l|}
\hline $\begin{array}{c}\text { Test } \\
\#\end{array}$ & $\begin{array}{c}\text { Input } \\
\text { Pulse } \\
\text { Charge }\end{array}$ & Gain & $\begin{array}{c}\text { Output } \\
\text { Pulse } \\
\text { Amplitude }\end{array}$ & $\begin{array}{c}\text { Calculated } \\
\text { Gain }\end{array}$ & $\begin{array}{c}\text { Peak } \\
\text { Channel }\end{array}$ \\
\hline 1 & & & & & \\
\hline 2 & & & & & \\
\hline 3 & & & & & \\
\hline 4 & & & & & \\
\hline 5 & & & & & \\
\hline
\end{tabular}

Table C.4. Gain Results for High-Range Gain (Charge Sensitive)

\begin{tabular}{|l|c|l|l|l|l|}
\hline $\begin{array}{c}\text { Test } \\
\#\end{array}$ & $\begin{array}{c}\text { Input } \\
\text { Pulse } \\
\text { Charge }\end{array}$ & Gain & $\begin{array}{c}\text { Output } \\
\text { Pulse } \\
\text { Amplitude }\end{array}$ & $\begin{array}{c}\text { Calculated } \\
\text { Gain }\end{array}$ & $\begin{array}{c}\text { Peak } \\
\text { Channel }\end{array}$ \\
\hline 1 & & & & & \\
\hline 2 & & & & & \\
\hline 3 & & & & & \\
\hline 4 & & & & & \\
\hline 5 & & & & & \\
\hline
\end{tabular}

Table C.5. Gain Results for Low-Range Gain (Current Sensitive)

\begin{tabular}{|l|c|l|l|l|l|}
\hline $\begin{array}{c}\text { Test } \\
\#\end{array}$ & $\begin{array}{c}\text { Input } \\
\text { Pulse } \\
\text { Amplitude }\end{array}$ & Gain & $\begin{array}{c}\text { Output } \\
\text { Pulse } \\
\text { Amplitude }\end{array}$ & $\begin{array}{c}\text { Calculated } \\
\text { Gain }\end{array}$ & $\begin{array}{c}\text { Peak } \\
\text { Channel }\end{array}$ \\
\hline 1 & & & & & \\
\hline 2 & & & & & \\
\hline 3 & & & & & \\
\hline 4 & & & & & \\
\hline 5 & & & & & \\
\hline
\end{tabular}


Table C.6. Gain Results for Mid-Range Gain (Current Sensitive)

\begin{tabular}{|l|c|l|l|l|l|}
\hline $\begin{array}{c}\text { Test } \\
\#\end{array}$ & $\begin{array}{c}\text { Input } \\
\text { Pulse } \\
\text { Amplitude }\end{array}$ & Gain & $\begin{array}{c}\text { Output } \\
\text { Pulse } \\
\text { Amplitude }\end{array}$ & $\begin{array}{c}\text { Calculated } \\
\text { Gain }\end{array}$ & $\begin{array}{c}\text { Peak } \\
\text { Channel }\end{array}$ \\
\hline 1 & & & & & \\
\hline 2 & & & & & \\
\hline 3 & & & & & \\
\hline 4 & & & & & \\
\hline 5 & & & & & \\
\hline
\end{tabular}

Table C.7. Gain Results for High-Range Gain (Current Sensitive)

\begin{tabular}{|l|c|l|l|l|l|}
\hline $\begin{array}{c}\text { Test } \\
\#\end{array}$ & $\begin{array}{c}\text { Input } \\
\text { Pulse } \\
\text { Amplitude }\end{array}$ & Gain & $\begin{array}{c}\text { Output } \\
\text { Pulse } \\
\text { Amplitude }\end{array}$ & $\begin{array}{c}\text { Calculated } \\
\text { Gain }\end{array}$ & $\begin{array}{c}\text { Peak } \\
\text { Channel }\end{array}$ \\
\hline 1 & & & & & \\
\hline 2 & & & & & \\
\hline 3 & & & & & \\
\hline 4 & & & & & \\
\hline 5 & & & & & \\
\hline
\end{tabular}




\section{C.2 TEST 5 - Discriminator Threshold}

\section{C.2.1 Purpose:}

This test is to evaluate the functionality and linearity of the discriminator threshold over the full range of operation.

\section{C.2.2 Required Equipment:}

Power supply for DUT

AWG

Multi-channel Analyzer

Oscilloscope

Testing cable to connect DUT digital input to BNC jack

Jewelers' screwdriver (for toggling configuration dipswitches, if applicable)

Tweezers (for changing jumper settings, if applicable)

\section{C.2.3 References:}

DUT documentation provided by vendor

\section{C.2.4 Preparation:}

Ensure that the testing surface is ESD safe. 


\section{C.2.5 Procedure:}

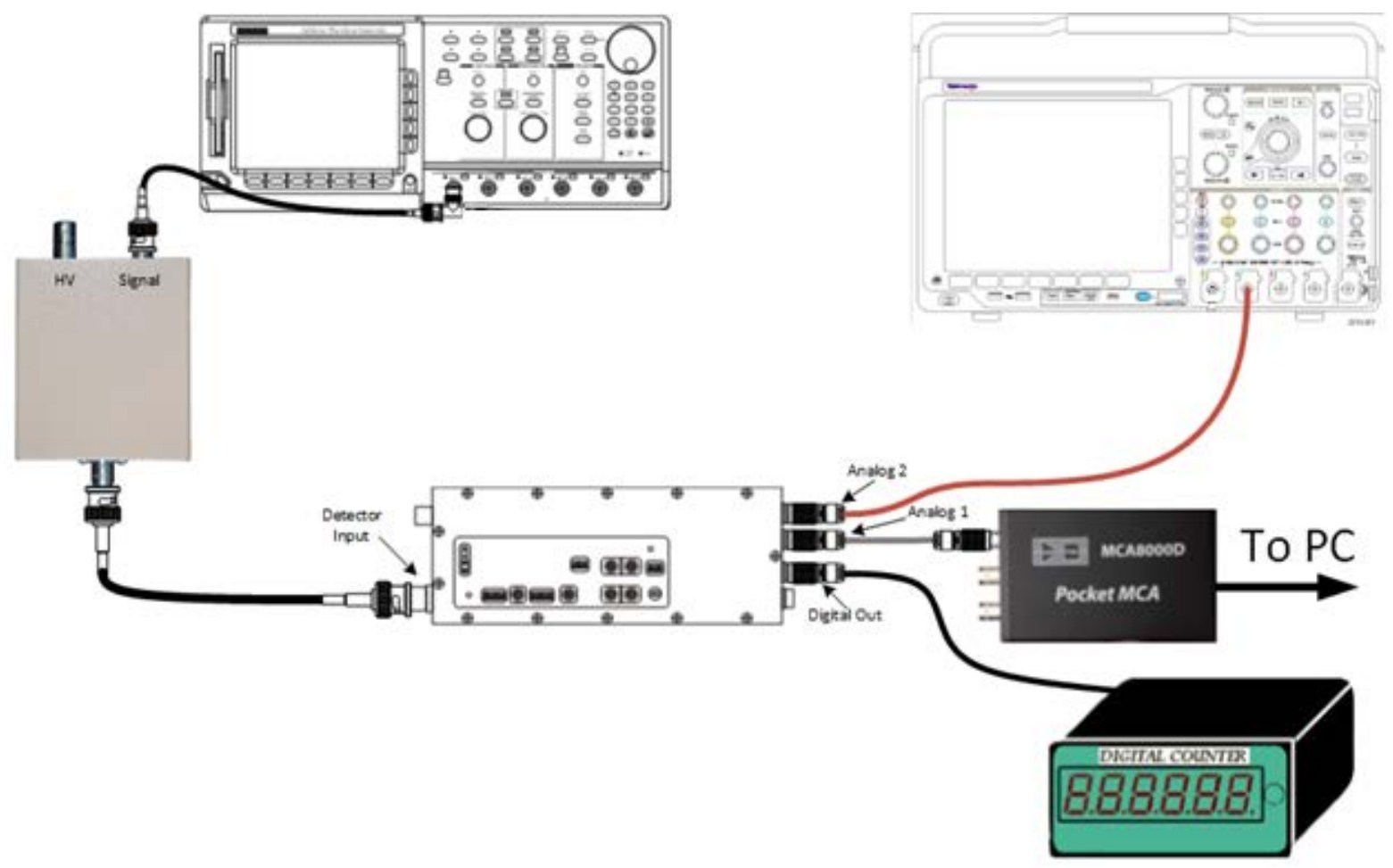

1. Figure C.3.

2. Configure the DUT for nominal operation (charge-sensitive).

3. Record the DUT settings used in Table C.8 if different than nominal.

4. Set the discriminator setting on the DUT to $0 \mathrm{~V}$.

5. Set the AWG output and the DUT gain to the lowest setting possible.

6. Adjust the DUT output pulse height to measure the LLD (lower level discriminator). This is accomplished by raising the AWG amplitude in the smallest increment possible until the discriminator no longer filters out the pulse and the digital output begins to provide pulses.

7. Record the AWG setting and output pulse amplitude from the oscilloscope and the peak energy from the MCA for this discriminator setting in Table C.9.

8. Adjust the discriminator setting on the DUT up four steps $(60 \mathrm{mV})$.

9. Repeat steps 5-9 63 times until the highest discriminator setting is tested.

10. Repeat all steps for the DUT in current sensitive mode and record results in Table C.10.

\section{C.2.6 Test Data}

DUT Serial Number:

DUT Part Number:

Tested By:

Test Date: 


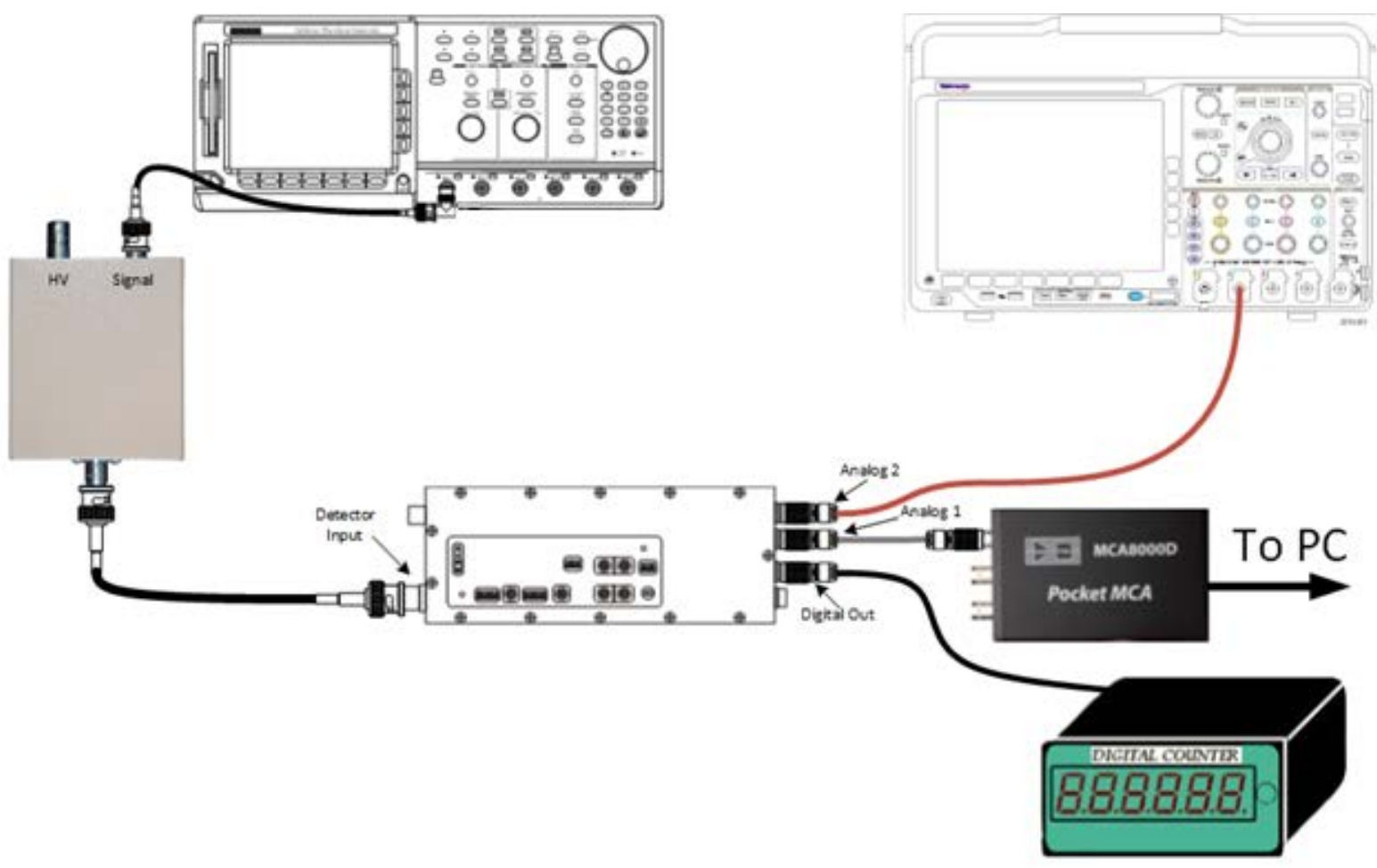

Figure C.3. Discriminator Threshold Test Setup

\section{C.2.6.1 Data Tables:}

Table C.8. DUT Configuration

\begin{tabular}{|l|l|}
\hline \multicolumn{1}{|c|}{ Parameter } & \multicolumn{1}{c|}{ Setting } \\
\hline Input Signal Mode (Q or I) & \\
\hline Input Termination & \\
\hline Charge Gain (range) & \\
\hline G1 - Gain & \\
\hline G2 - Gain & \\
\hline HVH - High Voltage & \\
\hline HVL - High Voltage & \\
\hline SW1 - Shaping Time & \\
\hline SW2 - Shaping Time & \\
\hline DH - Discriminator High & \\
\hline DL - Discriminator Low & \\
\hline Digital Ouput Pulse Width & \\
\hline HV Power Switch & Off \\
\hline
\end{tabular}


Table C.9. Discriminator Measurement Results (Charge Sensitive)

\begin{tabular}{|c|c|c|c|c|}
\hline $\begin{array}{c}\text { Test } \\
\#\end{array}$ & $\begin{array}{c}\text { Discriminator } \\
\text { Threshold }\end{array}$ & $\begin{array}{c}\text { Measured } \\
\text { LLD } \\
\text { Voltage }\end{array}$ & $\begin{array}{c}\text { AWG } \\
\text { Voltage } \\
\text { Amplitude }\end{array}$ & $\begin{array}{c}\text { MCA LLD } \\
\text { Energy }\end{array}$ \\
\hline 1 & $60 \mathrm{mV}$ & & & \\
\hline 2 & $120 \mathrm{mV}$ & & & \\
\hline 3 & $180 \mathrm{mV}$ & & & \\
\hline 4 & & & & \\
\hline 5 & & & & \\
\hline 6 & & & & \\
\hline 7 & & & & \\
\hline 8 & & & & \\
\hline 9 & & & & \\
\hline 10 & & & & \\
\hline 11 & & & & \\
\hline 12 & & & & \\
\hline 13 & & & & \\
\hline 14 & & & & \\
\hline 15 & & & & \\
\hline 16 & & & & \\
\hline 17 & & & & \\
\hline 18 & & & & \\
\hline 19 & & & & \\
\hline 20 & & & & \\
\hline 21 & & & & \\
\hline 22 & & & & \\
\hline 23 & & & & \\
\hline 24 & & & & \\
\hline 25 & & & & \\
\hline 26 & & & & \\
\hline 27 & & & & \\
\hline 28 & & & & \\
\hline 29 & & & & \\
\hline 30 & & & & \\
\hline 31 & & & & \\
\hline 32 & & & & \\
\hline 33 & & & & \\
\hline 34 & & & & \\
\hline 35 & & & & \\
\hline 36 & & & & \\
\hline 37 & & & & \\
\hline 38 & & & & \\
\hline 39 & & & & \\
\hline 40 & & & & \\
\hline 41 & & & & \\
\hline 42 & & & & \\
\hline 43 & & & & \\
\hline 44 & & & & \\
\hline 45 & & & & \\
\hline 46 & & & & \\
\hline 47 & & & & \\
\hline 48 & & & & \\
\hline 49 & & & & \\
\hline 50 & & & & \\
\hline 51 & & & & \\
\hline 52 & & & & \\
\hline 53 & & & & \\
\hline 54 & & & & \\
\hline
\end{tabular}




\begin{tabular}{|c|c|c|c|c|}
\hline $\begin{array}{c}\text { Test } \\
\#\end{array}$ & $\begin{array}{c}\text { Discriminator } \\
\text { Threshold }\end{array}$ & $\begin{array}{c}\text { Measured } \\
\text { LLD } \\
\text { Voltage }\end{array}$ & $\begin{array}{c}\text { AWG } \\
\text { Voltage } \\
\text { Amplitude }\end{array}$ & $\begin{array}{c}\text { MCA LLD } \\
\text { Energy }\end{array}$ \\
\hline 55 & & & & \\
\hline 56 & & & & \\
\hline 57 & & & & \\
\hline 58 & & & & \\
\hline 59 & & & & \\
\hline 60 & & & & \\
\hline 61 & & & & \\
\hline 62 & & & & \\
\hline 63 & & & & \\
\hline 64 & $3825 \mathrm{mV}$ & & & \\
\hline
\end{tabular}

Table C.10. Discriminator Measurement Results (Current Sensitive)

\begin{tabular}{|c|c|c|c|c|}
\hline $\begin{array}{c}\text { Test } \\
\#\end{array}$ & $\begin{array}{c}\text { Discriminator } \\
\text { Threshold }\end{array}$ & $\begin{array}{c}\text { Measured } \\
\text { LLD } \\
\text { Voltage }\end{array}$ & $\begin{array}{c}\text { AWG } \\
\text { Voltage } \\
\text { Amplitude }\end{array}$ & $\begin{array}{c}\text { MCA LLD } \\
\text { Energy }\end{array}$ \\
\hline 1 & $60 \mathrm{mV}$ & & & \\
\hline 2 & $120 \mathrm{mV}$ & & & \\
\hline 3 & $180 \mathrm{mV}$ & & & \\
\hline \multicolumn{5}{|l|}{4} \\
\hline \multicolumn{5}{|l|}{5} \\
\hline \multicolumn{5}{|l|}{6} \\
\hline \multicolumn{5}{|l|}{7} \\
\hline \multicolumn{5}{|l|}{8} \\
\hline \multicolumn{5}{|l|}{9} \\
\hline \multicolumn{5}{|l|}{10} \\
\hline \multicolumn{5}{|l|}{11} \\
\hline \multicolumn{5}{|l|}{12} \\
\hline \multicolumn{5}{|l|}{13} \\
\hline \multicolumn{5}{|l|}{14} \\
\hline \multicolumn{5}{|l|}{15} \\
\hline \multicolumn{5}{|l|}{16} \\
\hline \multicolumn{5}{|l|}{17} \\
\hline \multicolumn{5}{|l|}{18} \\
\hline \multicolumn{5}{|l|}{19} \\
\hline \multicolumn{5}{|l|}{20} \\
\hline \multicolumn{5}{|l|}{21} \\
\hline \multicolumn{5}{|l|}{22} \\
\hline \multicolumn{5}{|l|}{23} \\
\hline \multicolumn{5}{|l|}{24} \\
\hline \multicolumn{5}{|l|}{25} \\
\hline \multicolumn{5}{|l|}{26} \\
\hline \multicolumn{5}{|l|}{27} \\
\hline \multicolumn{5}{|l|}{28} \\
\hline \multicolumn{5}{|l|}{29} \\
\hline \multicolumn{5}{|l|}{30} \\
\hline \multicolumn{5}{|l|}{31} \\
\hline 32 & & & & \\
\hline 33 & & & & \\
\hline 34 & & & & \\
\hline 35 & & & & \\
\hline 36 & & & & \\
\hline
\end{tabular}




\begin{tabular}{|c|c|c|c|c|}
\hline $\begin{array}{c}\text { Test } \\
\#\end{array}$ & $\begin{array}{c}\text { Discriminator } \\
\text { Threshold }\end{array}$ & $\begin{array}{c}\text { Measured } \\
\text { LLD } \\
\text { Voltage }\end{array}$ & $\begin{array}{c}\text { AWG } \\
\text { Voltage } \\
\text { Amplitude }\end{array}$ & $\begin{array}{c}\text { MCA LLD } \\
\text { Energy }\end{array}$ \\
\hline \multicolumn{5}{|l|}{37} \\
\hline \multicolumn{5}{|l|}{38} \\
\hline \multicolumn{5}{|l|}{39} \\
\hline \multicolumn{5}{|l|}{40} \\
\hline \multicolumn{5}{|l|}{41} \\
\hline \multicolumn{5}{|l|}{42} \\
\hline \multicolumn{5}{|l|}{43} \\
\hline \multicolumn{5}{|l|}{44} \\
\hline \multicolumn{5}{|l|}{45} \\
\hline \multicolumn{5}{|l|}{46} \\
\hline \multicolumn{5}{|l|}{47} \\
\hline \multicolumn{5}{|l|}{48} \\
\hline \multicolumn{5}{|l|}{49} \\
\hline \multicolumn{5}{|l|}{50} \\
\hline \multicolumn{5}{|l|}{51} \\
\hline \multicolumn{5}{|l|}{52} \\
\hline \multicolumn{5}{|l|}{53} \\
\hline \multicolumn{5}{|l|}{54} \\
\hline \multicolumn{5}{|l|}{55} \\
\hline \multicolumn{5}{|l|}{56} \\
\hline \multicolumn{5}{|l|}{57} \\
\hline \multicolumn{5}{|l|}{58} \\
\hline \multicolumn{5}{|l|}{59} \\
\hline \multicolumn{5}{|l|}{60} \\
\hline \multicolumn{5}{|l|}{61} \\
\hline \multicolumn{5}{|l|}{62} \\
\hline \multicolumn{5}{|l|}{63} \\
\hline 64 & $3825 \mathrm{mV}$ & & & \\
\hline
\end{tabular}




\section{C.3 TEST 6, TEST 10, TEST 16 - TTL Pulse Width, LED Blink Rate Output Logic Levels}

\section{C.3.1 Purpose:}

This test is to verify that the logic output is compatible with interfacing devices by inspecting the output voltage levels and the signal's pulse width.

This test also verifies that the LED blinks at an appropriate rate.

\section{C.3.2 Required Equipment:}

Power supply for DUT

Oscilloscope with one scope probe (0-5V) and single shot functionality

AWG

Testing cable to connect DUT digital input to BNC jack

Jewelers’ screwdriver (for toggling configuration dipswitches, if applicable)

Tweezers (for changing jumper settings, if applicable)

\section{C.3.3 References:}

DUT documentation provided by vendor

\section{C.3.4 Preparation:}

Ensure that the testing surface is ESD safe.

\section{C.3.5 Procedure:}

1. Configure the DUT for nominal operation (charge-sensitive)

2. Record the DUT settings in Table C.11.

3. Set the DUT TTL pulse width to $2.0 \mu \mathrm{s}$.

4. Select a AWG output amplitude and record

5. Connect the AWG to the detector input and an oscilliscope to the digital output as shown in Figure C.4.

6. Connect the power supply to the DUT.

7. Power on the DUT.

8. Measure and record at least three pulses from the digital output using the oscilloscope's single shot function. Record the rise time, fall time, pulse width, low voltage, high voltage, and ending low voltage in Table C.12 to Table C.17 as appropriate.

9. Repeat measurements with the DUT's pulse width set to:
a. $600 \mathrm{~ns}$
b. $200 \mathrm{~ns}$
c. $50 \mathrm{~ns}$ 
10. For several of the tests previous, visually verify that the LED blinks at the rate of the AWG input pulse $(10 \mathrm{~Hz})$.

\section{C.3.6 Test Data}

UUT Serial Number:

UUT Part Number:

Tested By:

Test Date:

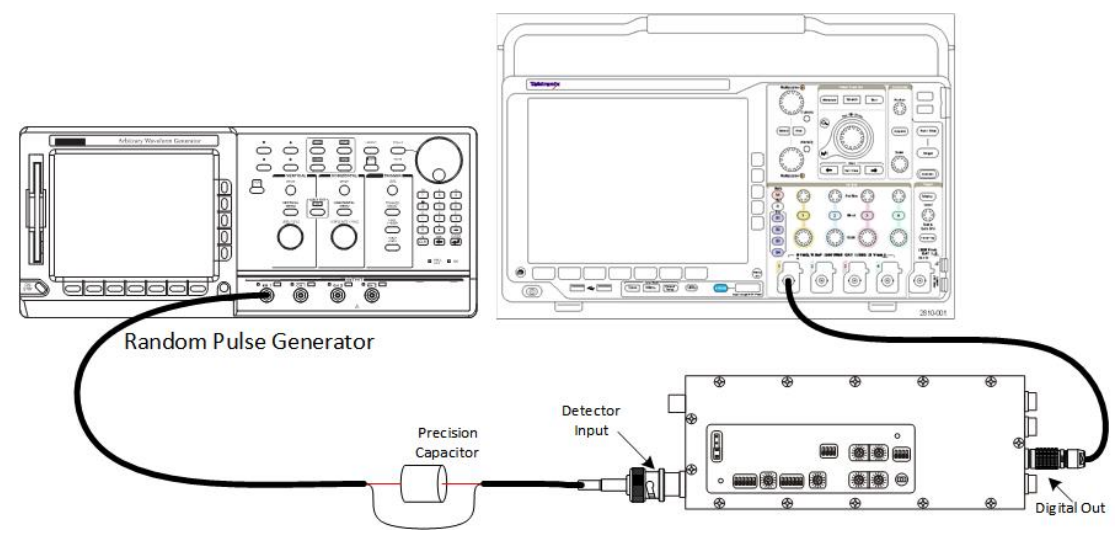

Figure C.4. Using O-Scope to Measure Output Logic Levels Triggered by Pulse Generator

\section{C.3.6.1 Data Tables:}

Table C.11. DUT Configuration

\begin{tabular}{|l|l|}
\hline \multicolumn{1}{|c|}{ Parameter } & \multicolumn{1}{c|}{ Setting } \\
\hline Input Signal Mode (Q or I) & \\
\hline Input Termination & \\
\hline Charge Gain (range) & \\
\hline G1 - Gain & \\
\hline G2 - Gain & \\
\hline HVH - High Voltage & \\
\hline HVL - High Voltage & \\
\hline SW1 - Shaping Time & \\
\hline SW2 - Shaping Time & \\
\hline DH - Discriminator High & \\
\hline DL - Discriminator Low & \\
\hline Digital Ouput Pulse Width & \\
\hline
\end{tabular}


Table C.12. Output Logic Characteristics, pulse width $2.0 \mu \mathrm{s}$

\begin{tabular}{|l|c|c|c|c|c|c|}
\hline Test \# & $\begin{array}{c}\text { Rise } \\
\text { Time }\end{array}$ & $\begin{array}{c}\text { Fall } \\
\text { Time }\end{array}$ & $\begin{array}{c}\text { Pulse } \\
\text { Width }\end{array}$ & $\begin{array}{c}\text { Low 1 } \\
\text { (V) }\end{array}$ & $\begin{array}{c}\text { High } \\
\text { (V) }\end{array}$ & $\begin{array}{c}\text { Low 2 } \\
\text { (V) }\end{array}$ \\
\hline 1 & & & & & & \\
\hline 2 & & & & & & \\
\hline 3 & & & & & & \\
\hline
\end{tabular}

Rise time (the time required for the signal to rise from $10 \%$ to $90 \%$ of pulse height)

Fall time (the time required for the signal to fall from $90 \%$ to $10 \%$ of pulse height)

Pulse width (the time interval from the rising edge to falling edge of pulse where the amplitude is $50 \%$ of pulse height)

Low 1 - stable voltage prior to the pulse

High - stable voltage at high logic level

Low 2 - stable voltage prior to the pulse

Table C.13. Output Logic Characteristics, pulse width to $1.8 \mu \mathrm{s}$

\begin{tabular}{|l|c|c|c|c|c|c|}
\hline Test \# & $\begin{array}{c}\text { Rise } \\
\text { Time }\end{array}$ & $\begin{array}{c}\text { Fall } \\
\text { Time }\end{array}$ & $\begin{array}{c}\text { Pulse } \\
\text { Width }\end{array}$ & $\begin{array}{c}\text { Low 1 } \\
\text { (V) }\end{array}$ & $\begin{array}{c}\text { High } \\
\text { (V) }\end{array}$ & $\begin{array}{c}\text { Low 2 } \\
\text { (V) }\end{array}$ \\
\hline 1 & & & & & & \\
\hline 2 & & & & & & \\
\hline 3 & & & & & & \\
\hline
\end{tabular}

Table C.14. Output Logic Characteristics, pulse width to $1.2 \mu \mathrm{s}$

\begin{tabular}{|l|c|c|c|c|c|c|}
\hline Test \# & $\begin{array}{c}\text { Rise } \\
\text { Time }\end{array}$ & $\begin{array}{c}\text { Fall } \\
\text { Time }\end{array}$ & $\begin{array}{c}\text { Pulse } \\
\text { Width }\end{array}$ & $\begin{array}{c}\text { Low 1 } \\
\text { (V) }\end{array}$ & $\begin{array}{c}\text { High } \\
\text { (V) }\end{array}$ & $\begin{array}{c}\text { Low 2 } \\
\text { (V) }\end{array}$ \\
\hline 1 & & & & & & \\
\hline 2 & & & & & & \\
\hline 3 & & & & & & \\
\hline
\end{tabular}


Table C.15. Output Logic Characteristics, pulse width to 800 ns

\begin{tabular}{|l|c|c|c|c|c|c|}
\hline Test \# & $\begin{array}{c}\text { Rise } \\
\text { Time }\end{array}$ & $\begin{array}{c}\text { Fall } \\
\text { Time }\end{array}$ & $\begin{array}{c}\text { Pulse } \\
\text { Width }\end{array}$ & $\begin{array}{c}\text { Low 1 } \\
\text { (V) }\end{array}$ & $\begin{array}{c}\text { High } \\
\text { (V) }\end{array}$ & $\begin{array}{c}\text { Low 2 } \\
\text { (V) }\end{array}$ \\
\hline 1 & & & & & & \\
\hline 2 & & & & & & \\
\hline 3 & & & & & & \\
\hline
\end{tabular}

Table C.16. Output Logic Characteristics, pulse width to 400 ns

\begin{tabular}{|l|c|c|c|c|c|c|}
\hline Test \# & $\begin{array}{c}\text { Rise } \\
\text { Time }\end{array}$ & $\begin{array}{c}\text { Fall } \\
\text { Time }\end{array}$ & $\begin{array}{c}\text { Pulse } \\
\text { Width }\end{array}$ & $\begin{array}{c}\text { Low 1 } \\
\text { (V) }\end{array}$ & $\begin{array}{c}\text { High } \\
\text { (V) }\end{array}$ & $\begin{array}{c}\text { Low 2 } \\
\text { (V) }\end{array}$ \\
\hline 1 & & & & & & \\
\hline 2 & & & & & & \\
\hline 3 & & & & & & \\
\hline
\end{tabular}

Table C.17. Output Logic Characteristics, pulse width to $200 \mathrm{~ns}$

\begin{tabular}{|l|c|c|c|c|c|c|}
\hline Test \# & $\begin{array}{c}\text { Rise } \\
\text { Time }\end{array}$ & $\begin{array}{c}\text { Fall } \\
\text { Time }\end{array}$ & $\begin{array}{c}\text { Pulse } \\
\text { Width }\end{array}$ & $\begin{array}{c}\text { Low 1 } \\
\text { (V) }\end{array}$ & $\begin{array}{c}\text { High } \\
(\mathbf{V})\end{array}$ & $\begin{array}{c}\text { Low 2 } \\
(\mathbf{V})\end{array}$ \\
\hline 1 & & & & & & \\
\hline 2 & & & & & & \\
\hline 3 & & & & & & \\
\hline
\end{tabular}




\section{C.4 TEST 7- Bias Supply Output Voltage}

\section{C.4.1 Purpose:}

This test is to determine operational range of the detector bias voltage and ensure that minimal noise is present

\section{C.4.2 Required Equipment:}

Power supply for the DUT

Multimeter with a HV probe (rated to at least $2000 \mathrm{~V}_{\mathrm{DC}}$ )

Oscilloscope

Jewelers' screwdriver (for toggling configuration dipswitches, if applicable)

Tweezers (for changing jumper settings, if applicable)

\section{C.4.3 References:}

DUT Documentation Provided by Vendor

\section{C.4.4 Preparation:}

Ensure that the testing surface is ESD safe.

\section{C.4.5 Procedure:}

1. Set the DUT high-voltage setting to the minimum value.

2. Connect the DUT to the power supply.

3. Power on the DUT.

4. Measure and record the bias voltage using the multimeter and the 1000:1 HV probe. (see Figure C.5). Multiply the value read by 1000, and record the voltage in Table C.18.

5. Power off the DUT.

6. Increment the high-voltage bias supply by eight units (50 V).

7. Repeat steps $3-7$ until testing has completed measurements at the maximum voltage output and all 32 high-voltage settings have been measured.

\section{C.4.6 Test Data}

DUT Serial Number:

DUT Part Number:

Tested By:

Test Date: 


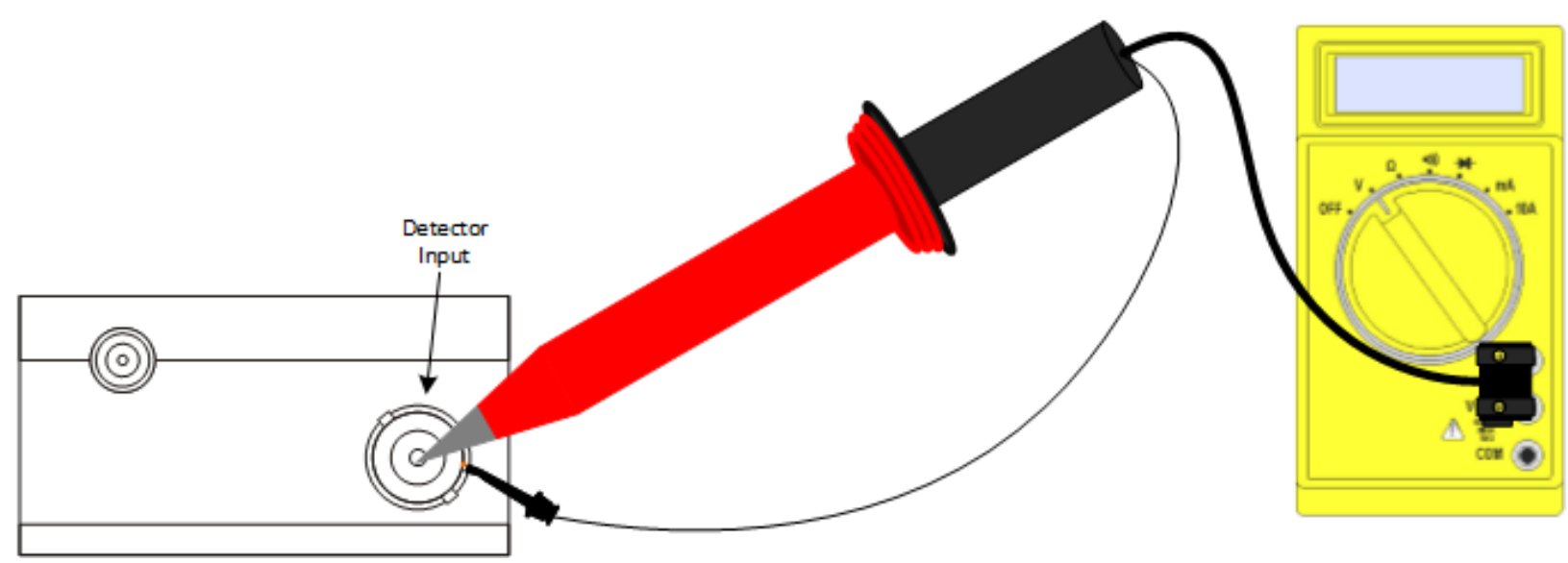

Figure C.5. Using Multimeter to Measure Bias Voltage

\section{C.4.6.1 Data Table:}

Table C.18. HV Bias Characteristics

\begin{tabular}{|l|l|l|}
\hline \multicolumn{1}{|c|}{ Test \# } & \multicolumn{1}{|c|}{ Setting (V) } & Measured (V) \\
\hline 1 & Minimum $400 \mathrm{~V}$ & \\
\hline 2 & & \\
\hline 3 & & \\
\hline 4 & & \\
\hline 5 & & \\
\hline 6 & & \\
\hline 7 & & \\
\hline 8 & & \\
\hline 9 & & \\
\hline 10 & & \\
\hline 11 & & \\
\hline 12 & & \\
\hline 13 & & \\
\hline 14 & & \\
\hline 15 & & \\
\hline 16 & & \\
\hline 17 & & \\
\hline 18 & & \\
\hline 19 & & \\
\hline
\end{tabular}




\begin{tabular}{|l|l|l|}
\hline \multicolumn{1}{|c|}{ Test \# } & Setting (V) & Measured (V) \\
\hline 20 & & \\
\hline 21 & & \\
\hline 22 & & \\
\hline 23 & & \\
\hline 24 & & \\
\hline 25 & & \\
\hline 26 & & \\
\hline 27 & & \\
\hline 28 & & \\
\hline 29 & & \\
\hline 30 & & \\
\hline 31 & & \\
\hline 32 & Maximum 1993.75V V & \\
\hline
\end{tabular}




\section{C.5 TEST 8 - Bias Supply Stability}

\section{C.5.1 Purpose:}

This test is to determine the stability of the detector's bias voltage. Measurements will be taken, starting at the minimum output voltage, for an hour and then for several days. After each hour the voltage output will be incremented by $1 / 4$ of the operating range till the maximum output voltage is reached.

\section{C.5.2 Required Equipment:}

Power supply for the DUT

DAQ /Data logger capable of:

- Measuring up to $10 \mathrm{~V}$ with divide by 500 voltage divider to achieve $2000 \mathrm{~V}_{\mathrm{DC}}$

- Accuracy to at least 2.5 significant figures

- Resolution high enough to measure $50 \mathrm{mV}$

- Logging once every $100 \mathrm{~ms}$ and every $1 \mathrm{~s}$

Testing cable to connect from the DUT's detector input to the DAQ

Jeweler's screwdriver (for toggling configuration dipswitches, if applicable)

Tweezers (for changing jumper settings, if applicable)

\section{C.5.3 References:}

DUT documentation Provided by Vendor

\section{C.5.4 Preparation:}

Ensure that the testing surface is ESD safe.

\section{C.5.5 Procedure:}

1. Set the DUT high-voltage bias to the minimum value.

2. Configure the power supply for $12 \mathrm{~V}$ DC and connect it to the DUT.

3. Connect the test cable from the DUT detector input to the DAQ (see Figure C.6). Insert a 500:1 voltage divider in series with the DAQ in order to measure up to a $2000 \mathrm{~V}$ signal (resistors should be as large as possible to reduce the loading effect on HV power supply).

4. Power on the DUT.

5. Configure the DAQ to log once every 100ms, and log the bias supply voltage for 1 hour.

6. Configure the DAQ to log once every $1 \mathrm{~s}$ and log the bias supply voltage for several days as allowed by the DAQ.

7. Calculate and record the average, minimum, maximum, and standard deviation for the data set in Table C.19 Verify that the minimum and maximum do not exceed $50 \mathrm{mV}$ of the average voltage.

8. Power off the DUT. 
9. Increase the high-voltage bias supply $1 / 4$ of the interval from minimum to maximum voltage. Repeat steps $4-8$ for the remaining voltages.

\section{C.5.6 Test Data}

DUT Serial Number:

DUT Part Number:

Tested By:

Test Date:

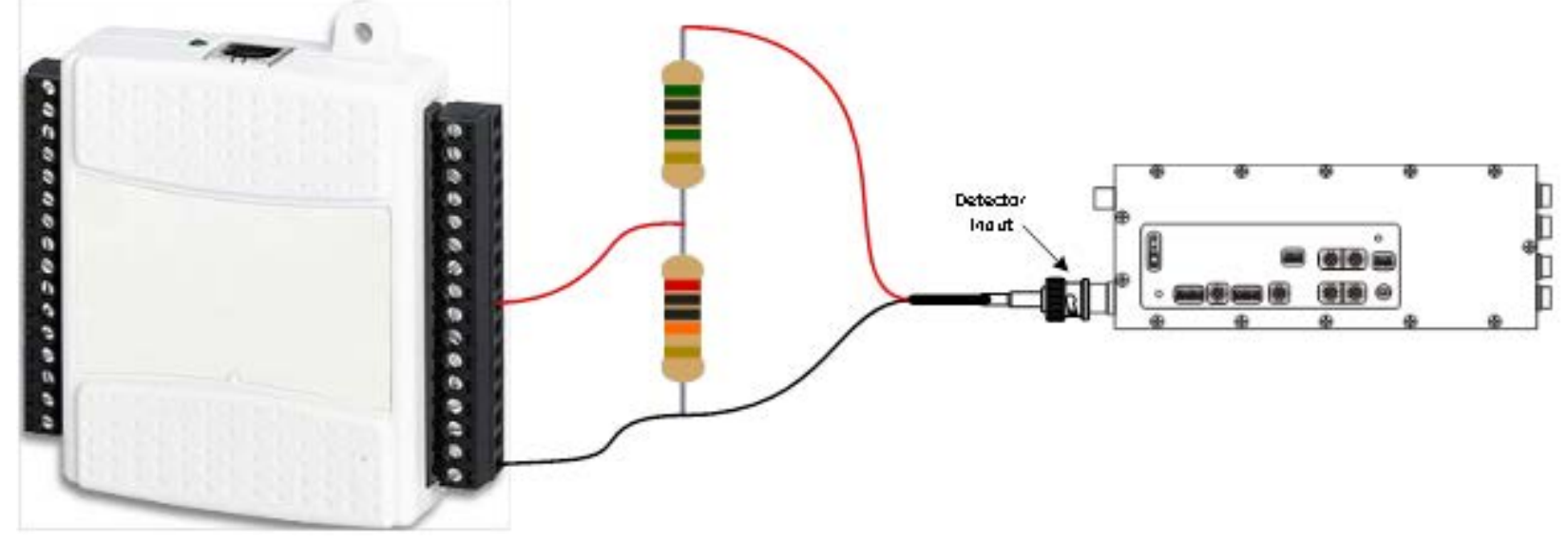

Figure C.6. Using DAQ with Data Logger to Measure Bias Voltage

\section{C.5.6.1 Data Table:}

Table C.19. HV Stability Characteristics

\begin{tabular}{|l|l|l|l|l|l|}
\hline \multicolumn{1}{|c|}{ Test \# } & $\begin{array}{c}\text { Voltage } \\
\text { (V) }\end{array}$ & Mean (V) & $\operatorname{Max~(V)~}$ & Min (V) & Std Dev. (V) \\
\hline $\begin{array}{l}1 \text { (min) } \\
100 \mathrm{~ms}\end{array}$ & & & & & \\
\hline 2 & & & & & \\
\hline 3 & & & & & \\
\hline 4 & & & & & \\
\hline $5(\max )$ & & & & & \\
\hline $6(\min ) 1 \mathrm{~s}$ & & & & & \\
\hline 7 & & & & & \\
\hline 8 & & & & & \\
\hline 9 & & & & & \\
\hline $10(\max )$ & & & & & \\
\hline
\end{tabular}




\section{C.6 TEST 11, Test 14 - Isolated and Grounded Power Input Ranges}

\section{C.6.1 Purpose:}

This test is to verify that the DUT will function as expected over a variety of input voltages: +8 to $+15 \mathrm{~V}$ DC on the isolated power input and $+10.5 \mathrm{~V}$ to $+15 \mathrm{~V}$ DC on the analog output \#2 port.

This test also verifies that the power input on analog output \#2 functions equivalently to the isolated power input.

\section{C.6.2 Required Equipment:}

Variable power supply

Oscilloscope

AWG

Voltmeter

High-Voltage Probes up to 2000 V DC.

\section{C.6.3 References:}

DUT documentation provided by vendor

\section{C.6.4 Preparation:}

Ensure that the testing surface is ESD safe.

\section{C.6.5 Procedure:}

\section{High-Voltage Bias}

1. Configure the DUT for nominal settings. If other settings are necessary for the test, record the settings used in Table C.20.

2. Connect the variable power supply to the isolated power input port.

3. Configure the power supply for $8 \mathrm{~V} \mathrm{DC}$ and power on the DUT.

4. Set the DUT high-voltage bias to the minimum value.

5. Measure the high-voltage bias as shown in Figure C.7 using 1000:1 high-voltage probes.

6. Set the DUT high-voltage bias to the maximum value.

7. Measure the high-voltage bias as shown in Figure C.7 using 1000:1 high-voltage probes.

8. Multiply the values measured by 1000 and record in Table C.21.

9. Increase the supply voltage by $0.5 \mathrm{~V}$ and repeat steps $4-8$ for the entire input voltage range.

10. Repeat steps 4-9 for the power supply connected to analog output \#2.

11. Turn off power and disconnect the power supply. 


\section{Pulse Verification}

12. Return the DUT to nominal settings.

13. Connect the variable power supply to the isolated power input port. Connect the AWG to the detector input port, and analog output \#1 to the oscilloscope.

14. Configure the power supply for 8V DC and power on the DUT.

15. Configure the AWG for pulses with amplitude in the mid-range of the DUT.

16. Verify on the oscilloscope that the output pulse shape is reasonable.

17. Measure the output amplitude and record it in Table C.22

18. Repeat steps $15-17$ with the gain at the maximum and minimum setting.

19. Repeat steps 14-19 for each voltage in Table C.22.

20. Connect the power supply to analog output port \#2.

21. Repeat steps 14-20 for each voltage in

22. Table C.23.

23. If any anomalies are noted repeate measurements for more voltages in the specified range for each input.

\section{C.6.6 Test Data}

DUT Serial Number:

DUT Part Number:

Tested By:

Test Date:

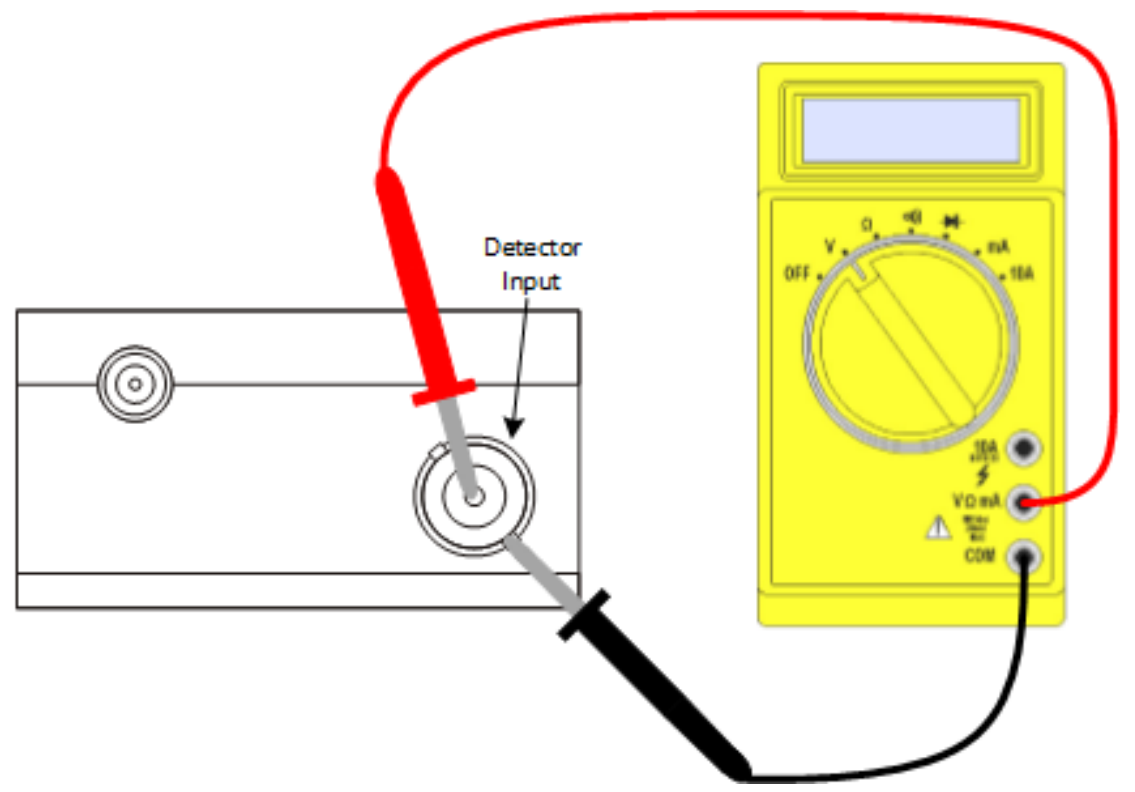

Figure C.7. Measuring Detector Bias Voltage on the DUT 


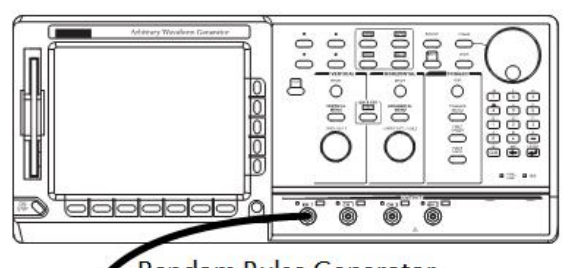

Random Pulse Generator
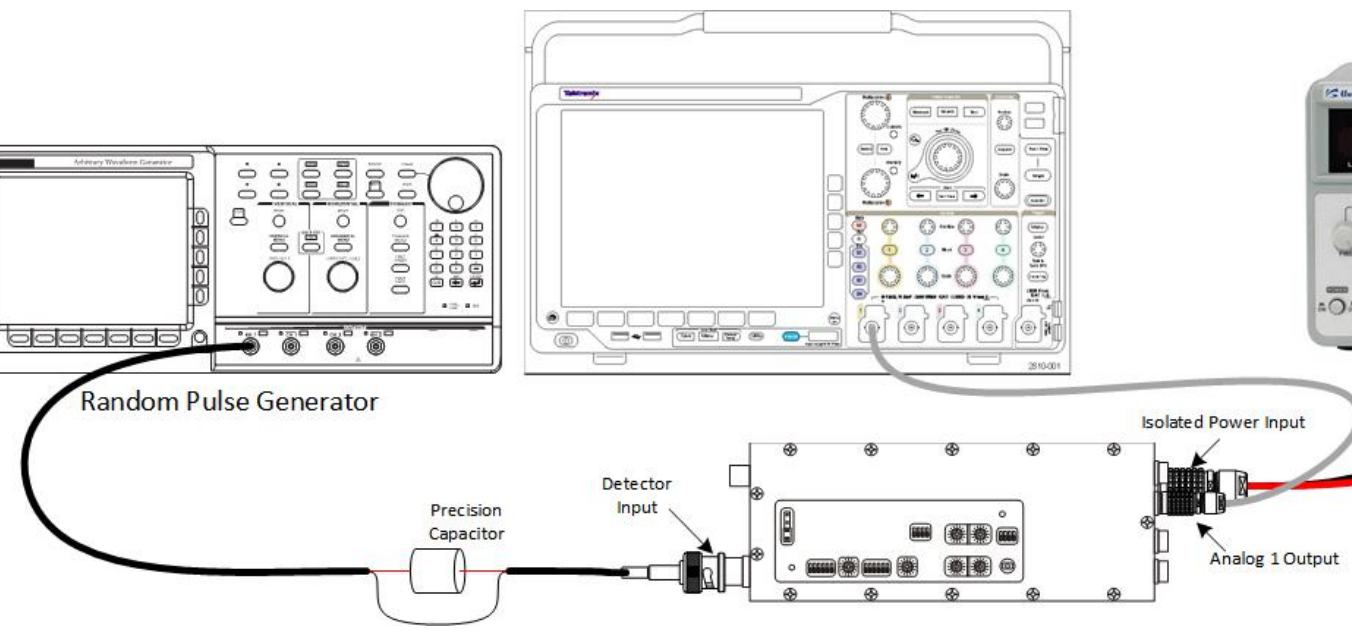

Figure C.8. Using a Variable Power Supply to Verify DUT at Multiple Voltage Inputs

\section{C.6.6.1 Data Table:}

Table C.20. DUT Configuration

\begin{tabular}{|l|l|}
\hline \multicolumn{1}{|c|}{ Parameter } & \multicolumn{1}{c|}{ Setting } \\
\hline Input Signal Mode (Q or I) & \\
\hline Input Termination & \\
\hline Charge Gain (range) & \\
\hline G1 - Gain & \\
\hline G2 - Gain & \\
\hline HVH - High Voltage & \\
\hline HVL - High Voltage & \\
\hline SW1 - Shaping Time & \\
\hline SW2 - Shaping Time & \\
\hline DH - Discriminator High & \\
\hline DL - Discriminator Low & \\
\hline Digital Ouput Pulse Width & \\
\hline
\end{tabular}


Table C.21. Variable Supply Voltage HV Characteristics

\begin{tabular}{|l|l|c|c|c|c|}
\hline Test \# & $\begin{array}{c}\text { Supply } \\
\text { Voltage (V) }\end{array}$ & $\begin{array}{c}\text { Isolated } \\
\text { Supply HV } \\
\text { Bias Min } \\
(\mathbf{V})\end{array}$ & $\begin{array}{c}\text { Isolated } \\
\text { Supply HV } \\
\text { Bias Max } \\
\text { (V) }\end{array}$ & $\begin{array}{c}\text { Grounded } \\
\text { Supply HV } \\
\text { Bias Min } \\
(\text { V) }\end{array}$ & $\begin{array}{c}\text { Grounded } \\
\text { Supply HV } \\
\text { Bias Max } \\
\text { (V) }\end{array}$ \\
\hline 1 & 8.0 & & & N/A & N/A \\
\hline 2 & 10.5 & & & & \\
\hline 3 & 15 & & & & \\
\hline
\end{tabular}

Table C.22. Gain Response for Isolated Power at Various Voltages

\begin{tabular}{|l|l|c|l|l|}
\hline Test \# & $\begin{array}{c}\text { Supply } \\
\text { Voltage (V) }\end{array}$ & $\begin{array}{c}\text { Output } \\
\text { Amplitude } \\
\text { Nominal } \\
\text { Gain }\end{array}$ & $\begin{array}{c}\text { Output } \\
\text { Amplitude } \\
\text { Max Gain }\end{array}$ & $\begin{array}{c}\text { Output } \\
\text { Amplitude } \\
\text { Min Gain }\end{array}$ \\
\hline 1 & 8.0 & & & \\
\hline 2 & 15 & & & \\
\hline
\end{tabular}

Table C.23. Gain Response for Grounded Power Input at Various Voltages

\begin{tabular}{|l|l|c|c|c|}
\hline Test \# & $\begin{array}{c}\text { Supply } \\
\text { Voltage (V) }\end{array}$ & $\begin{array}{c}\text { Output } \\
\text { Amplitude } \\
\text { Nominal } \\
\text { Gain }\end{array}$ & $\begin{array}{c}\text { Output } \\
\text { Amplitude } \\
\text { Max Gain }\end{array}$ & $\begin{array}{c}\text { Output } \\
\text { Amplitude } \\
\text { Min Gain }\end{array}$ \\
\hline 1 & 10.5 & & & \\
\hline 2 & 15 & & & \\
\hline
\end{tabular}




\section{C.7 TEST 12, TEST 13 - Digital Input Logic Levels \& Summing}

\section{C.7.1 Purpose:}

This test is to verify that the DUT recognizes valid 5V TTL logic inputs. This test also verifies that the digital summing function works correctly, such that a pulse from either the digital input or the detector input produce pulses on the digital output, and that coincident pulses produce two separate digital pulses. Required Equipment:

Power supply for DUT

Oscilloscope with one scope probe and single shot functionality

Pulse generator (AWG or BNC pulser) capable of:

- Dual channel, random pulses

- Generating pulse with rise time of 100 ns and fall time of several microseconds

Three $50 \Omega$ BNC cable (e.g. RG-58)

One $50 \Omega$ BNC-T

Testing cable to connect the DUT digital input to BNC jack

Jewelers’ screwdriver (for toggling configuration dipswitches, if applicable)

Tweezers (for changing jumper settings, if applicable)

\section{C.7.2 References:}

DUT documentation provided by vendor

\section{C.7.3 Preparation:}

Ensure that the testing surface is ESD safe.

\section{C.7.4 Procedure:}

\section{Logic Levels}

1. Configure the DUT for nominal operation with the pulse generator

2. Record the DUT settings in Table C.24.

3. Set the DUT digital pulse width to $2.0 \mu \mathrm{s}$.

4. Configure the equipment per Figure C.9and set the AWG output as follows:
a. Output wave set to square
b. Frequency set to $25 \mathrm{kHz}$ (wavelength $=40 \mu \mathrm{s}$ )
c. Duty Cycle set to $5 \%(0.05 * 40 \mu \mathrm{s}=2 \mu \mathrm{s})$
d. Amplitude set to $5 \mathrm{~V}$

5. Enable the waveform output and verify that AWG output is from 0 to $5 \mathrm{~V}$.

6. Disable the waveform output.

7. Connect the BNC-T to the DUT's digital input. 
8. Connect the power supply to the DUT and configure for $12 \mathrm{~V}$ DC.

9. Power on the DUT.

10. Enable the waveform output (verify output using the oscilloscope).

11. Using the oscilloscope's single shot function, verify that input pulses match the output pulses (see Figure C.9)

12. Begin adjusting the AWG output, maintaining the signal minimum at $0 \mathrm{~V}$ while reducing the maximum voltage by increments of $0.1 \mathrm{~V}$ until output pulses stop being generated. Record the last voltage at which a logic high is recognized in Table C.25.

13. Return signal to 0 to $5 \mathrm{~V}$.

14. Begin adjusting the AWG output, maintaining the signal maximum at $5 \mathrm{~V}$ while increasing the minimum voltage by $0.1-\mathrm{V}$ increments until the output becomes a constant logic high). Record the last voltage at which a logic low is recognized in Table C.25.

\section{Digital Summing}

15. Return the DUT to nominal settings.

16. Connect the test equipment to the DUT as shown in Figure C.10.

17. Configure the digital input pulse generator to output a pulse width of approximately 50 ns width.

18. Configure the detector input pulse generator to output a pulse with several ns of fall time and several microseconds of rise time and a voltage in the middle of the DUT range.

19. Set the random pulse generators to output count rates of approximately 1 kcps.

20. Measure the input and output count rates for the 1) digital input only, 2) detector input only, and 3) both the digital and detector inputs.

21. Verify that the measured count rates match the expected count rates. Record the count rates in Table C.26.

22. Repeate steps 19 through 22 for each of the count rates listed in Table C.26.

\section{C.7.5 Test data}

DUT Serial Number:

DUT Part Number:

Tested By:

Test Date: 


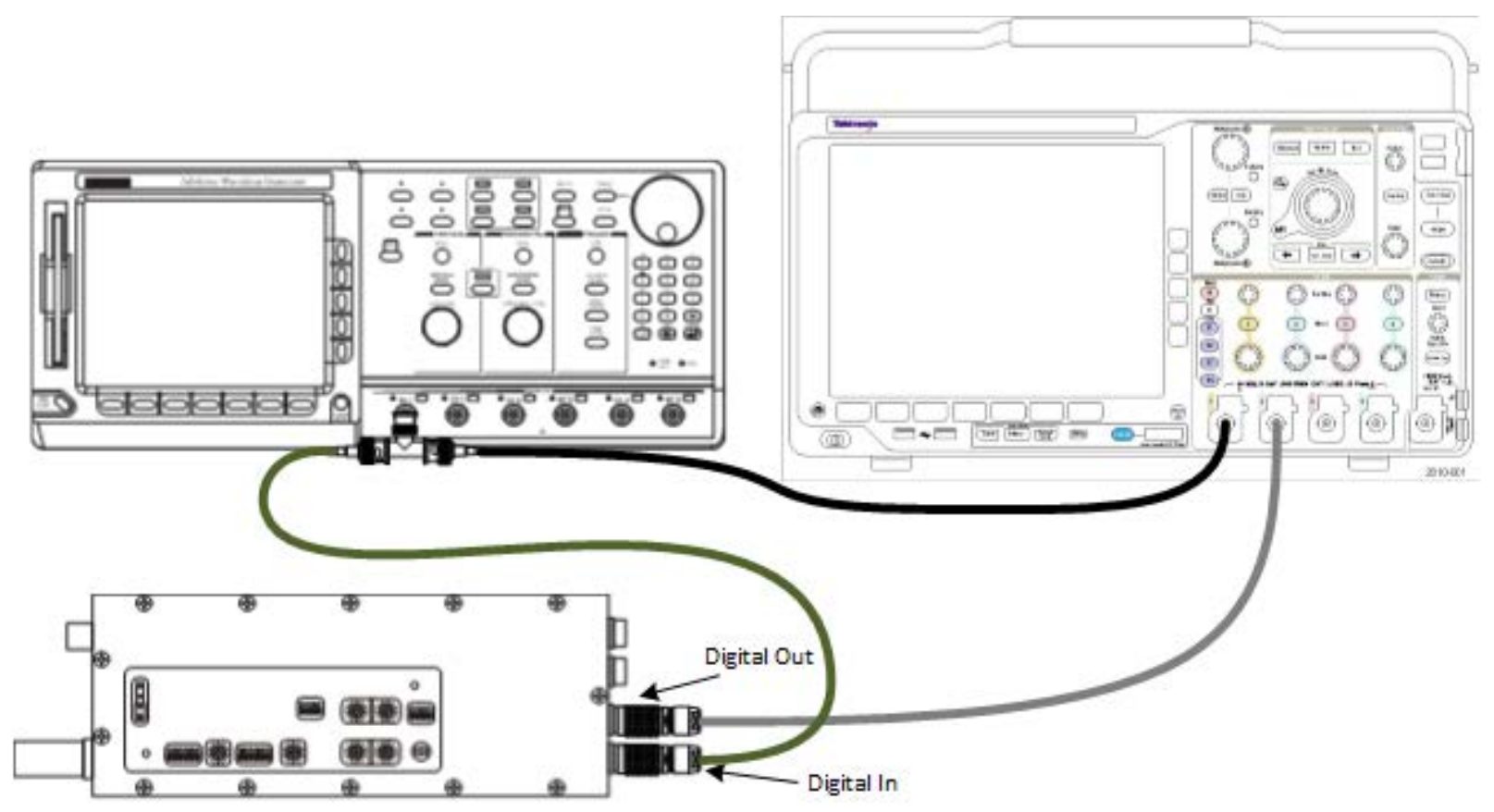

Figure C.9. Logic Voltage Levels Test Setup

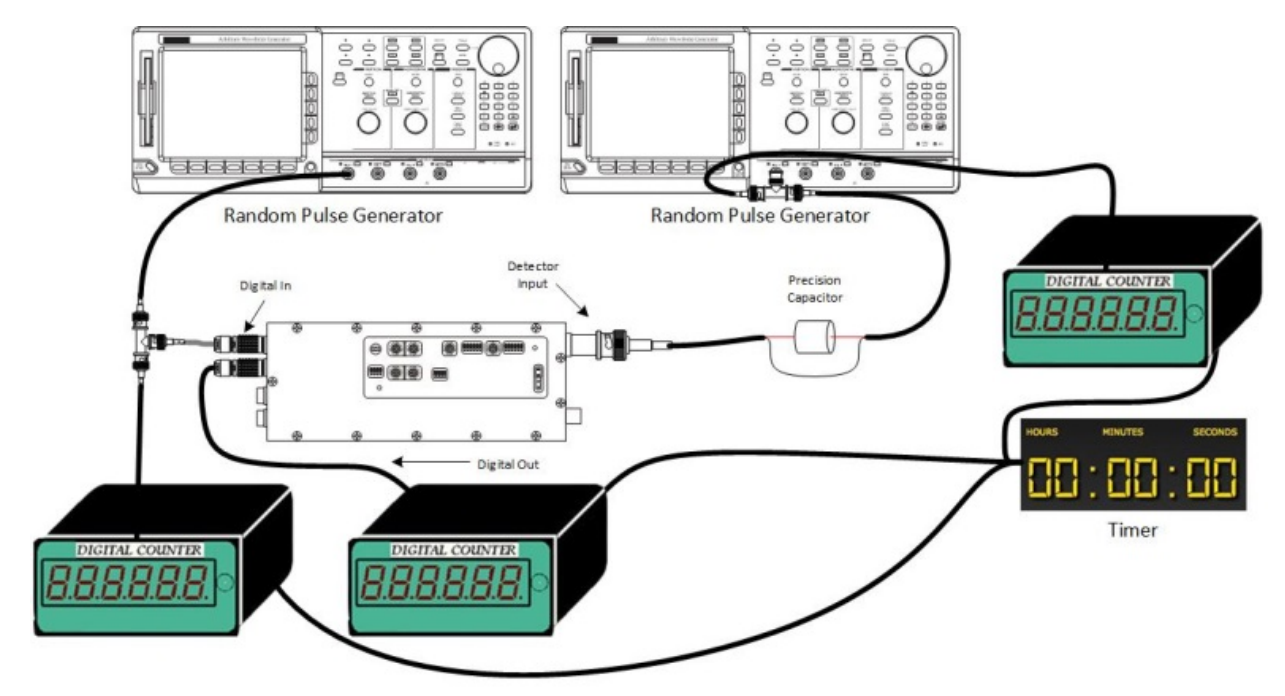

Figure C.10. Digital Summing Test Setup 


\section{C.7.5.1 Data Table:}

Table C.24. DUT Configuration

\begin{tabular}{|l|l|}
\hline \multicolumn{1}{|c|}{ Parameter } & \multicolumn{1}{c|}{ Setting } \\
\hline Input Signal Mode (Q or I) & \\
\hline Input Termination & \\
\hline Charge Gain (range) & \\
\hline G1 - Gain & \\
\hline G2 - Gain & \\
\hline HVH - High Voltage & \\
\hline HVL - High Voltage & \\
\hline SW1 - Shaping Time & \\
\hline SW2 - Shaping Time & \\
\hline DH - Discriminator High & \\
\hline DL - Discriminator Low & \\
\hline Digital Ouput Pulse Width & \\
\hline
\end{tabular}

Table C.25. Input Logic High Characteristics

\begin{tabular}{|l|l|}
\hline \multicolumn{2}{|c|}{ Input $(\mathrm{V})$} \\
\hline Logic Low $\left(\mathrm{V}_{\mathrm{IL}}\right)$ & Logic High $\left(\mathrm{V}_{\mathrm{IH}}\right)$ \\
\hline & \\
\hline
\end{tabular}

Table C.26. Summed Digital Output Results

\begin{tabular}{|l|l|l|l|l|l|l|l|l|}
\hline \multirow{2}{*}{\begin{tabular}{l} 
Average \\
Counts \\
\cline { 2 - 9 } \\
(kcps)
\end{tabular}} & $\begin{array}{l}\text { Input } \\
\text { rate } \\
(\mathrm{kcps})\end{array}$ & $\begin{array}{l}\text { Output } \\
\text { rate } \\
(\mathrm{kcps})\end{array}$ & $\begin{array}{l}\text { Input } \\
\text { rate } \\
\text { (kcps) }\end{array}$ & $\begin{array}{l}\text { Output } \\
\text { rate } \\
\text { (kcps) }\end{array}$ & $\begin{array}{l}\text { Detector } \\
\text { input } \\
\text { rate } \\
\text { (kcps) }\end{array}$ & $\begin{array}{l}\text { Digital } \\
\text { input } \\
\text { rate } \\
\text { (kcps) }\end{array}$ & $\begin{array}{l}\text { Ideal } \\
\text { summed } \\
\text { rate } \\
\text { (kcps) }\end{array}$ & $\begin{array}{l}\text { Output } \\
\text { summed } \\
\text { rate } \\
\text { (kcps) }\end{array}$ \\
\hline 0.1667 & & & & & & & & \\
\hline 1.67 & & & & & & & & \\
\hline 10 & & & & & & & & \\
\hline 100 & & & & & & & & \\
\hline 1000 & & & & & & & & \\
\hline
\end{tabular}




\section{C.8 TEST 15 - Analog Output \#1 and \#2 Functionality}

\section{C.8.1 Purpose:}

This test is to verify that the shaping amplifier's output is compatible with interfacing devices by inspecting the output voltage levels and pulse shape and to verify outputs are decoupled or superimposed on $\mathrm{V}_{\mathrm{cc}}$.

\section{C.8.2 Required Equipment:}

Variable Power supply

Multimeter

Banana jack to BNC adapter

Oscilloscope with two scope probes or two $50 \Omega$ BNC cables (e.g. RG-58)

AWG

Precision Capacitor

Jewelers’ screwdriver (for toggling configuration dipswitches, if applicable)

Tweezers (for changing jumper settings, if applicable)

\section{C.8.3 References:}

DUT documentation provided by vendor

\section{C.8.4 Preparation:}

Ensure that the testing surface is ESD safe.

\section{C.8.5 Procedure:}

1. Configure the DUT as necesary for nominal operation.

2. Record the DUT settings in Table C.27 if different than nominal settings.

3. Configure the power supply for $12 \mathrm{~V} \mathrm{DC}$ and turn it on while disconnected from the DUT.

4. Measure and record in Table C.28 the power supply's output with the multimeter.

5. Turn off the power supply.

6. Connect the $12 \mathrm{~V}$ power supply and the oscilloscope channel 1 to the DUT $\mathrm{V}_{\text {cc }}$ superimposed output via a BNC-T as shown in Figure C.11. Connect the oscilloscope channel 2 to the DUT isolated output as shown in Figure C.11.

7. Power on the DUT.

8. Measure and record the stable output voltages from analog output \#1 and \#2 with the multimeter or oscilloscope and record the values in Table C.28.

9. Configure the AWG to output pulses at a mid-range voltage. 
10. Measure and record at least ten pulses using the oscilloscope's single shot function.. Record values in Table C.29.

11. Verify output \#1 and \#2 have similar pulse shapes and amplitudes.

\section{C.8.6 Test data}

DUT Serial Number:

DUT Part Number:

Tested By:

Test Date:

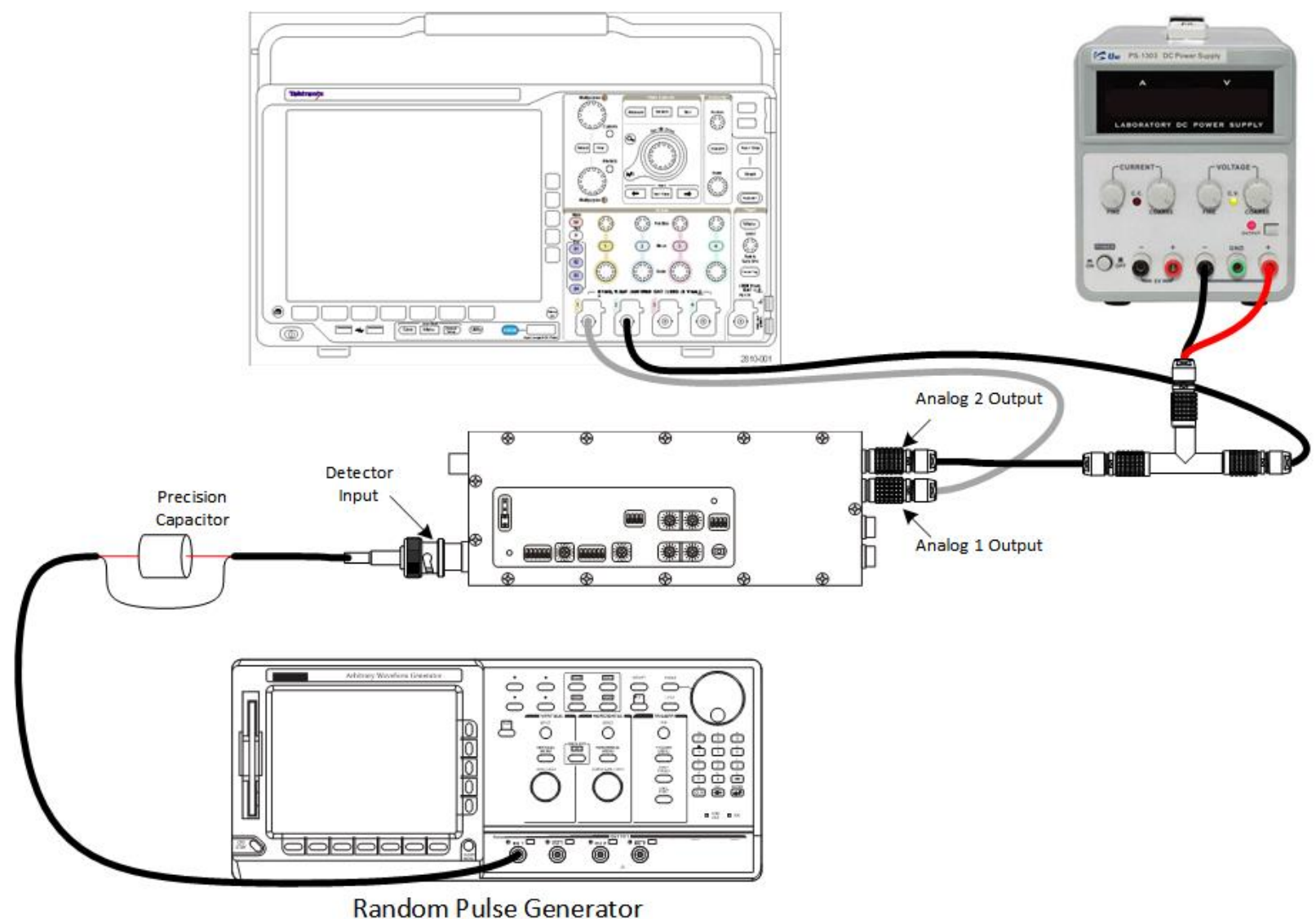

Figure C.11. Using O-Scope to Measure Output Logic Levels 


\section{C.8.6.1 Data Table:}

Table C.27. DUT Configuration

\begin{tabular}{|l|l|}
\hline \multicolumn{1}{|c|}{ Parameter } & \multicolumn{1}{c|}{ Setting } \\
\hline Input Signal Mode (Q or I) & \\
\hline Input Termination & \\
\hline Charge Gain (range) & \\
\hline G1 - Gain & \\
\hline G2 - Gain & \\
\hline HVH - High Voltage & \\
\hline HVL - High Voltage & \\
\hline SW1 - Shaping Time & \\
\hline SW2 - Shaping Time & \\
\hline DH - Discriminator High & \\
\hline DL - Discriminator Low & \\
\hline Digital Ouput Pulse Width & \\
\hline
\end{tabular}

Table C.28. DUT Power and Signal Voltages

\begin{tabular}{|c|c|l|}
\hline $\begin{array}{c}\text { Power Supply } \\
\text { Voltage }\end{array}$ & $\begin{array}{c}\text { Baseline Output } \\
\# 1 \text { Voltage }\end{array}$ & $\begin{array}{l}\text { Baseline Output } \\
\# 2 \text { Voltage }\end{array}$ \\
\hline & & \\
\hline
\end{tabular}


Table C.29. DUT Analog Output Characteristics

\begin{tabular}{|l|l|l|l|l|l|}
\hline Test \# & $\begin{array}{c}\text { AWG } \\
\text { Setting }\end{array}$ & $\begin{array}{c}\text { Output \#1 } \\
\text { Amplitude }\end{array}$ & $\begin{array}{c}\text { Output \#1 } \\
\text { Pulse } \\
\text { Width }\end{array}$ & $\begin{array}{c}\text { Output \#2 } \\
\text { Amplitude }\end{array}$ & $\begin{array}{c}\text { \#2Pulse } \\
\text { Width }\end{array}$ \\
\hline 1 & & & & & \\
\hline 2 & & & & & \\
\hline 3 & & & & & \\
\hline 4 & & & & & \\
\hline 5 & & & & & \\
\hline 6 & & & & & \\
\hline 7 & & & & & \\
\hline 8 & & & & & \\
\hline 9 & & & & & \\
\hline 10 & & & & & \\
\hline
\end{tabular}




\section{C.9 TEST 17 - Ground Isolation}

\section{C.9.1 Purpose:}

It desirable to have sufficient isolation from signal to ground and between various signal grounds in order to reduce noise issues that propagate via the ground and formed by ground loops. The resistance between the input grounds, output grounds and chassis ground will be checked to determine how well they are isolated. Also, if the DUT provides the ability to configure grounding isolation, those configurations will be confirmed.

This test also measures impedance of the ports for proper impedance matching.to connected equipment, both at DC and at standard impedance reporting frequency of $1 \mathrm{KHz}$.

\section{C.9.2 Required Equipment:}

2 Ohm-Meters or multimeters

Impedance Analyzer (if not available AWG and fixed resistor)

Jewelers’ screwdriver (for toggling configuration dipswitches, if applicable)

Tweezers (for changing jumper settings, if applicable)

\section{C.9.3 References:}

None

\section{C.9.4 Preparation:}

Determine if device grounding isolation is configurable

- Create a new data table for each configuration

- Caption each table with the configuration name from the manual or a similar descriptor Ensure that the testing surface is ESD safe.

Don personal grounding equipment (e.g. wrist or shoe straps)

\section{C.9.5 Procedure:}

1. If grounding isolation is configurable, configure for the first setting.

2. If using a multimeter, set it to measure resistance.

3. Measure the DC resistance between each point listed in the Table C.30 (see Figure C.12).

a. Port 1 ground conductor to Port 2 ground conductor

b. Input ground conductor to chassis ground

c. Output ground conductor to chassis ground

4. Measure the DC resistance from signal to ground reference for each port in Table C.30. (See

Figure C.13 for example measurement setup) 


\section{C.9.5.1 Test Data:}

DUT Serial Number:

DUT Part Number:

Tested By:

Test Date:

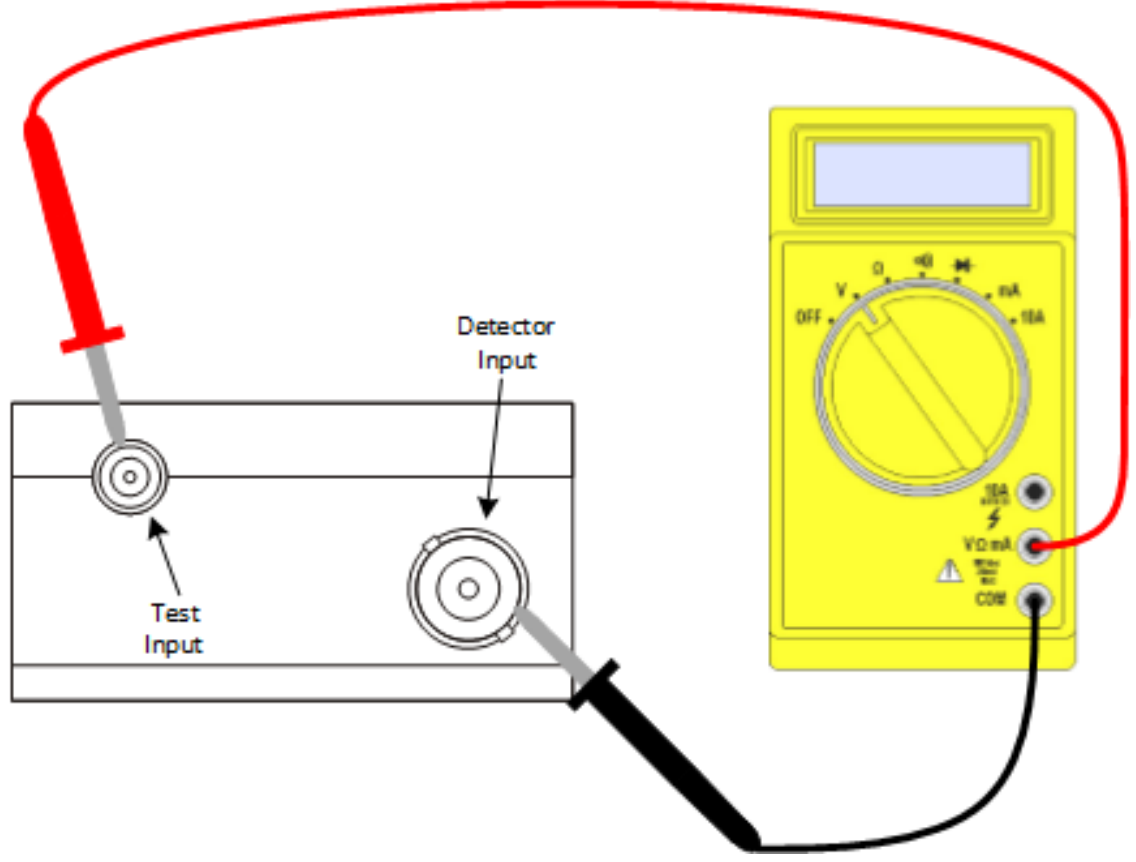

Figure C.12. Measuring Between Grounding Points

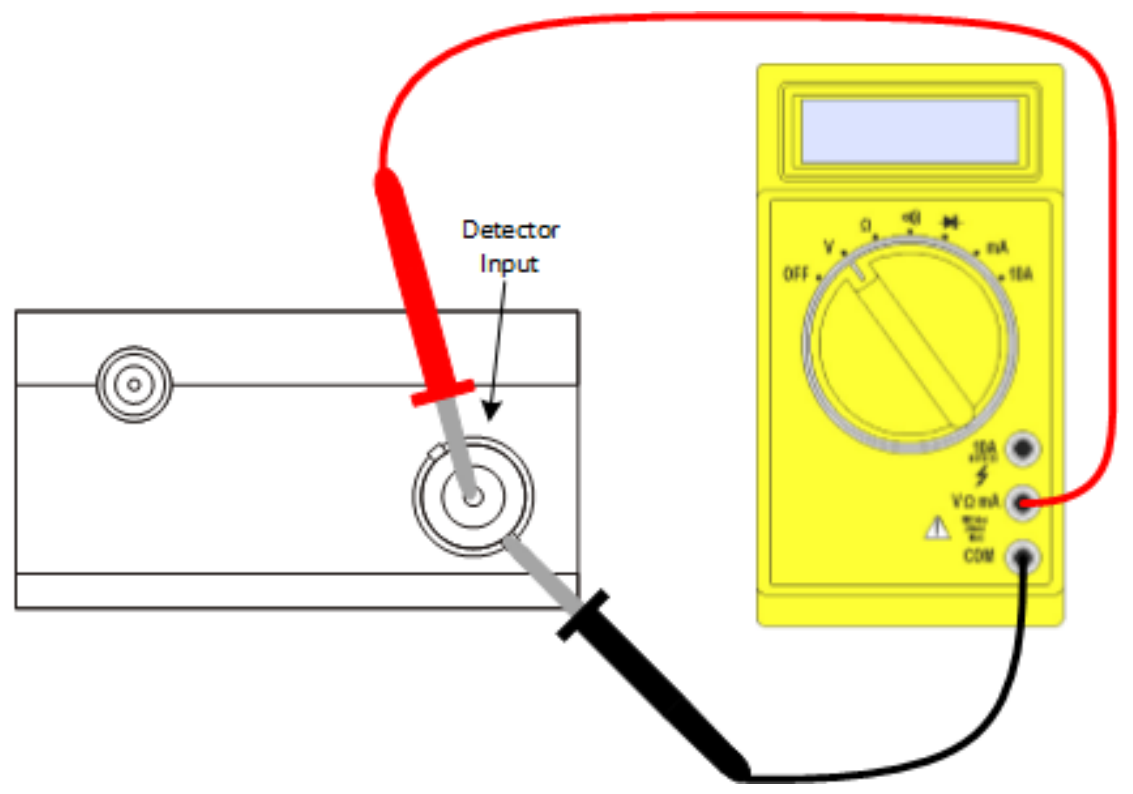

Figure C.13. Measuring DC Port Input/Output Resistance 


\section{C.9.5.2 Data Table:}

Table C.30. Grounding Schema: Record actual resistance measured, short or open

\begin{tabular}{c|c|c|c|c|c|c|c|} 
& $\begin{array}{c}\text { Test } \\
\text { In }\end{array}$ & $\begin{array}{c}\text { Power } \\
\text { In }\end{array}$ & $\begin{array}{c}\text { Analog1 } \\
\text { Out }\end{array}$ & $\begin{array}{c}\text { Analog2 } \\
\text { Out }\end{array}$ & $\begin{array}{c}\text { Digital } \\
\text { In }\end{array}$ & $\begin{array}{c}\text { Digital } \\
\text { Out }\end{array}$ & Chassis \\
\hline Detector In & & & & & & & \\
\hline Test In & & & & & & & \\
\hline Power In & & & & & & \\
\hline Analog1 Out & & & & & \\
\hline Analog2 Out & & & & & \\
\hline Digital In & & & & & \\
\hline Digital Out & & & & & \\
\hline
\end{tabular}




\section{C.10 TEST 19- Baseline FEUM Performance}

\section{C.10.1 Purpose:}

This test will examine how well the DUT performs in a standard environment, relative to the detector efficiency versus cable length and intrinsic noise. The setup in

Figure C.14 and various configurations in Table C.31 will be used.

\section{C.10.2 Required Equipment:}

AWG

Precision Capacitor

12V DC Power Supply

He3 detector

Fission Chamber

NaI (TI) Detector

Multi-channel Analyzer

Digital Pulse Counter

Jewelers' screwdriver (for toggling configuration dipswitches, if applicable)

Tweezers (for changing jumper settings, if applicable)

\section{C.10.3 References:}

DUT documentation provided by vendor

\section{C.10.4 Preparation:}

Gather the test equipment and setup the equipment as shown in Figure C.14. 


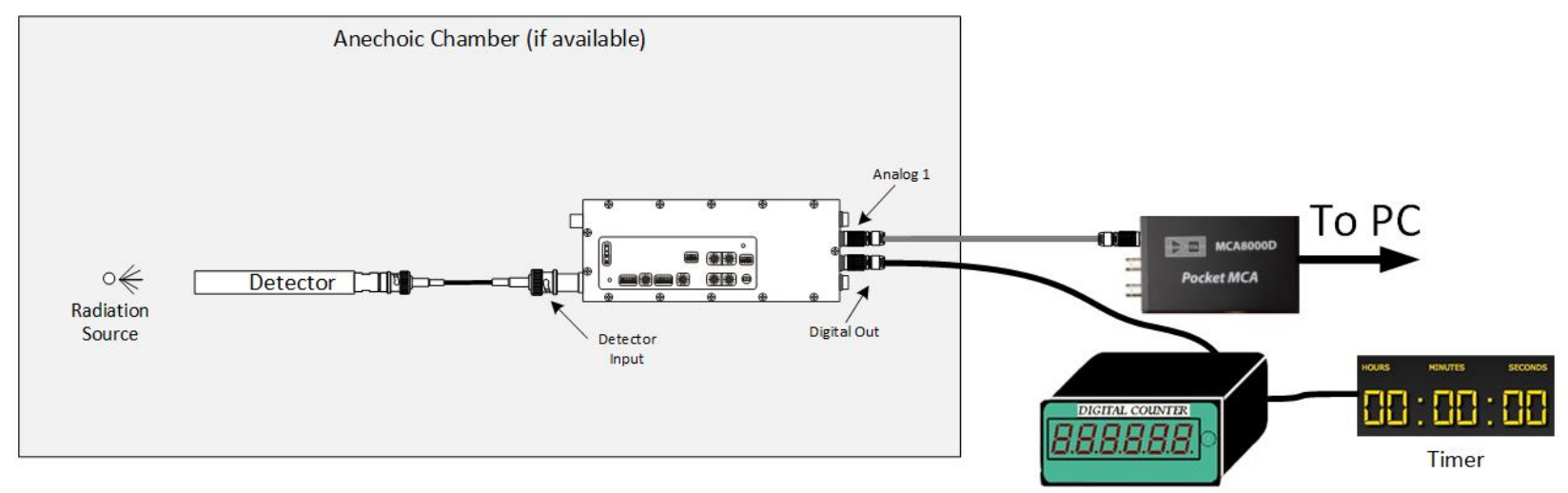

Figure C.14. Baseline Performance Testing Setup

Prepare equipment and setup for variations in test setup per Table C.31.

Table C.31. Configurations for Baseline Performance Testing

\begin{tabular}{|c|c|c|c|c|}
\hline \# & Detector Type & Cable/Length & $\begin{array}{c}\text { Pulse } \\
\text { Shaping } \\
\text { Time }\end{array}$ & Output Port \\
\hline 1 & Pulse Generator & RG-71/12cm & $0.1 \mu \mathrm{s}$ & Isolated \\
\hline 2 & Pulse Generator & RG-71/12cm & $0.1 \mu \mathrm{s}$ & Ground-Coupled \\
\hline 3 & Pulse Generator & RG-71/12cm & $0.4 \mu \mathrm{s}$ & Isolated \\
\hline 4 & Pulse Generator & RG-71/12cm & $2.4 \mu \mathrm{s}$ & Isolated \\
\hline 5 & Pulse Generator & RG-71/1m & $0.1 \mu \mathrm{s}$ & Isolated \\
\hline 6 & Pulse Generator & RG-71/1m & $0.4 \mu \mathrm{s}$ & Isolated \\
\hline 7 & Pulse Generator & RG-71/1m & $2.4 \mu \mathrm{s}$ & Isolated \\
\hline 8 & Pulse Generator & RG-71/10m & $0.1 \mu \mathrm{s}$ & Isolated \\
\hline 9 & Pulse Generator & RG-71/10m & $0.4 \mu \mathrm{s}$ & Isolated \\
\hline 10 & Pulse Generator & RG-71/10m & $2.4 \mu \mathrm{s}$ & Isolated \\
\hline 11 & Pulse Generator & RG-71/50m & $0.1 \mu \mathrm{s}$ & Isolated \\
\hline 12 & Pulse Generator & RG-71/50m & $0.4 \mu \mathrm{s}$ & Isolated \\
\hline 13 & Pulse Generator & RG-71/50m & $2.4 \mu \mathrm{s}$ & Isolated \\
\hline 14 & Pulse Generator & RG-71/100m & $0.1 \mu \mathrm{s}$ & Isolated \\
\hline 15 & Pulse Generator & RG-71/100m & $0.4 \mu \mathrm{s}$ & Isolated \\
\hline 16 & Pulse Generator & RG-71/100m & $2.4 \mu \mathrm{s}$ & Isolated \\
\hline 17 & Pulse Generator & RG-174/100m & $0.1 \mu \mathrm{s}$ & Isolated \\
\hline 18 & Pulse Generator & $\mathrm{RG}-174 / 100 \mathrm{~m}$ & $0.4 \mu \mathrm{s}$ & Isolated \\
\hline 19 & Pulse Generator & RG-174/100m & $2.4 \mu \mathrm{s}$ & Isolated \\
\hline
\end{tabular}




\begin{tabular}{|c|c|c|c|c|}
\hline$\#$ & Detector Type & Cable/Length & $\begin{array}{c}\text { Pulse } \\
\text { Shaping } \\
\text { Time }\end{array}$ & Output Port \\
\hline 20 & He3 & RG-71/12cm & $0.1 \mu \mathrm{s}$ & Isolated \\
\hline 21 & He3 & RG-71/12cm & $0.1 \mu \mathrm{s}$ & Ground-Coupled \\
\hline 22 & He3 & RG-71/12cm & $0.4 \mu \mathrm{s}$ & Isolated \\
\hline 23 & He3 & RG-71/12cm & $2.4 \mu \mathrm{s}$ & Isolated \\
\hline 24 & He3 & RG-71/1m & $0.1 \mu \mathrm{s}$ & Isolated \\
\hline 25 & He3 & RG-71/1m & $0.4 \mu \mathrm{s}$ & Isolated \\
\hline 26 & He3 & RG-71/1m & $2.4 \mu \mathrm{s}$ & Isolated \\
\hline 27 & He3 & RG-71/10m & $0.1 \mu \mathrm{s}$ & Isolated \\
\hline 28 & He3 & RG-71/10m & $0.4 \mu \mathrm{s}$ & Isolated \\
\hline 29 & He3 & RG-71/10m & $2.4 \mu \mathrm{s}$ & Isolated \\
\hline 30 & He3 & RG-71/50m & $0.1 \mu \mathrm{s}$ & Isolated \\
\hline 31 & He3 & RG-71/50m & $0.4 \mu \mathrm{s}$ & Isolated \\
\hline 32 & He3 & RG-71/50m & $2.4 \mu \mathrm{s}$ & Isolated \\
\hline 33 & He3 & RG-71/100m & $0.1 \mu \mathrm{s}$ & Isolated \\
\hline 34 & He3 & RG-71/100m & $0.4 \mu \mathrm{s}$ & Isolated \\
\hline 35 & He3 & RG-71/100m & $2.4 \mu \mathrm{s}$ & Isolated \\
\hline 36 & He3 & RG-174/100m & $0.1 \mu \mathrm{s}$ & Isolated \\
\hline 37 & He3 & RG-174/100m & $0.4 \mu \mathrm{s}$ & Isolated \\
\hline 38 & He3 & RG-174/100m & $2.4 \mu \mathrm{s}$ & Isolated \\
\hline 39 & Fission Chamber & RG-71/12cm & $0.1 \mu \mathrm{s}$ & Isolated \\
\hline 40 & Fission Chamber & RG-71/12cm & $0.1 \mu \mathrm{s}$ & Ground-Coupled \\
\hline 41 & Fission Chamber & RG-71/12cm & $0.4 \mu \mathrm{s}$ & Isolated \\
\hline 42 & Fission Chamber & RG-71/12cm & $2.4 \mu \mathrm{s}$ & Isolated \\
\hline 43 & Fission Chamber & RG-71/1m & $0.1 \mu \mathrm{s}$ & Isolated \\
\hline 44 & Fission Chamber & RG-71/1m & $0.4 \mu \mathrm{s}$ & Isolated \\
\hline 45 & Fission Chamber & RG-71/1m & $2.4 \mu \mathrm{s}$ & Isolated \\
\hline 46 & Fission Chamber & RG-71/10m & $0.1 \mu \mathrm{s}$ & Isolated \\
\hline 47 & Fission Chamber & RG-71/10m & $0.4 \mu \mathrm{s}$ & Isolated \\
\hline 48 & Fission Chamber & RG-71/10m & $2.4 \mu \mathrm{s}$ & Isolated \\
\hline 49 & Fission Chamber & RG-71/50m & $0.1 \mu \mathrm{s}$ & Isolated \\
\hline 50 & Fission Chamber & RG-71/50m & $0.4 \mu \mathrm{s}$ & Isolated \\
\hline 51 & Fission Chamber & RG-71/50m & $2.4 \mu \mathrm{s}$ & Isolated \\
\hline
\end{tabular}




\begin{tabular}{|c|c|c|c|c|}
\hline$\#$ & Detector Type & Cable/Length & $\begin{array}{c}\text { Pulse } \\
\text { Shaping } \\
\text { Time }\end{array}$ & Output Port \\
\hline 52 & Fission Chamber & RG-71/100m & $0.1 \mu \mathrm{s}$ & Isolated \\
\hline 53 & Fission Chamber & RG-71/100m & $0.4 \mu \mathrm{s}$ & Isolated \\
\hline 54 & Fission Chamber & RG-71/100m & $2.4 \mu \mathrm{s}$ & Isolated \\
\hline 55 & Fission Chamber & RG-174/100m & $0.1 \mu \mathrm{s}$ & Isolated \\
\hline 56 & Fission Chamber & RG-174/100m & $0.4 \mu \mathrm{s}$ & Isolated \\
\hline 57 & Fission Chamber & RG-174/100m & $2.4 \mu \mathrm{s}$ & Isolated \\
\hline 58 & $\mathrm{NaI}$ & RG-71/12cm & $0.1 \mu \mathrm{s}$ & Isolated \\
\hline 59 & $\mathrm{NaI}$ & RG-71/12cm & $0.1 \mu \mathrm{s}$ & Ground-Coupled \\
\hline 60 & $\mathrm{NaI}$ & RG-71/12cm & $0.4 \mu \mathrm{s}$ & Isolated \\
\hline 61 & $\mathrm{NaI}$ & RG-71/12cm & $2.4 \mu \mathrm{s}$ & Isolated \\
\hline 62 & $\mathrm{NaI}$ & RG-71/1m & $0.1 \mu \mathrm{s}$ & Isolated \\
\hline 63 & $\mathrm{NaI}$ & RG-71/1m & $0.4 \mu \mathrm{s}$ & Isolated \\
\hline 64 & $\mathrm{NaI}$ & RG-71/1m & $2.4 \mu \mathrm{s}$ & Isolated \\
\hline 65 & $\mathrm{NaI}$ & RG-71/10m & $0.1 \mu \mathrm{s}$ & Isolated \\
\hline 66 & $\mathrm{NaI}$ & RG-71/10m & $0.4 \mu \mathrm{s}$ & Isolated \\
\hline 67 & $\mathrm{NaI}$ & RG-71/10m & $2.4 \mu \mathrm{s}$ & Isolated \\
\hline 68 & $\mathrm{NaI}$ & RG-71/50m & $0.1 \mu \mathrm{s}$ & Isolated \\
\hline 69 & $\mathrm{NaI}$ & RG-71/50m & $0.4 \mu \mathrm{s}$ & Isolated \\
\hline 70 & $\mathrm{NaI}$ & RG-71/50m & $2.4 \mu \mathrm{s}$ & Isolated \\
\hline 71 & $\mathrm{NaI}$ & RG-71/100m & $0.1 \mu \mathrm{s}$ & Isolated \\
\hline 72 & $\mathrm{NaI}$ & RG-71/100m & $0.4 \mu \mathrm{s}$ & Isolated \\
\hline 73 & $\mathrm{NaI}$ & RG-71/100m & $2.4 \mu \mathrm{s}$ & Isolated \\
\hline 74 & $\mathrm{NaI}$ & RG-174/100m & $0.1 \mu \mathrm{s}$ & Isolated \\
\hline 75 & $\mathrm{NaI}$ & RG-174/100m & $0.4 \mu \mathrm{s}$ & Isolated \\
\hline 76 & $\mathrm{NaI}$ & RG-174/100m & $2.4 \mu \mathrm{s}$ & Isolated \\
\hline
\end{tabular}

\section{C.10.5 Procedure:}

1. Connect the equipment for configuration \#1.

2. Place an appropriate source (e.g., Cf-252 for neutron sensors and Cs-137 for gamma sensors) at a fixed distance from the detector. Record the source type, strength and geometry relative to the detector in Table C.32.

3. Configure the DUT as appropriate for the detector type and parameters to be varied. Record the settings selected in Table C.32. 
a. If applicable to the detector, adjust the HV Setting to be appropriate for typical operation (e.g., for He-3, above the knee of the counting plateau). Record the HV setting used.

b. Adjust the DUT gain settings to be appropriate for the detector pulse height spectrum, DUT amplifier output voltage range, and the MCA voltage range. Record the setting used.

c. Using the longest pulse shaping time, and a short cable $(\sim 10 \mathrm{~cm})$ measure the peak efficiency in this configuration. Record the value in Table C.32. Save the pulse height spectrum. This value will be used as a reference for $100 \%$ relative efficiency for the remaining measurements taken.

4. Power on the DUT, using the standard isolated power port, and test equipment.

5. For just a few of the configurations, adjust the discriminator threshold in uniform increments over the full range of the DUT amplifier output and record the corresponding digital output count rate, each discriminator value, and the MCA-calculated count rate in Table C.33. For the other configurations, leave the discriminator at a sufficiently low level such that unwanted noise is not introduced, but the full spectral data can be captured on an MCA.

6. Save the MCA pulse height spectrum for subsequent integral pulse height spectrum analysis (post processing).

7. Repeat steps 3-6 for the rest of the configurations in Table C.31. Make copies of Table C.33 as necessary.

8. Repeat all steps for the current-sensitive mode of operation.

\section{C.10.6 Test Data}

DUT Serial Number:

DUT Part Number:

Tested By:

Test Date: 


\section{C.10.6.1 Data Table:}

Table C.32. DUT and Test Configuration

\begin{tabular}{|l|l|l|l|c|}
\hline \multicolumn{1}{|c|}{ Parameter } & AWG Settings & He-3 Settings & $\begin{array}{c}\text { Fission } \\
\text { Chamber } \\
\text { Settings }\end{array}$ & $\begin{array}{c}\text { NaI (TI) } \\
\text { Settings }\end{array}$ \\
\hline AWG Setting & & NA & NA & NA \\
\hline Input Signal Mode (Q or I) & & & & \\
\hline Input Termination & & & & \\
\hline Charge Gain (range) & & & & \\
\hline G1 - Gain & & & & \\
\hline G2 - Gain & & & & \\
\hline HVH - High Voltage & & & & \\
\hline HVL - High Voltage & & & & \\
\hline DH - Discriminator High & & & & \\
\hline DL - Discriminator Low & & & & \\
\hline Digital Ouput Pulse Width & & & & \\
\hline Source Type & & & & \\
\hline Source Strength & & & & \\
\hline Source Geometry & & & & \\
\hline Peak Efficieny & & & & \\
\hline
\end{tabular}


Table C.33. Baseline FEUM Performance Data

\begin{tabular}{|c|c|c|c|c|c|c|c|}
\hline $\begin{array}{c}\text { Config } \\
\#\end{array}$ & $\begin{array}{c}\text { Discriminator } \\
\text { Threshold }\end{array}$ & $\begin{array}{c}\text { Digital } \\
\text { Counter } \\
\text { Count } \\
\text { Rate } \\
\end{array}$ & $\begin{array}{c}\text { MCA- } \\
\text { Calculated } \\
\text { Count } \\
\text { Rate }\end{array}$ & $\begin{array}{c}\text { Config } \\
\# \\
\end{array}$ & $\begin{array}{c}\text { Discriminator } \\
\text { Threshold }\end{array}$ & $\begin{array}{c}\text { Count } \\
\text { Rate }\end{array}$ & $\begin{array}{c}\text { MCA- } \\
\text { Calculated } \\
\text { Count } \\
\text { Rate } \\
\end{array}$ \\
\hline & & & & & & & \\
\hline & & & & & & & \\
\hline & & & & & & & \\
\hline & & & & & & & \\
\hline & & & & & & & \\
\hline & & & & & & & \\
\hline & & & & & & & \\
\hline & & & & & & & \\
\hline & & & & & & & \\
\hline & & & & & & & \\
\hline & & & & & & & \\
\hline & & & & & & & \\
\hline & & & & & & & \\
\hline & & & & & & & \\
\hline & & & & & & & \\
\hline & & & & & & & \\
\hline & & & & & & & \\
\hline & & & & & & & \\
\hline & & & & & & & \\
\hline & & & & & & & \\
\hline & & & & & & & \\
\hline & & & & & & & \\
\hline & & & & & & & \\
\hline & & & & & & & \\
\hline & & & & & & & \\
\hline & & & & & & & \\
\hline & & & & & & & \\
\hline & & & & & & & \\
\hline & & & & & & & \\
\hline
\end{tabular}




\section{C.11 TEST 20- Radiated EMI/RFI Susceptibility}

\section{C.11.1 Purpose:}

This test examines how well the FEUM performs under stress from radiated EMI/RFI. RS103 from MILSTD-461E is referenced and used as a base document for the RF field setup and measurement. The base range of MIL-STD-461E, RS103 are used (30 MHz - 2.45 GHz), but larger frequency steps are utilized to minimize the amount of data collected. The number of frequencies used and variations in Table C.38 may be reduced to accommodate schedule.

\section{C.11.2 Required Equipment:}

Pulse Generator

He3 detector

Fission Chamber

NaI Detector

Anechoic Chamber

Antenna

RF Generator

Digital Pulse Counter

Jewelers’ screwdriver (for toggling configuration dipswitches, if applicable)

Tweezers (for changing jumper settings, if applicable)

\section{C.11.3 References:}

DUT documentation provided by vendor MIL-STD-461E, RS103

\section{C.11.4 Preparation:}

Gather the test equipment and arrange the equipment as shown in Figure C.15. 


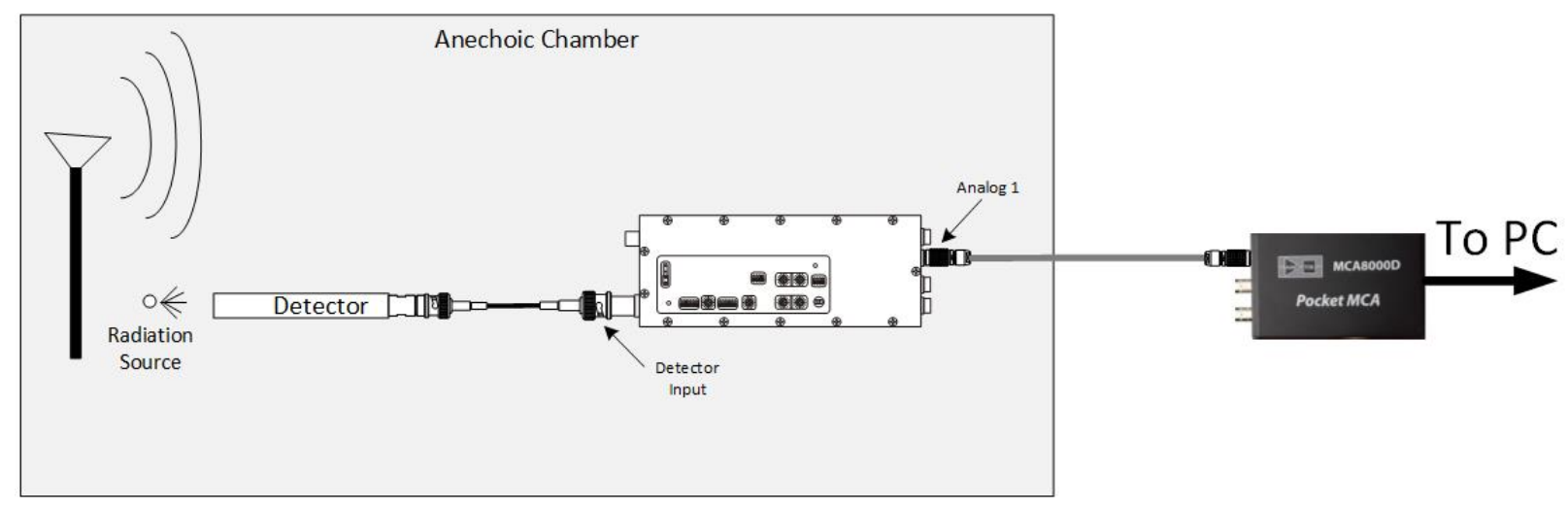

Figure C.15. Radiated EMI/RFI Performance Testing Setup

Prepare equipment and arrange for variations in test setup per Table C.34.

Table C.34. Configurations for EMI/RFI Performance Testing

\begin{tabular}{|c|c|c|c|c|}
\hline \# & Detector Type & Cable/Length & $\begin{array}{c}\text { Pulse } \\
\text { Shaping } \\
\text { Time }\end{array}$ & Output Port \\
\hline 1 & Pulse Generator & RG-71/1m & $0.1 \mu \mathrm{s}$ & Isolated \\
\hline 2 & Pulse Generator & RG-71/1m & $0.4 \mu \mathrm{s}$ & Isolated \\
\hline 3 & Pulse Generator & RG-71/1m & $2.4 \mu \mathrm{s}$ & Isolated \\
\hline 4 & Pulse Generator & RG-71/10m & $0.1 \mu \mathrm{s}$ & Isolated \\
\hline 5 & Pulse Generator & RG-71/10m & $0.4 \mu \mathrm{s}$ & Isolated \\
\hline 6 & Pulse Generator & RG-71/10m & $2.4 \mu \mathrm{s}$ & Isolated \\
\hline 7 & Pulse Generator & RG-71/50m & $0.1 \mu \mathrm{s}$ & Isolated \\
\hline 8 & Pulse Generator & RG-71/50m & $0.4 \mu \mathrm{s}$ & Isolated \\
\hline 9 & Pulse Generator & RG-71/50m & $2.4 \mu \mathrm{s}$ & Isolated \\
\hline 10 & Pulse Generator & RG-71/100m & $0.1 \mu \mathrm{s}$ & Isolated \\
\hline 11 & Pulse Generator & RG-71/100m & $0.4 \mu \mathrm{s}$ & Isolated \\
\hline 12 & Pulse Generator & RG-71/100m & $2.4 \mu \mathrm{s}$ & Isolated \\
\hline 13 & Pulse Generator & RG-174/100m & $0.1 \mu \mathrm{s}$ & Isolated \\
\hline 14 & Pulse Generator & RG-174/100m & $0.4 \mu \mathrm{s}$ & Isolated \\
\hline 15 & Pulse Generator & RG-174/100m & $2.4 \mu \mathrm{s}$ & Isolated \\
\hline 16 & He3 & RG-71/1m & $0.1 \mu \mathrm{s}$ & Isolated \\
\hline 17 & He3 & RG-71/1m & $0.4 \mu \mathrm{s}$ & Isolated \\
\hline 18 & He3 & RG-71/1m & $2.4 \mu \mathrm{s}$ & Isolated \\
\hline
\end{tabular}




\begin{tabular}{|c|c|c|c|c|}
\hline$\#$ & Detector Type & Cable/Length & $\begin{array}{c}\text { Pulse } \\
\text { Shaping } \\
\text { Time }\end{array}$ & Output Port \\
\hline 19 & He3 & RG-71/10m & $0.1 \mu \mathrm{s}$ & Isolated \\
\hline 20 & He3 & RG-71/10m & $0.4 \mu \mathrm{s}$ & Isolated \\
\hline 21 & He3 & RG-71/10m & $2.4 \mu \mathrm{s}$ & Isolated \\
\hline 22 & He3 & RG-71/50m & $0.1 \mu \mathrm{s}$ & Isolated \\
\hline 23 & He3 & RG-71/50m & $0.4 \mu \mathrm{s}$ & Isolated \\
\hline 24 & He3 & RG-71/50m & $2.4 \mu \mathrm{s}$ & Isolated \\
\hline 25 & He3 & RG-71/100m & $0.1 \mu \mathrm{s}$ & Isolated \\
\hline 26 & He3 & RG-71/100m & $0.4 \mu \mathrm{s}$ & Isolated \\
\hline 27 & He3 & RG-71/100m & $2.4 \mu \mathrm{s}$ & Isolated \\
\hline 28 & He3 & RG-174/100m & $0.1 \mu \mathrm{s}$ & Isolated \\
\hline 29 & He3 & RG-174/100m & $0.4 \mu \mathrm{s}$ & Isolated \\
\hline 30 & He3 & RG-174/100m & $2.4 \mu \mathrm{s}$ & Isolated \\
\hline 31 & Fission Chamber & RG-71/1m & $0.1 \mu \mathrm{s}$ & Isolated \\
\hline 32 & Fission Chamber & RG-71/1m & $0.4 \mu \mathrm{s}$ & Isolated \\
\hline 33 & Fission Chamber & RG-71/1m & $2.4 \mu \mathrm{s}$ & Isolated \\
\hline 34 & Fission Chamber & RG-71/10m & $0.1 \mu \mathrm{s}$ & Isolated \\
\hline 35 & Fission Chamber & RG-71/10m & $0.4 \mu \mathrm{s}$ & Isolated \\
\hline 36 & Fission Chamber & RG-71/10m & $2.4 \mu \mathrm{s}$ & Isolated \\
\hline 37 & Fission Chamber & RG-71/50m & $0.1 \mu \mathrm{s}$ & Isolated \\
\hline 38 & Fission Chamber & RG-71/50m & $0.4 \mu \mathrm{s}$ & Isolated \\
\hline 39 & Fission Chamber & RG-71/50m & $2.4 \mu \mathrm{s}$ & Isolated \\
\hline 40 & Fission Chamber & RG-71/100m & $0.1 \mu \mathrm{s}$ & Isolated \\
\hline 41 & Fission Chamber & RG-71/100m & $0.4 \mu \mathrm{s}$ & Isolated \\
\hline 42 & Fission Chamber & RG-71/100m & $2.4 \mu \mathrm{s}$ & Isolated \\
\hline 43 & Fission Chamber & RG-174/100m & $0.1 \mu \mathrm{s}$ & Isolated \\
\hline 44 & Fission Chamber & RG-174/100m & $0.4 \mu \mathrm{s}$ & Isolated \\
\hline 45 & Fission Chamber & RG-174/100m & $2.4 \mu \mathrm{s}$ & Isolated \\
\hline 46 & $\mathrm{NaI}$ & RG-71/1m & $0.1 \mu \mathrm{s}$ & Isolated \\
\hline 47 & $\mathrm{NaI}$ & RG-71/1m & $0.4 \mu \mathrm{s}$ & Isolated \\
\hline 48 & $\mathrm{NaI}$ & RG-71/1m & $2.4 \mu \mathrm{s}$ & Isolated \\
\hline 49 & $\mathrm{NaI}$ & RG-71/10m & $0.1 \mu \mathrm{s}$ & Isolated \\
\hline 50 & $\mathrm{NaI}$ & RG-71/10m & $0.4 \mu \mathrm{s}$ & Isolated \\
\hline 51 & $\mathrm{NaI}$ & RG-71/10m & $2.4 \mu \mathrm{s}$ & Isolated \\
\hline
\end{tabular}




\begin{tabular}{|l|l|l|l|l|}
\hline$\#$ & Detector Type & Cable/Length & $\begin{array}{c}\text { Pulse } \\
\text { Shaping } \\
\text { Time }\end{array}$ & \multicolumn{1}{|c|}{ Output Port } \\
\hline 52 & NaI & RG-71/50m & $0.1 \mu \mathrm{s}$ & Isolated \\
\hline 53 & NaI & RG-71/50m & $0.4 \mu \mathrm{s}$ & Isolated \\
\hline 54 & NaI & RG-71/50m & $2.4 \mu \mathrm{s}$ & Isolated \\
\hline 55 & NaI & RG-71/100m & $0.1 \mu \mathrm{s}$ & Isolated \\
\hline 56 & NaI & RG-71/100m & $0.4 \mu \mathrm{s}$ & Isolated \\
\hline 57 & NaI & RG-71/100m & $2.4 \mu \mathrm{s}$ & Isolated \\
\hline 58 & NaI & RG-174/100m & $0.1 \mu \mathrm{s}$ & Isolated \\
\hline 59 & NaI & RG-174/100m & $0.4 \mu \mathrm{s}$ & Isolated \\
\hline 60 & NaI & RG-174/100m & $2.4 \mu \mathrm{s}$ & Isolated \\
\hline
\end{tabular}

\section{C.11.5 Procedure:}

1. Setup the anechoic chamber and antenna in accordance with MIL-STD-461E, RS103.

2. Set the RF field to $50 \mathrm{~V} / \mathrm{m}$. Do not turn on yet.

3. Connect the equipment for configuration \#1, frequency \#1.

4. Place an appropriate source (e.g., Cf-252 for neutron sensors and Cs-137 for gamma sensors) at a fixed distance from the detector. Record the source type, strength and geometry relative to the detector in Table C.35.

5. Configure the DUT as appropriate for the detector type and parameters to be varied. Record the settings selected in Table C.32.

a. If applicable to the detector, adjust the HV Setting to be appropriate for typical operation (e.g., for He-3, above the knee of the counting plateau). Record the HV setting used.

b. Adjust the DUT gain settings to be appropriate for the detector pulse height spectrum, amplifier output voltage range, and the MCA voltage range. Record the setting used.

6. Turn on the RF antenna and verify $50 \mathrm{~V} / \mathrm{m}$ at the face of DUT.

7. Sweep through the frequencies from $700 \mathrm{MHz}-2.00 \mathrm{GHz}$ by decade.

8. Repeat steps 4 - for the rest of the configurations in Table C.34 
9. Table C.36 as necessary.

10. Repeat all steps for the current-sensitive mode of operation.

\section{C.11.6 Test data}

DUT Serial Number:

DUT Part Number:

Tested By:

Test Date:

\section{C.11.6.1 Data Table:}

Table C.35. DUT and Test Configuration

\begin{tabular}{|l|l|l|l|c|}
\hline \multicolumn{1}{|c|}{ Parameter } & AWG Settings & He-3 Settings & $\begin{array}{c}\text { Fission } \\
\text { Chamber } \\
\text { Settings }\end{array}$ & $\begin{array}{c}\text { NaI (TI) } \\
\text { Settings }\end{array}$ \\
\hline AWG Setting & & NA & NA & NA \\
\hline Input Signal Mode (Q or I) & & & & \\
\hline Input Termination & & & & \\
\hline Charge Gain (range) & & & & \\
\hline G1 - Gain & & & & \\
\hline G2 - Gain & & & & \\
\hline HVH - High Voltage & & & & \\
\hline HVL - High Voltage & & & & \\
\hline DH - Discriminator High & & & & \\
\hline DL - Discriminator Low & & & & \\
\hline Digital Ouput Pulse Width & & & & \\
\hline Source Type & & & & \\
\hline Source Strength & & & & \\
\hline Source Geometry & & & & \\
\hline Peak Efficieny & & & & \\
\hline
\end{tabular}


Table C.36. Performance Data for Radiated EMI/RFI

\begin{tabular}{|c|c|c|c|c|}
\hline Config \# & Frequency & $\begin{array}{c}\text { Discriminator } \\
\text { Threshold }\end{array}$ & $\begin{array}{c}\text { Digital } \\
\text { Counter } \\
\text { Count Rate }\end{array}$ & $\begin{array}{l}\text { MCA-Calculated } \\
\text { Count Rate }\end{array}$ \\
\hline & & & & \\
\hline & & & & \\
\hline & & & & \\
\hline & & & & \\
\hline & & & & \\
\hline & & & & \\
\hline & & & & \\
\hline & & & & \\
\hline & & & & \\
\hline & & & & \\
\hline & & & & \\
\hline & & & & \\
\hline & & & & \\
\hline & & & & \\
\hline & & & & \\
\hline & & & & \\
\hline & & & & \\
\hline & & & & \\
\hline & & & & \\
\hline & & & & \\
\hline & & & & \\
\hline & & & & \\
\hline & & & & \\
\hline & & & & \\
\hline & & & & \\
\hline & & & & \\
\hline & & & & \\
\hline & & & & \\
\hline & & & & \\
\hline & & & & \\
\hline & & & & \\
\hline & & & & \\
\hline
\end{tabular}




\section{C.12 TEST 21- Conducted EMI/RFI Susceptibility}

\section{C.12.1 Purpose:}

This test examines how well the FEUM performs under stress from conducted EMI/RFI. CS114 from MIL-STD-461E is referenced and used as a base document for the conducted RFI setup and measurement. The base range of MIL-STD-461E, CS114 is used (10 kHz - 30 MHz), but larger frequency steps are utilized to minimize the amount of data collected. The number of frequencies used and variations in Table C.41 may be reduced to accommodate schedule.

\section{C.12.2 Required Equipment:}

He3 detector

Fission Chamber

NaI Detector

AWG

Noise injector probe (Induction or Direct)

Digital Pulse Counter

Jewelers’ screwdriver (for toggling configuration dipswitches, if applicable)

Tweezers (for changing jumper settings, if applicable)

\section{C.12.3 References:}

DUT documentation provided by vendor MIL-STD-461E, CS114

\section{C.12.4 Preparation:}

Gather the test equipment and arrange the equipment as shown in Figure C.16.

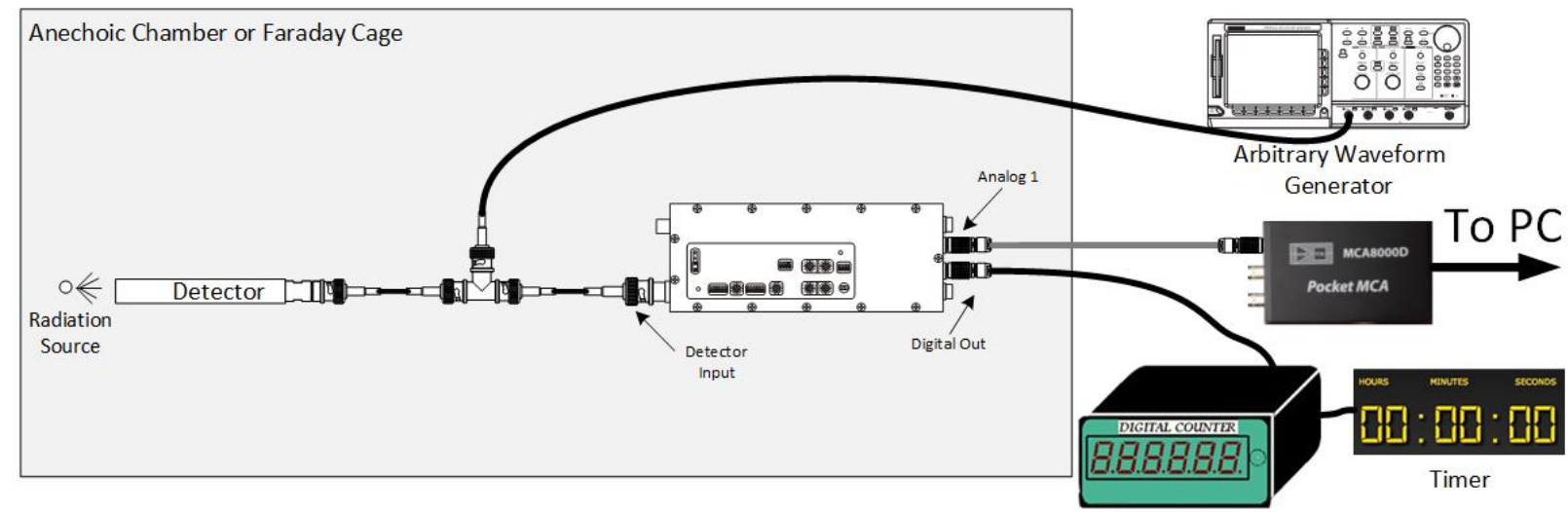

Figure C.16. Conducted EMI/RFI Performance Testing Setup 
Prepare equipment and arrange for variations in test setup per Table C.37.

Table C.37. Configurations for Conducted EMI/RFI Performance Testing

\begin{tabular}{|c|c|c|c|c|}
\hline$\#$ & Detector Type & Cable/Length & $\begin{array}{c}\text { Pulse } \\
\text { Shaping } \\
\text { Time }\end{array}$ & Output Port \\
\hline 1 & Pulse Generator & RG-71/1m & $0.1 \mu \mathrm{s}$ & Isolated \\
\hline 2 & Pulse Generator & RG-71/1m & $0.4 \mu \mathrm{s}$ & Isolated \\
\hline 3 & Pulse Generator & RG-71/1m & $2.4 \mu \mathrm{s}$ & Isolated \\
\hline 4 & Pulse Generator & RG-71/10m & $0.1 \mu \mathrm{s}$ & Isolated \\
\hline 5 & Pulse Generator & RG-71/10m & $0.4 \mu \mathrm{s}$ & Isolated \\
\hline 6 & Pulse Generator & RG-71/10m & $2.4 \mu \mathrm{s}$ & Isolated \\
\hline 7 & Pulse Generator & RG-71/50m & $0.1 \mu \mathrm{s}$ & Isolated \\
\hline 8 & Pulse Generator & RG-71/50m & $0.4 \mu \mathrm{s}$ & Isolated \\
\hline 9 & Pulse Generator & RG-71/50m & $2.4 \mu \mathrm{s}$ & Isolated \\
\hline 10 & Pulse Generator & RG-71/100m & $0.1 \mu \mathrm{s}$ & Isolated \\
\hline 11 & Pulse Generator & RG-71/100m & $0.4 \mu \mathrm{s}$ & Isolated \\
\hline 12 & Pulse Generator & RG-71/100m & $2.4 \mu \mathrm{s}$ & Isolated \\
\hline 13 & Pulse Generator & RG-174/100m & $0.1 \mu \mathrm{s}$ & Isolated \\
\hline 14 & Pulse Generator & RG-174/100m & $0.4 \mu \mathrm{s}$ & Isolated \\
\hline 15 & Pulse Generator & RG-174/100m & $2.4 \mu \mathrm{s}$ & Isolated \\
\hline 16 & He3 & RG-71/1m & $0.1 \mu \mathrm{s}$ & Isolated \\
\hline 17 & He3 & RG-71/1m & $0.4 \mu \mathrm{s}$ & Isolated \\
\hline 18 & He3 & RG-71/1m & $2.4 \mu \mathrm{s}$ & Isolated \\
\hline 19 & He3 & RG-71/10m & $0.1 \mu \mathrm{s}$ & Isolated \\
\hline 20 & He3 & RG-71/10m & $0.4 \mu \mathrm{s}$ & Isolated \\
\hline 21 & He3 & RG-71/10m & $2.4 \mu \mathrm{s}$ & Isolated \\
\hline 22 & He3 & RG-71/50m & $0.1 \mu \mathrm{s}$ & Isolated \\
\hline 23 & He3 & RG-71/50m & $0.4 \mu \mathrm{s}$ & Isolated \\
\hline 24 & He3 & RG-71/50m & $2.4 \mu \mathrm{s}$ & Isolated \\
\hline 25 & He3 & RG-71/100m & $0.1 \mu \mathrm{s}$ & Isolated \\
\hline 26 & He3 & RG-71/100m & $0.4 \mu \mathrm{s}$ & Isolated \\
\hline 27 & He3 & RG-71/100m & $2.4 \mu \mathrm{s}$ & Isolated \\
\hline 28 & He3 & RG-174/100m & $0.1 \mu \mathrm{s}$ & Isolated \\
\hline 29 & He3 & RG-174/100m & $0.4 \mu \mathrm{s}$ & Isolated \\
\hline 30 & He3 & RG-174/100m & $2.4 \mu \mathrm{s}$ & Isolated \\
\hline
\end{tabular}




\begin{tabular}{|c|c|c|c|c|}
\hline$\#$ & Detector Type & Cable/Length & $\begin{array}{c}\text { Pulse } \\
\text { Shaping } \\
\text { Time }\end{array}$ & Output Port \\
\hline 31 & Fission Chamber & RG-71/1m & $0.1 \mu \mathrm{s}$ & Isolated \\
\hline 32 & Fission Chamber & RG-71/1m & $0.4 \mu \mathrm{s}$ & Isolated \\
\hline 33 & Fission Chamber & RG-71/1m & $2.4 \mu \mathrm{s}$ & Isolated \\
\hline 34 & Fission Chamber & RG-71/10m & $0.1 \mu \mathrm{s}$ & Isolated \\
\hline 35 & Fission Chamber & RG-71/10m & $0.4 \mu \mathrm{s}$ & Isolated \\
\hline 36 & Fission Chamber & RG-71/10m & $2.4 \mu \mathrm{s}$ & Isolated \\
\hline 37 & Fission Chamber & RG-71/50m & $0.1 \mu \mathrm{s}$ & Isolated \\
\hline 38 & Fission Chamber & RG-71/50m & $0.4 \mu \mathrm{s}$ & Isolated \\
\hline 39 & Fission Chamber & RG-71/50m & $2.4 \mu \mathrm{s}$ & Isolated \\
\hline 40 & Fission Chamber & RG-71/100m & $0.1 \mu \mathrm{s}$ & Isolated \\
\hline 41 & Fission Chamber & RG-71/100m & $0.4 \mu \mathrm{s}$ & Isolated \\
\hline 42 & Fission Chamber & RG-71/100m & $2.4 \mu \mathrm{s}$ & Isolated \\
\hline 43 & Fission Chamber & RG-174/100m & $0.1 \mu \mathrm{s}$ & Isolated \\
\hline 44 & Fission Chamber & RG-174/100m & $0.4 \mu \mathrm{s}$ & Isolated \\
\hline 45 & Fission Chamber & RG-174/100m & $2.4 \mu \mathrm{s}$ & Isolated \\
\hline 46 & $\mathrm{NaI}$ & RG-71/1m & $0.1 \mu \mathrm{s}$ & Isolated \\
\hline 47 & $\mathrm{NaI}$ & RG-71/1m & $0.4 \mu \mathrm{s}$ & Isolated \\
\hline 48 & $\mathrm{NaI}$ & RG-71/1m & $2.4 \mu \mathrm{s}$ & Isolated \\
\hline 49 & $\mathrm{NaI}$ & RG-71/10m & $0.1 \mu \mathrm{s}$ & Isolated \\
\hline 50 & $\mathrm{NaI}$ & RG-71/10m & $0.4 \mu \mathrm{s}$ & Isolated \\
\hline 51 & $\mathrm{NaI}$ & RG-71/10m & $2.4 \mu \mathrm{s}$ & Isolated \\
\hline 52 & $\mathrm{NaI}$ & RG-71/50m & $0.1 \mu \mathrm{s}$ & Isolated \\
\hline 53 & $\mathrm{NaI}$ & RG-71/50m & $0.4 \mu \mathrm{s}$ & Isolated \\
\hline 54 & $\mathrm{NaI}$ & RG-71/50m & $2.4 \mu \mathrm{s}$ & Isolated \\
\hline 55 & $\mathrm{NaI}$ & RG-71/100m & $0.1 \mu \mathrm{s}$ & Isolated \\
\hline 56 & $\mathrm{NaI}$ & RG-71/100m & $0.4 \mu \mathrm{s}$ & Isolated \\
\hline 57 & $\mathrm{NaI}$ & RG-71/100m & $2.4 \mu \mathrm{s}$ & Isolated \\
\hline 58 & $\mathrm{NaI}$ & RG-174/100m & $0.1 \mu \mathrm{s}$ & Isolated \\
\hline 59 & $\mathrm{NaI}$ & RG-174/100m & $0.4 \mu \mathrm{s}$ & Isolated \\
\hline 60 & $\mathrm{NaI}$ & RG-174/100m & $2.4 \mu \mathrm{s}$ & Isolated \\
\hline
\end{tabular}

\section{C.12.5 Procedure:}

1. Setup the noise injector and auxiliary equipment in accordance with MIL-STD-461E, CS114. 
2. Set the noise stimulus to $130 \mathrm{db} \mu \mathrm{V}$. Do not turn on yet.

3. Connect equipment for configuration \#1.

4. Place an appropriate source (e.g., Cf-252 for neutron sensors and Cs-137 for gamma sensors) at a fixed distance from the detector. Record the source type, strength and geometry relative to the detector in Table C.38.

5. Configure the DUT as appropriate for the detector type and parameters to be varied. Record the settings selected in Table C.38.

a. If applicable to the detector, adjust the HV Setting to be appropriate for typical operation (e.g., for He-3, above the knee of the counting plateau). Record the HV setting used.

b. Adjust the DUT gain settings to be appropriate for the detector pulse height spectrum, amplifier output voltage range, and the MCA voltage range. Record the setting used.

6. Turn on the noise injection system and check noise induced per CS114 of MIL-STD-461E.

7. Sweep through the frequencies from $10 \mathrm{kHz}-30 \mathrm{MHz}$ by decade.

8. Repeat steps 4-7 for the rest of the configurations in Table C.37. Make copies of Table C.39 as necessary.

9. Repeat all steps for the current-sensitive mode of operation.

\section{C.12.6 Test Data}

DUT Serial Number:

DUT Part Number:

Tested By:

Test Date: 


\section{C.12.6.1 Data Table:}

Table C.38. Configuration Settings for Conducted EMI/RFI Testing

\begin{tabular}{|l|l|l|l|c|}
\hline \multicolumn{1}{|c|}{ Parameter } & AWG Settings & He-3 Settings & $\begin{array}{c}\text { Fission } \\
\text { Chamber } \\
\text { Settings }\end{array}$ & $\begin{array}{c}\text { NaI (TI) } \\
\text { Settings }\end{array}$ \\
\hline AWG Setting & & NA & NA & NA \\
\hline Input Signal Mode (Q or I) & & & & \\
\hline Input Termination & & & & \\
\hline Charge Gain (range) & & & & \\
\hline G1 - Gain & & & & \\
\hline G2 - Gain & & & & \\
\hline HVH - High Voltage & & & & \\
\hline HVL - High Voltage & & & & \\
\hline DH - Discriminator High & & & & \\
\hline DL - Discriminator Low & & & & \\
\hline Digital Ouput Pulse Width & & & & \\
\hline Source Type & & & & \\
\hline Source Strength & & & & \\
\hline Source Geometry & & & & \\
\hline Peak Efficieny & & & & \\
\hline
\end{tabular}

Table C.39. Conducted Susceptibility Performance Data

\begin{tabular}{|l|l|l|l|l|}
\hline Config \# & Frequency & $\begin{array}{c}\text { Discriminator } \\
\text { Threshold }\end{array}$ & $\begin{array}{c}\text { Digital } \\
\text { Counter } \\
\text { Count Rate }\end{array}$ & $\begin{array}{c}\text { MCA-Calculated } \\
\text { Count Rate }\end{array}$ \\
\hline & & & & \\
\hline & & & & \\
\hline & & & & \\
\hline & & & & \\
\hline & & & & \\
\hline & & & & \\
\hline & & & & \\
\hline & & & & \\
\hline & & & & \\
\hline
\end{tabular}




\begin{tabular}{|c|c|c|c|c|}
\hline Config \# & Frequency & $\begin{array}{c}\text { Discriminator } \\
\text { Threshold }\end{array}$ & $\begin{array}{c}\text { Digital } \\
\text { Counter } \\
\text { Count Rate }\end{array}$ & $\begin{array}{l}\text { MCA-Calculated } \\
\text { Count Rate }\end{array}$ \\
\hline & & & & \\
\hline & & & & \\
\hline & & & & \\
\hline & & & & \\
\hline & & & & \\
\hline & & & & \\
\hline & & & & \\
\hline & & & & \\
\hline & & & & \\
\hline & & & & \\
\hline & & & & \\
\hline & & & & \\
\hline & & & & \\
\hline & & & & \\
\hline & & & & \\
\hline & & & & \\
\hline & & & & \\
\hline & & & & \\
\hline
\end{tabular}




\section{C.13 TEST 23- Deadtime}

\section{C.13.1 Purpose:}

This test performs basic investigation of the deadtime of the prototype FEUM device under a number of shaping time and output pulse width settings. This procedure details three methods for deadtime calculation: 1) random pulse-generator, 2) two- source, and 3) time interval histogram.

\section{C.13.2 Required Equipment:}

Arbritrary Waveform Generator (AWG)

Random Pulse Generator

Variable Power Supply

BNC, SHV and Lemo Connectors and Cables

2 Digital Pulse Counters

Timer Module

Precision Capacitor (2.2 nF)

Jewelers' screwdriver (for toggling configuration dipswitches, if applicable)

Tweezers (for changing jumper settings, if applicable)

2 Cs-137 sources with a combined activity to exceed $20 \%$ dead time of the DUT

$\mathrm{NaI}$ detector

He3 detector

Digital pulse time acquisition instrument(s)

\section{C.13.3 References:}

DUT documentation provided by vendor

\section{C.13.4 Preparation:}

Gather the test equipment and arrange the equipment as shown in Figure C.17.

Setup AWG to trigger off of pulse from the random pulse generator

Prepare equipment and arrange for variations in test setup per Error! Reference source not found.. 


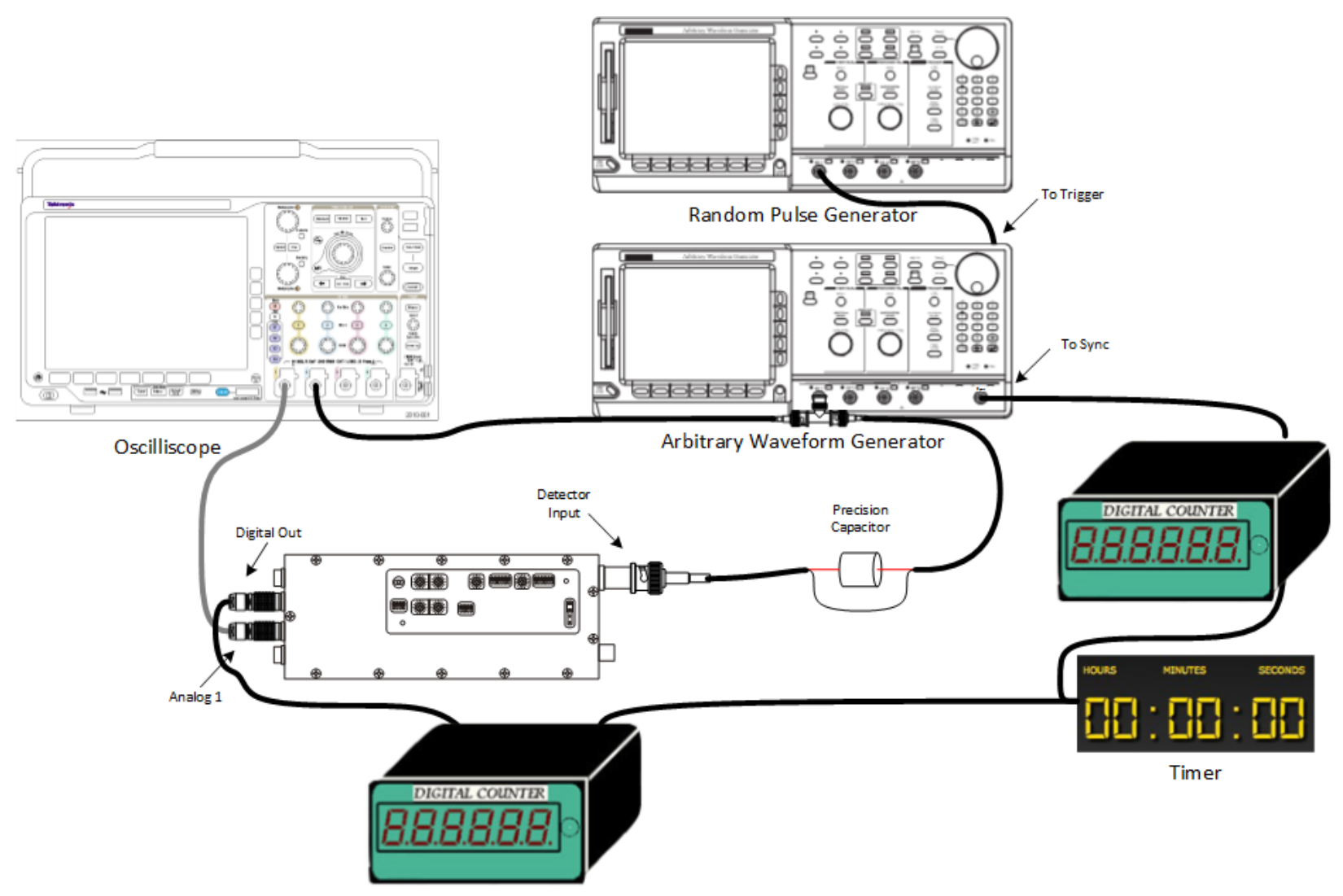

Figure C.17. Performance Testing Setup for Dead Time, using Pulse Generator Method

Table C.40. Configurations for Deadtime Performance Testing with the Pulse Generator Method

\begin{tabular}{|l|l|l|l|}
\hline$\#$ & $\begin{array}{c}\text { Pulse } \\
\text { Shaping } \\
\text { Time (us) }\end{array}$ & $\begin{array}{c}\text { Output } \\
\text { Pulse } \\
\text { Width (us) }\end{array}$ & $\begin{array}{c}\text { RPG } \\
\text { Avg. } \\
\text { Rate } \\
\text { (cps) }\end{array}$ \\
\hline 1 & 0.08 & 0.2 & 1 \\
\hline 2 & 0.08 & 0.2 & $10 \mathrm{~K}$ \\
\hline 3 & 0.08 & 0.2 & $100 \mathrm{~K}$ \\
\hline 4 & 0.08 & 0.2 & $200 \mathrm{~K}$ \\
\hline 5 & 0.08 & 0.2 & $500 \mathrm{~K}$ \\
\hline 6 & 0.08 & 0.2 & $750 \mathrm{~K}$ \\
\hline 7 & 0.08 & 0.2 & $1 \mathrm{M}$ \\
\hline 8 & 1.8 & 0.2 & 1 \\
\hline 9 & 1.8 & 0.2 & $10 \mathrm{~K}$ \\
\hline 10 & 1.8 & 0.2 & $100 \mathrm{~K}$ \\
\hline 11 & 1.8 & 0.2 & $200 \mathrm{~K}$ \\
\hline 12 & 1.8 & 0.2 & $500 \mathrm{~K}$ \\
\hline
\end{tabular}




\begin{tabular}{|l|l|l|l|}
\hline$\#$ & $\begin{array}{c}\text { Pulse } \\
\text { Shaping } \\
\text { Time (us) }\end{array}$ & $\begin{array}{c}\text { Output } \\
\text { Pulse } \\
\text { Width (us) }\end{array}$ & $\begin{array}{c}\text { RPG } \\
\text { Avg. } \\
\text { Rate } \\
\text { (cps) }\end{array}$ \\
\hline 13 & 1.8 & 0.2 & $750 \mathrm{~K}$ \\
\hline 14 & 1.8 & 0.2 & $1 \mathrm{M}$ \\
\hline 15 & 0.08 & 2.0 & 1 \\
\hline 16 & 0.08 & 2.0 & $10 \mathrm{~K}$ \\
\hline 17 & 0.08 & 2.0 & $100 \mathrm{~K}$ \\
\hline 18 & 0.08 & 2.0 & $200 \mathrm{~K}$ \\
\hline 19 & 0.08 & 2.0 & $500 \mathrm{~K}$ \\
\hline 20 & 0.08 & 2.0 & $750 \mathrm{~K}$ \\
\hline 21 & 0.08 & 2.0 & $1 \mathrm{M}$ \\
\hline 22 & 1.8 & 2.0 & 1 \\
\hline 23 & 1.8 & 2.0 & $10 \mathrm{~K}$ \\
\hline 24 & 1.8 & 2.0 & $100 \mathrm{~K}$ \\
\hline 25 & 1.8 & 2.0 & $200 \mathrm{~K}$ \\
\hline 26 & 1.8 & 2.0 & $500 \mathrm{~K}$ \\
\hline 27 & 1.8 & 2.0 & $750 \mathrm{~K}$ \\
\hline 28 & 1.8 & 2.0 & $1 \mathrm{M}$ \\
\hline
\end{tabular}

\section{C.13.5 Procedure for Random Pulse Generator Method:}

1. Connect the equipment for configuration \#1.

2. Configure the DUT and AWG according to Figure C.17

3. Power on the DUT, using the standard isolated power port, and test equipment.

4. Set RPG to the tested rate.

5. Clear both counters.

6. Start timer.

7. Record real events and measured events in Table C.42.

8. Repeat steps for the rest of the configurations in Table C. 40.

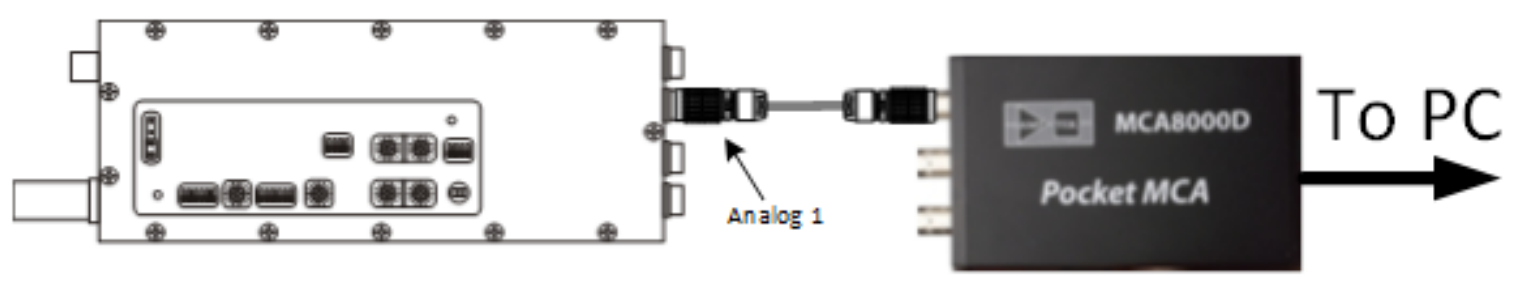

Figure C.18 Test Setup for Two-Source Deadtime Method 


\section{C.13.6 Procedure for Two-Source Method:}

9. Connect the NaI to the detector input port as shown in Figure C.18. Connect the digital output to the digital counter.

10. Connect a 12V DC power supply to the DUT isolated power input.

11. Configure the DUT for nominal operation (charge-sensitive).

12. Record the DUT settings if different than nominal.

13. Place the $1^{\text {st }}$ Cs-137 source into position and acquire counts for $\mathrm{X}$ hours

14. Record the number of counts $\left(m_{1}\right)$ and clear counter

15. Place the $2^{\text {nd }}$ Cs- 137 source into position and acquire counts for $\mathrm{X}$ hours

16. Record the number of counts $\left(m_{12}\right)$ and clear counter

17. Remove the $1^{\text {st }}$ Cs-137 source and acquire counts for $\mathrm{X}$ hours

18. Record the number of counts $\left(m_{2}\right)$ and clear counter

19. Remove the $2^{\text {nd }} \mathrm{Cs}-137$ source and acquire counts for $\mathrm{X}$ hours

20. Record the number of counts $\left(m_{b}\right)$ and clear counter

21. Calculate dead time using the following formula (non-paralyzable model):

22. Record real events and measured events in Table C.42.

23. Repeat steps for the rest of the configurations in Table C.40.

$$
\begin{gathered}
\tau=\frac{X(1-\sqrt{1-Z})}{Y} \\
X \equiv m_{1} m_{2}-m_{b} m_{12} \\
Y \equiv m_{1} m_{2}\left(m_{12}+m_{b}\right)-m_{b} m_{12}\left(m_{1}+m_{2}\right) \\
Z \equiv \frac{Y\left(m_{1}+m_{2}-m_{12}-m_{b}\right)}{X^{2}} \\
m_{1}=\text { Observed rate of source } 1 \\
m_{2}=\text { Observed rate of source } 2 \\
m_{12}=\text { Observed rate of source } 1 \& 2 \\
m_{b}=\text { Observed rate of background }
\end{gathered}
$$

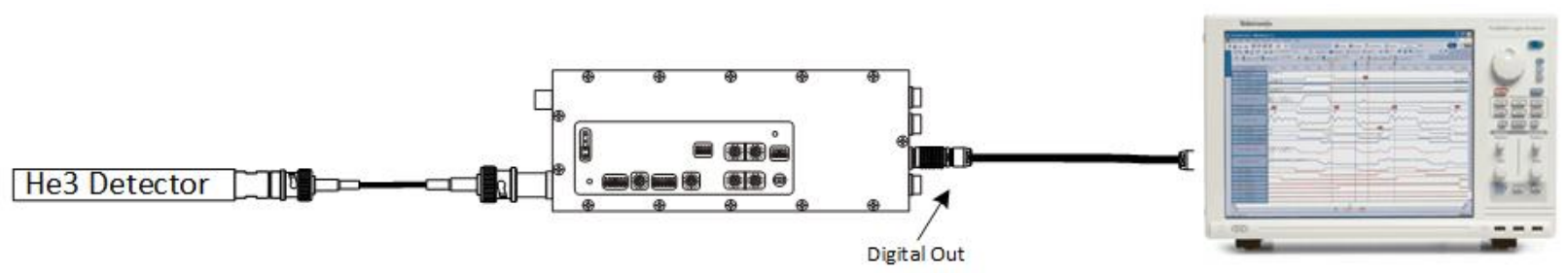

Figure C.19 Test Setup for Time Interval Histogram Deadtime Method

\section{C.13.7 Procedure for Time Interval Histogram Method:}

1. Connect the He3 to the detector input port as shown in Figure C.18. Connect the digital output to the digital pulse acquisition instrument.

2. Connect a $12 \mathrm{~V}$ DC power supply to the DUT isolated power input.

3. Configure the DUT for nominal operation (charge-sensitive). 
4. Record the DUT settings if different than nominal.

5. Acquire sufficient data to create a time interval histogram that has a peak greater than 1000 counts. This may be over 20 million counts.

\section{C.13.8 Test Data}

DUT Serial Number:

DUT Part Number:

Tested By:

Test Date:

\section{C.13.8.1 Data Table:}

Table C.41. FEUM and AWG Configuration

\begin{tabular}{|l|l|l|}
\hline Device & \multicolumn{1}{|c|}{ Parameter } & \multicolumn{1}{c|}{ Setting } \\
\hline DUT & Input Signal Mode (Q or I) & \\
\hline DUT & Input Termination & \\
\hline DUT & Charge Gain (range) & \\
\hline DUT & G1 - Gain & \\
\hline DUT & G2 - Gain & \\
\hline DUT & HVH - High Voltage & \\
\hline DUT & HVL - High Voltage & \\
\hline DUT & SW1 - Shaping Time & \\
\hline DUT & SW2 - Shaping Time & \\
\hline DUT & DH - Discriminator High & \\
\hline DUT & DL - Discriminator Low & \\
\hline DUT & Digital Ouput Pulse Width & \\
\hline AWG & Pulse Type & Tail \\
\hline AWG & Pulse Period & 0.5 us \\
\hline AWG & Pulse Low Voltage & \\
\hline AWG & Pulse High Voltage & \\
\hline AWG & Output Impedance & High-Z \\
\hline
\end{tabular}


Table C.42. Deadtime DUT Performance Data

\begin{tabular}{|l|l|l|}
\hline $\begin{array}{c}\text { Config } \\
\#\end{array}$ & $\begin{array}{c}\text { Real Count } \\
\text { Rate (cps) }\end{array}$ & $\begin{array}{c}\text { Measured } \\
\text { Count Rate } \\
\text { (cps) }\end{array}$ \\
\hline 1 & & \\
\hline 2 & & \\
\hline 3 & & \\
\hline 4 & & \\
\hline 5 & & \\
\hline 6 & & \\
\hline 7 & & \\
\hline 8 & & \\
\hline 9 & & \\
\hline 10 & & \\
\hline 11 & & \\
\hline 12 & & \\
\hline 13 & & \\
\hline 14 & & \\
\hline 15 & & \\
\hline 16 & & \\
\hline 17 & & \\
\hline 18 & & \\
\hline 19 & & \\
\hline 20 & & \\
\hline 21 & & \\
\hline 22 & & \\
\hline 23 & & \\
\hline 24 & & \\
\hline 25 & & \\
\hline 26 & & \\
\hline 27 & & \\
\hline 28 & & \\
\hline
\end{tabular}


Table 8. 2 Source Method Data

\begin{tabular}{|l|l|l|l|l|}
\hline Config \# & No Source & $\begin{array}{c}\mathbf{1}^{\text {st }} \text { Source } \\
\text { Only }\end{array}$ & $\begin{array}{c}2^{\text {nd }} \text { Source } \\
\text { Only }\end{array}$ & Both Sources \\
\hline 1 & & & & \\
\hline
\end{tabular}




\section{C.14 TEST 24- Equivalent Noise Charge}

\section{C.14.1 Purpose:}

This test performs measures the Equivalent Noise Charge (ENC) under a variety of FEUM settings and input capacitance.

\section{C.14.2 Required Equipment:}

Arbritrary Waveform Generator (AWG)

Variable Power Supply

BNC, SHV and Lemo Connectors and Cables

Multi-Channel Analyzer

Precision Capacitor $(\mathrm{X} \mathrm{pF})$

Jewelers’ screwdriver (for toggling configuration dipswitches, if applicable)

Tweezers (for changing jumper settings, if applicable)

\section{C.14.3 References:}

DUT documentation provided by vendor

IEEE Standard Test Procedures for Amplifiers and Preamplifiers for Semiconductor Radiation Detectors for Ionizing Radition (1976)

\section{C.14.4 Preparation:}

Gather the test equipment and arrange the equipment as shown in Figure C.20.

Prepare equipment and arrange for variations in test setup per Table C.43. 


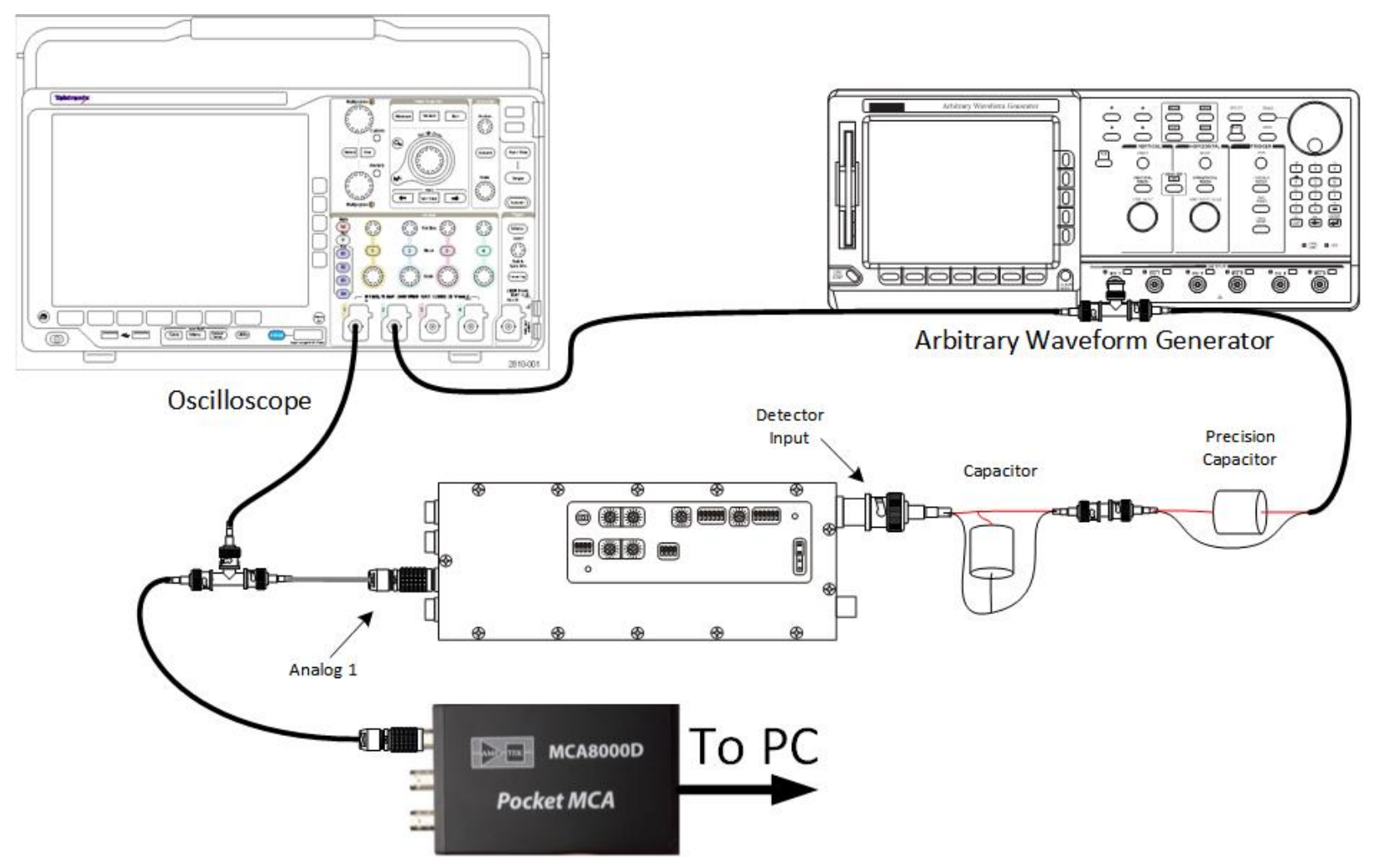

Figure C.20. Performance Testing Setup for ENC

Table C.43. Configurations for ENC Performance Testing

\begin{tabular}{|l|l|l|l|}
\hline$\#$ & $\begin{array}{c}\text { High } \\
\text { Voltage } \\
\text { (VDC) }\end{array}$ & $\begin{array}{c}\text { Input } \\
\text { Capacitance } \\
(\mathbf{p F})\end{array}$ & $\begin{array}{c}\text { Shaping } \\
\text { Time } \\
\text { (us) }\end{array}$ \\
\hline 1 & 400 & Minimum & 0.08 \\
\hline 2 & 400 & Minimum & 0.3 \\
\hline 3 & 400 & Minimum & 0.5 \\
\hline 4 & 400 & Minimum & 0.8 \\
\hline 5 & 400 & Minimum & 1.4 \\
\hline 6 & 400 & Minimum & 1.8 \\
\hline 7 & 2000 & Minimum & 0.08 \\
\hline 8 & 2000 & Minimum & 0.3 \\
\hline 9 & 2000 & Minimum & 0.5 \\
\hline 10 & 2000 & Minimum & 0.8 \\
\hline 11 & 2000 & Minimum & 1.4 \\
\hline 12 & 2000 & Minimum & 1.8 \\
\hline 13 & 400 & 100 & 0.08 \\
\hline 14 & 400 & 560 & 0.08 \\
\hline
\end{tabular}




\begin{tabular}{|l|l|l|l|}
\hline$\#$ & $\begin{array}{c}\text { High } \\
\text { Voltage } \\
\text { (VDC) }\end{array}$ & $\begin{array}{c}\text { Input } \\
\text { Capacitance } \\
(\mathbf{p F})\end{array}$ & $\begin{array}{c}\text { Shaping } \\
\text { Time } \\
(\mathbf{u s )}\end{array}$ \\
\hline 15 & 400 & 5000 & 0.08 \\
\hline 16 & 400 & 10000 & 0.08 \\
\hline 17 & 400 & 100 & 0.5 \\
\hline 18 & 400 & 560 & 0.5 \\
\hline 19 & 400 & 5000 & 0.5 \\
\hline 20 & 400 & 10000 & 0.5 \\
\hline 21 & 400 & 100 & 1.8 \\
\hline 22 & 400 & 560 & 1.8 \\
\hline 23 & 400 & 5000 & 1.8 \\
\hline 24 & 400 & 10000 & 1.8 \\
\hline
\end{tabular}

\section{C.14.5 Procedure:}

1. Connect the equipment for configuration \#1.

2. Configure the DUT, AWG and MCA according to Table C.44.

3. Power on the DUT, using the standard isolated power port, and test equipment.

4. Configure the DUT and input capacitance for configuration \#1.

5. Set the AWG to the high peak value

6. Acquire a spectra on the MCA

7. Determine the peak centroid and FWHM and record to Table C.45.

8. Set the AWG to the low peak value

9. Acquire a spectra on the MCA

10. Determine the peak centroid and FWHM and record to Table C.45.

11. Use the following formula to determine ENC and record in Table C.45.

a. $\quad \Delta_{Q}=\frac{V_{p 1}-V_{p 2}}{\hat{x}_{1}-\hat{x}_{2}} C_{c} \overline{\Delta_{N}}$, where $\mathrm{V}_{\mathrm{px}}$ are high and low AWG voltage values, $\hat{x}_{x}$ are the high and low peak centroids, $\mathrm{C}_{\mathrm{c}}$ is the precision capacitor value, $\overline{\Delta_{N}}$ is the average of the high and low peak FWHM values

12. Repeat steps for the rest of the configurations in Table C.44..

\section{C.14.6 Test Data}

DUT Serial Number:

DUT Part Number:

Tested By:

Test Date: 


\section{C.14.6.1 Data Table:}

Table C.44. DUT, AWG and MCA Configuration

\begin{tabular}{|l|l|l|}
\hline Device & \multicolumn{1}{|c|}{ Parameter } & \multicolumn{1}{c|}{ Setting } \\
\hline DUT & Input Signal Mode (Q or I) & \\
\hline DUT & Input Termination & \\
\hline DUT & Charge Gain (range) & \\
\hline DUT & G1 - Gain & \\
\hline DUT & G2 - Gain & \\
\hline DUT & HVH - High Voltage & \\
\hline DUT & HVL - High Voltage & \\
\hline DUT & SW1 - Shaping Time & \\
\hline DUT & SW2 - Shaping Time & \\
\hline DUT & DH - Discriminator High & \\
\hline DUT & DL - Discriminator Low & \\
\hline DUT & Digital Ouput Pulse Width & \\
\hline AWG & Pulse Type & Tail \\
\hline AWG & Pulse Period & 0.5 us \\
\hline AWG & Pulse Low Voltage & \\
\hline AWG & Pulse High Voltage & \\
\hline AWG & Output Impedance & High-Z \\
\hline MCA & Number of bins & Maximum (16384) \\
\hline MCA & Voltage Range & 5 V \\
\hline
\end{tabular}

Table C.45. ENC DUT Performance Data

\begin{tabular}{|c|c|c|c|c|c|}
\hline $\begin{array}{c}\text { Config } \\
\#\end{array}$ & $\begin{array}{l}\text { High Peak } \\
\text { Centroid } \\
\text { (channel) }\end{array}$ & $\begin{array}{c}\text { High Peak } \\
\text { FWHM } \\
\text { (channel) }\end{array}$ & $\begin{array}{l}\text { Low Peak } \\
\text { Centroid } \\
\text { (channel) }\end{array}$ & $\begin{array}{c}\text { Low Peak } \\
\text { FWHM } \\
\text { (channel) }\end{array}$ & $\begin{array}{c}\text { ENC } \\
(\text { FWHM pC) }\end{array}$ \\
\hline 1 & & & & & \\
\hline 2 & & & & & \\
\hline 3 & & & & & \\
\hline 4 & & & & & \\
\hline 5 & & & & & \\
\hline 6 & & & & & \\
\hline 7 & & & & & \\
\hline 8 & & & & & \\
\hline 9 & & & & & \\
\hline
\end{tabular}




\begin{tabular}{|l|l|l|l|l|l|}
\hline $\begin{array}{c}\text { Config } \\
\#\end{array}$ & $\begin{array}{c}\text { High Peak } \\
\text { Centroid } \\
\text { (channel) }\end{array}$ & $\begin{array}{c}\text { High Peak } \\
\text { FWHM } \\
\text { (channel) }\end{array}$ & $\begin{array}{c}\text { Low Peak } \\
\text { Centroid } \\
\text { (channel) }\end{array}$ & $\begin{array}{c}\text { Low Peak } \\
\text { FWHM } \\
\text { (channel) }\end{array}$ & $\begin{array}{c}\text { ENC } \\
\text { (FWHM pC) }\end{array}$ \\
\hline 10 & & & & & \\
\hline 11 & & & & & \\
\hline 12 & & & & & \\
\hline 13 & & & & & \\
\hline 14 & & & & & \\
\hline 15 & & & & & \\
\hline 16 & & & & & \\
\hline 17 & & & & & \\
\hline 18 & & & & & \\
\hline 19 & & & & & \\
\hline 20 & & & & & \\
\hline 21 & & & & & \\
\hline 22 & & & & & \\
\hline 23 & & & & & \\
\hline 24 & & & & & \\
\hline
\end{tabular}




\section{C.15 TEST 25- High Radiation Fields}

\section{C.15.1 Purpose:}

This test will examine how well the FEUM performs in a high neutron environment, relative to the detector efficiency versus cable length and intrinsic noise. The setup in Figure C.21 and various configurations in Table C.46 will be used.

\section{C.15.2 Required Equipment:}

12V DC Power Supply

He3 detector

Fission Chamber

Neutron well and detector shielding/moderator

Multi-channel Analyzer

Digital Pulse Counter

Jewelers’ screwdriver (for toggling configuration dipswitches, if applicable)

Tweezers (for changing jumper settings, if applicable)

\section{C.15.3 References:}

DUT documentation provided by vendor

\section{C.15.4 Preparation:}

Gather the test equipment and setup the equipment as shown in Figure C.21. 


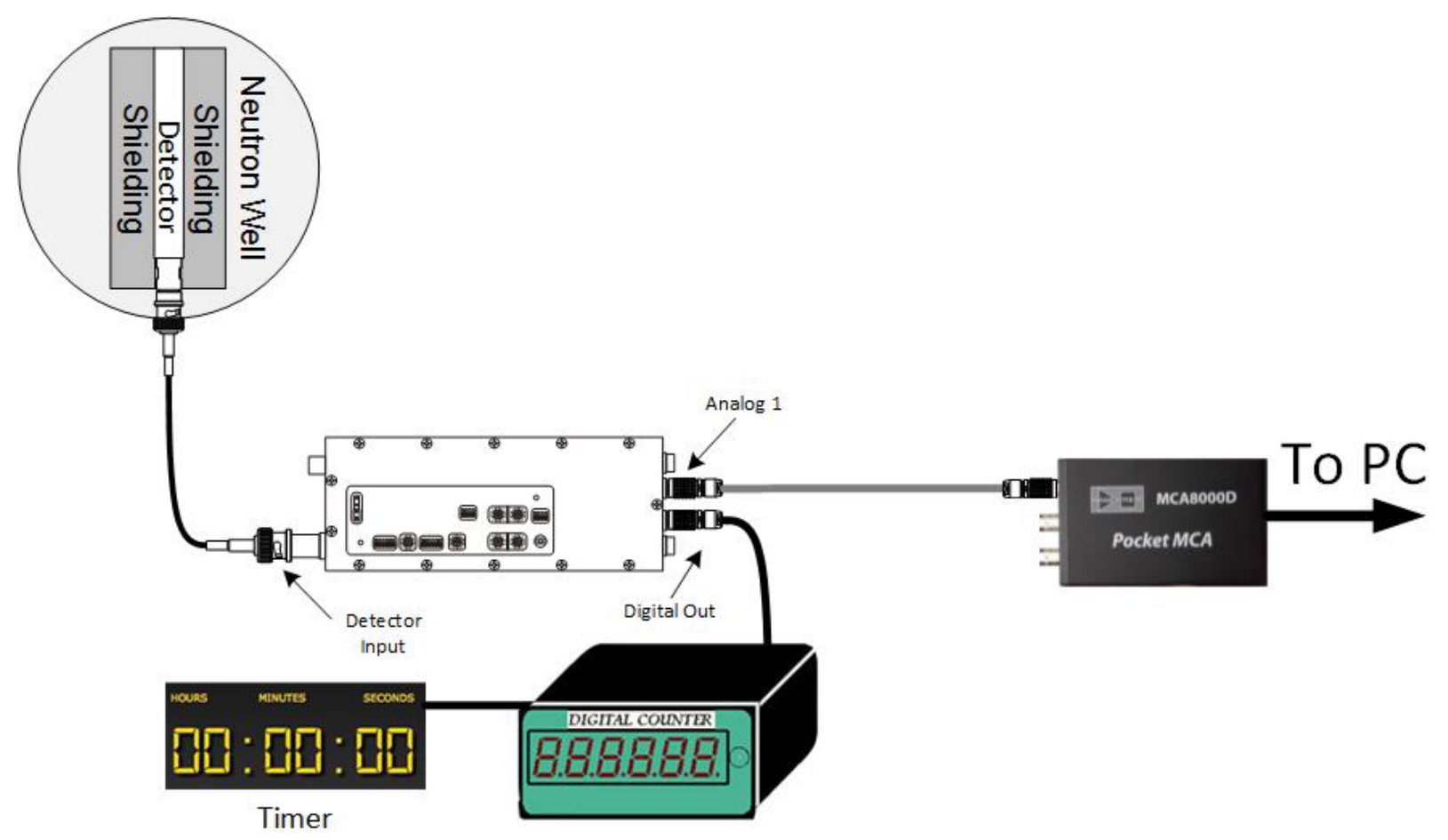

Figure C.21. Performance Testing Setup with Neutron Well

Prepare equipment and setup for variations in test setup per Table C.46.

Table C.46. Configurations for High Neutron Performance Testing

\begin{tabular}{|l|l|l|l|l|}
\hline$\#$ & Detector Type & Cable/Length & $\begin{array}{c}\text { Pulse } \\
\text { Shaping } \\
\text { Time }\end{array}$ & \multicolumn{1}{|c|}{ Output Port } \\
\hline 1 & He3 & RG-71/1m & $0.1 \mu \mathrm{s}$ & Isolated \\
\hline 2 & He3 & RG-71/1m & $0.4 \mu \mathrm{s}$ & Isolated \\
\hline 3 & He3 & RG-71/1m & $2.4 \mu \mathrm{s}$ & Isolated \\
\hline 4 & He3 & RG-71/10m & $0.1 \mu \mathrm{s}$ & Isolated \\
\hline 5 & He3 & RG-71/10m & $0.4 \mu \mathrm{s}$ & Isolated \\
\hline 6 & He3 & RG-71/10m & $2.4 \mu \mathrm{s}$ & Isolated \\
\hline 7 & He3 & RG-71/50m & $0.1 \mu \mathrm{s}$ & Isolated \\
\hline 8 & He3 & RG-71/50m & $0.4 \mu \mathrm{s}$ & Isolated \\
\hline 9 & He3 & RG-71/50m & $2.4 \mu \mathrm{s}$ & Isolated \\
\hline
\end{tabular}




\begin{tabular}{|c|c|c|c|c|}
\hline \# & Detector Type & Cable/Length & $\begin{array}{c}\text { Pulse } \\
\text { Shaping } \\
\text { Time }\end{array}$ & Output Port \\
\hline 10 & He3 & RG-71/100m & $0.1 \mu \mathrm{s}$ & Isolated \\
\hline 11 & He3 & RG-71/100m & $0.4 \mu \mathrm{s}$ & Isolated \\
\hline 12 & He3 & RG-71/100m & $2.4 \mu \mathrm{s}$ & Isolated \\
\hline 13 & He3 & RG-174/100m & $0.1 \mu \mathrm{s}$ & Isolated \\
\hline 14 & He3 & RG-174/100m & $0.4 \mu \mathrm{s}$ & Isolated \\
\hline 15 & He3 & RG-174/100m & $2.4 \mu \mathrm{s}$ & Isolated \\
\hline 16 & Fission Chamber & RG-71/1m & $0.1 \mu \mathrm{s}$ & Isolated \\
\hline 17 & Fission Chamber & RG-71/1m & $0.4 \mu \mathrm{s}$ & Isolated \\
\hline 18 & Fission Chamber & RG-71/1m & $2.4 \mu \mathrm{s}$ & Isolated \\
\hline 19 & Fission Chamber & RG-71/10m & $0.1 \mu \mathrm{s}$ & Isolated \\
\hline 20 & Fission Chamber & RG-71/10m & $0.4 \mu \mathrm{s}$ & Isolated \\
\hline 21 & Fission Chamber & RG-71/10m & $2.4 \mu \mathrm{s}$ & Isolated \\
\hline 22 & Fission Chamber & RG-71/50m & $0.1 \mu \mathrm{s}$ & Isolated \\
\hline 23 & Fission Chamber & RG-71/50m & $0.4 \mu \mathrm{s}$ & Isolated \\
\hline 24 & Fission Chamber & RG-71/50m & $2.4 \mu \mathrm{s}$ & Isolated \\
\hline 25 & Fission Chamber & RG-71/100m & $0.1 \mu \mathrm{s}$ & Isolated \\
\hline 26 & Fission Chamber & RG-71/100m & $0.4 \mu \mathrm{s}$ & Isolated \\
\hline 27 & Fission Chamber & RG-71/100m & $2.4 \mu \mathrm{s}$ & Isolated \\
\hline 28 & Fission Chamber & RG-174/100m & $0.1 \mu \mathrm{s}$ & Isolated \\
\hline 29 & Fission Chamber & RG-174/100m & $0.4 \mu \mathrm{s}$ & Isolated \\
\hline 30 & Fission Chamber & RG-174/100m & $2.4 \mu \mathrm{s}$ & Isolated \\
\hline
\end{tabular}

\section{C.15.5 Procedure:}

13. Connect the equipment for configuration \#1.

14. Configure the DUT as appropriate for the detector type and parameters to be varied (see settings recorded in section C.10).

15. Record the settings selected in Table C.47.

a. If applicable to the detector, adjust the HV Setting to be appropriate for typical operation (e.g., for He-3, above the knee of the counting plateau). Record the HV setting used.

b. Adjust the DUT gain settings to be appropriate for the detector pulse height spectrum, amplifier output voltage range, and the MCA voltage range. Record the setting used.

16. Power on the DUT, using the standard isolated power port, and test equipment.

17. Set source to deliver desired dose rate and record in Table C.47.

18. Save the MCA pulse height spectrum for subsequent integral pulse height spectrum analysis (post processing). 
19. Repeat steps for the rest of the configurations in Table C.46.

\section{C.15.6 Test Data}

DUT Serial Number:

DUT Part Number:

Tested By:

Test Date:

\section{C.15.6.1 Data Table:}

Table C.47. DUT and Test Configuration

\begin{tabular}{|l|l|l|}
\hline \multicolumn{1}{|c|}{ Parameter } & He-3 Settings & $\begin{array}{c}\text { Fission } \\
\text { Chamber } \\
\text { Settings }\end{array}$ \\
\hline Input Signal Mode (Q or I) & & \\
\hline Input Termination & & \\
\hline Charge Gain (range) & & \\
\hline G1 - Gain & & \\
\hline G2 - Gain & & \\
\hline HVH - High Voltage & & \\
\hline HVL - High Voltage & & \\
\hline DH - Discriminator High & & \\
\hline DL - Discriminator Low & & \\
\hline Digital Ouput Pulse Width & & \\
\hline SW1 - Shaping Time & & \\
\hline SW2 - Shaping Time & & \\
\hline Source Type & & \\
\hline Source Strength & & \\
\hline Source Geometry & & \\
\hline Peak Efficieny & & \\
\hline
\end{tabular}


Table C.48. High Neutron DUT Performance Data

\begin{tabular}{|c|c|c|c|c|c|c|c|}
\hline \multicolumn{4}{|c|}{ Charge Sensitive } & \multicolumn{4}{|c|}{ Charge Sensitive } \\
\hline $\begin{array}{c}\text { Config } \\
\#\end{array}$ & $\begin{array}{c}\text { Discriminator } \\
\text { Threshold }\end{array}$ & $\begin{array}{c}\text { Digital } \\
\text { Counter } \\
\text { Count } \\
\text { Rate }\end{array}$ & $\begin{array}{c}\text { MCA- } \\
\text { Calculated } \\
\text { Count } \\
\text { Rate }\end{array}$ & $\begin{array}{c}\text { Config } \\
\#\end{array}$ & $\begin{array}{c}\text { Discriminator } \\
\text { Threshold }\end{array}$ & $\begin{array}{c}\text { Count } \\
\text { Rate }\end{array}$ & $\begin{array}{l}\text { MCA- } \\
\text { Calculated } \\
\text { Count } \\
\text { Rate }\end{array}$ \\
\hline 1 & & & & 16 & & & \\
\hline 2 & & & & 17 & & & \\
\hline 3 & & & & 18 & & & \\
\hline 4 & & & & 19 & & & \\
\hline 5 & & & & 20 & & & \\
\hline 6 & & & & 21 & & & \\
\hline 7 & & & & 22 & & & \\
\hline 8 & & & & 23 & & & \\
\hline 9 & & & & 24 & & & \\
\hline 10 & & & & 25 & & & \\
\hline 11 & & & & 26 & & & \\
\hline 12 & & & & 27 & & & \\
\hline 13 & & & & 28 & & & \\
\hline 14 & & & & 29 & & & \\
\hline 15 & & & & 30 & & & \\
\hline
\end{tabular}




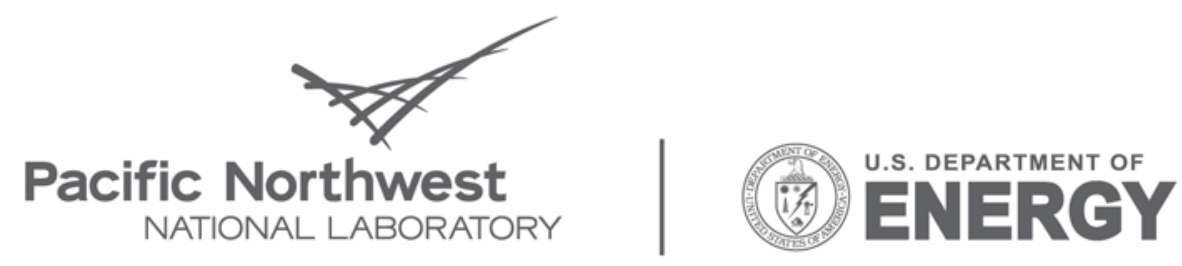

Proudly Operated by Battelle Since 1965

902 Battelle Boulevard

P.O. Box 999

Richland, WA 99352

1-888-375-PNNL (7665)

www.pnl.gov 